\title{
Links between juvenile sexually abusive behaviour and emerging severe personality disorder traits in childhood
}

Nicole Hickey

Eileen Vizard

Eamon McCrory

Lesley French 


\section{Abstract}

Young people presenting with sexually abusive behaviour (SAB) - juvenile sexual abusers (JSAs) - are responsible for a significant minority of sexual offences against children and adults (Home Office, 2003). A detailed study of 280 JSAs referred to a specialist Child and Adolescent Mental Health Service was conducted in order to provide a detailed description of this population. Data were obtained from a retrospective file review, and the Offenders Index. Two theoretical questions were addressed.

Firstly, whether the age of onset of SAB could distinguish distinct subgroups of JSAs. Such categories have proved clinically relevant for generally anti-social juveniles (Moffitt, 1993). Early Onset $(n=93)$ and Late Onset $(n=120)$ groups were identified depending on whether SAB began before or after the age of 11 . The results indicated that the Early Onset group were more likely to experience: inadequate family sexual boundaries; multiple forms of abuse; poorer parenting; and insecure attachment. The Late Onset group tended to misuse substances, sexually abuse specific groups, and were more likely to use verbal coercion.

Secondly, whether a distinct subgroup of juvenile sexual abusers could be identified on the basis of emerging severe personality disorder (ESPD) traits. An ESPD group $(n=54)$ presenting with marked conduct disorder and psychopathic personality disorder traits was compared with a non-ESPD group of JSAs $(n=149)$. The results indicated that the ESPD group was more likely to have: an early difficult temperament; more insecure attachment; inconsistent parenting; placement disruption; and parents with mental health problems. Their SAB was more predatory and premeditated. Notably, their 'lifetime' conviction rate for all offences was 67 per cent compared to 37 per cent in the non-ESPD group.

Clinical, policy and research implications are discussed. The need for JSA specialist services, integrated governmental approaches, and research on treatment efficacy, and ESPD traits in childhood are highlighted.

\section{Keywords}

Juvenile, Sexual, Abuser, Developmental, Trajectory, Psychopathy, Traits 


\section{Acknowledgments}

We would like to acknowledge the support of the Home Office who funded this study. In particular we are grateful to Samantha Foster, Matt Erikson and Malcolm Ramsay at the DSPD Unit. Finally, our thanks go to the peer reviewers who provided helpful comments on an earlier draft of the report.

Nicole Hickey is a Forensic Research Psychologist at the Young Abusers Project.

Dr Eileen Vizard is a Consultant Child and Adolescent Psychiatrist and Research Lead at the Young Abusers Project, and Honorary Senior Lecturer at UCL.

Dr Eamon McCrory is a Chartered Clinical Psychologist at the Young Abusers Project.

Dr Lesley French is the Lead Psychologist (Forensic Under 21 Provision) at the Bracton Centre. 


\section{Contents}

Acknowledgements

Executive summary $\quad$ v

1. Introduction 1

2. Developmental trajectories of juvenile anti-social behaviour 3

$\begin{array}{ll}\text { 3. Emerging severe personality disorder traits in young people } & 6\end{array}$

4. Juvenile sexual abusers and juvenile sexually abusive behaviour 9 Abuser characteristics $\quad 9$

$\begin{array}{lr}\text { Abuse characteristics } & 10\end{array}$

$\begin{array}{ll}\text { Recidivism } & 10\end{array}$

$\begin{array}{ll}\text { Typologies } & 10\end{array}$

Sexually abusive behaviour and emerging severe personality disorder traits 11

$\begin{array}{ll}\text { 5. Conclusions from the evidence base } & 13\end{array}$

6. Aims and hypotheses

$\begin{array}{ll}\text { Aims } & 15\end{array}$

$\begin{array}{ll}\text { Hypotheses } & 15\end{array}$

$\begin{array}{ll}\text { 7. Method } & 17\end{array}$

$\begin{array}{ll}\text { Sample } & 17\end{array}$

The Young Abusers Project (YAP) 17

$\begin{array}{ll}\text { Data collection and coding } & 17\end{array}$

$\begin{array}{ll}\text { Ethical considerations } & 19\end{array}$

$\begin{array}{ll}\text { Data analysis procedure } & 19\end{array}$

8. Characteristics of the sample $(\mathrm{N}=280) \quad 22$

Demographics 22

Psychosocial characteristics and psychiatric diagnoses $\quad 22$

Sexually abusive behaviour $\quad 23$

Conviction profiles $\quad 25$

Sexual offending in adulthood 26

Summary $\quad 26$

9. Early and Late Onset trajectories of juvenile sexually abusive behaviour $(n=213) 27$

Psychosocial characteristics and psychiatric diagnoses $\quad 27$

Psychosocial predictors of an Early Onset of sexually abusive behaviour $\quad 29$

Sexually abusive behaviour (during adolescence) $\quad 29$

Non-sexual anti-social behaviour $\quad 30$

Conviction profiles $\quad 32$

Summary 33

10. Emerging severe personality disorder traits in young sexual abusers $(n=203) \quad 34$

Emerging severe personality disorder traits $\quad 34$

Psychosocial characteristics $\quad 35$

Sexually abusive behaviour $\quad 36$

Non-sexual anti-social behaviour 36

Conviction profiles $\quad 39$

$\begin{array}{ll}\text { Summary } & 40\end{array}$

11. The relationship between Early and Late Onset trajectories of juvenile 41 sexually abusive behaviour and emerging severe personality disorder traits $(n=187)$

Psychosocial characteristics 
Sexually abusive behaviour $\quad 43$

$\begin{array}{ll}\text { Summary } & 43\end{array}$

12. Discussion $\quad 44$

Age of onset trajectories of juvenile sexually abusive behaviour 44

Emerging severer personality disorder traits $\quad 46$

$\begin{array}{ll}\text { The relationship between age of onset trajectories of juvenile } & 47\end{array}$

sexually abusive behaviour and emerging severe personality disorder traits

$\begin{array}{lr}\text { 13. Conclusions } & 48\end{array}$

$\begin{array}{lr}\text { 14. Limitations } & 54\end{array}$

$\begin{array}{lr}\text { 15. Implications } & 56\end{array}$

Clinical $\quad 56$

$\begin{array}{ll}\text { Policy } & 57\end{array}$

$\begin{array}{ll}\text { Research } & 58\end{array}$

$\begin{array}{lr}\text { 16. Recommendations } & 59\end{array}$

$\begin{array}{ll}\text { Clinical } & 59\end{array}$

$\begin{array}{ll}\text { Policy } & 59\end{array}$

$\begin{array}{ll}\text { Research } & 61\end{array}$

$\begin{array}{ll}\text { Appendix 1. } & \text { Glossary of terms }\end{array}$

Appendix 2. Items on the Psychopathy Checklist - Youth Version 67

Appendix 3. Survival rate graphs for first sexual and violent convictions post-YAP for Chapters 8 to $10 \quad 68$

Appendix 4. Comparing 'included' and 'excluded' samples 71

$\begin{array}{lr}\text { References } & 72\end{array}$ 


\section{List of tables}

8.1. Psychosocial characteristics and psychiatric diagnoses of the whole sample 23

8.2. Sexually abusive behaviour characteristics of the whole sample 24

8.3. Conviction profiles of those matched on the Offenders Index $(n=268)$

9.1. Comparisons between the Early and Late Onset trajectories on psychosocial characteristics $\quad 28$

9.2. Psychosocial predictors of an Early Onset of juvenile sexually abusive behaviour

9.3. Comparisons between the Early and Late Onset trajectories on sexually abusive behaviour during adolescence (11 to 17 years)

9.4. Comparisons between the Early and Late Onset trajectories for non-sexual anti-social behaviour across developmental periods

9.5. Conviction profiles of the Early and Late Onset trajectories

10.2. Comparisons between the ESPD trait groups on sexually abusive behaviour characteristics

10.3. Comparisons between the ESPD trait groups for non-sexual anti-social behaviour across developmental periods

10.4. Conviction profiles of the ESPD trait groups

11.1 Comparisons between the ESPD trait groups on the Early and Late Onset trajectories on psychosocial characteristics

11.2 Comparisons between the ESPD trait groups on the Early and Late Onset trajectories on SAB characteristics

13.1 Summary of hypotheses, results and evidence

Preliminary developmental profiles of Early Onset JSAs, Late Onset JSAs, and JSAs with ESPD traits

\section{List of figures}

7.1. Overview of the analysis undertaken in the study

11.1. Number of cases with ESPD and non-ESPD traits on the Early and Late Onset trajectories

13.1 Subgroups of JSAs: Inter-relationships between age of onset of SAB and ESPD traits 


\title{
Executive summary
}

\author{
Introduction
}

Young people presenting with sexually abusive behaviour (SAB) are referred to in this study as juvenile sexual abusers (JSAs). Sexually abusive behaviour refers to any acts of sexual behaviour perpetrated against non-consenting victims; it is not restricted to convicted offences. The term 'juvenile' is used in this study to refer to the range of children and adolescents included in the sample. As such, it includes pre-adolescent children, and young people up to the age of 21. Finally, the term 'anti-social behaviour' refers to a broad range of behaviours including delinquent acts such as running away from home or school truancy, as well as behaviours that could be prosecuted within the criminal justice system such as arson or assault. JSAs are responsible for a significant minority of sexual offences against children and adults (Home Office, 2003). The evidence base suggests that JSAs are comparable in many ways to anti-social juveniles who do not sexually abuse, presenting with high levels of childhood adversity and later convictions. However, the question arises whether it is possible to identify specific subgroups of juvenile sexual abusers in relation to the developmental trajectories they follow. To date the construct of developmental trajectories has only been applied to the general population of anti-social juveniles, rather than those presenting with specific forms of anti-social behaviour. Moffitt proposed a theoretical taxonomy between childhood and adolescent onset trajectories for anti-social behaviour (Moffitt, 1993). Empirical study indicates that those with a childhood onset are more likely to have neuropsychological deficits, and experience abuse or neglect early in childhood (Moffitt and Caspi, 2001). Such children are also exposed to 'criminogenic' environments, including parents with criminal records, or inadequate parenting skills. These contribute to the development of a 'pathological personality' that includes personality deficits such as lack of empathy, and, serious anti-social behaviour (Moffitt, 1993). Meanwhile, those with an adolescent onset of anti-social behaviour experience less adverse family environments, do not necessarily display pathological personality functioning, and tend to confine their anti-social behaviour to adolescence and/or early adulthood (Moffitt, Caspi, Harrington and Milne, 2002). However, it is not known whether age of onset defined trajectories are relevant for differentiating subgroups of juvenile sexual abusers.

A second question pursued in relation to anti-social youth in general has been how to identify those at risk of persistent serious offending in adulthood. They present with an early onset of anti-social behaviour, and persist with such behaviour through adolescence and adulthood. The seriousness of their anti-social behaviour escalates over time, and this group is responsible for a disproportionate amount of violent and sexual offending in adulthood (Moffitt et al., 2002). Persistent serious offending is highly correlated with anti-social and psychopathic personality disorders, both of which are developmental disorders (Vizard, French, Hickey and Bladon, 2004). A growing body of research has investigated the emergence of personality and behavioural traits associated with these disorders in children and adolescents (Frick et al., 1994, 2003). The subgroup of young people presenting with such trait characteristics comprise a subgroup of anti-social youth, displaying high rates of thrill-seeking behaviour, low sensitivity to punishment, and a wide variety of anti-social behaviours, including premeditated aggression (Frick et al., 2003). As with age of onset trajectory research, much of the work on these Emerging Severe Personality Disorder (ESPD) traits has focused on anti-social juveniles in general, rather than on those who engage in particular types of behaviour. Therefore, it is not known whether it is possible to identify a specific subgroup of JSAs displaying such traits.

The current study was therefore designed to investigate two questions.

- $\quad$ Firstly, is the age at which sexually abusive behaviour emerges associated with distinct developmental trajectories? 
Secondly, is it possible to identify a group of JSAs most at risk for developing ESPD traits?

\section{Aims}

The main aims of the study were:

- $\quad$ to describe the characteristics of a UK cohort of clinically high-risk children and young people presenting with sexually abusive behaviour;

- $\quad$ to explore whether 'age of onset' could identify distinct subgroups of juvenile sexual abusers whose developmental trajectories differed in relation to their psychosocial characteristics, anti-social behaviour, and conviction profiles;

- $\quad$ to explore whether high levels of ESPD traits could identify a subgroup of JSAs with a distinct developmental trajectory in relation to psychosocial characteristics, anti-social behaviour, and conviction profile; and

- $\quad$ to provide practical guidance for clinicians, policy makers and researchers in relation to the implications of the findings.

\section{Method}

\section{Sample}

The sample comprised $\mathrm{N}=280$ children and adolescents (male (91\%); Caucasian (83\%); IQ $\leq 70$ (24\%); mean age 13.9 years (sd 3.0)) referred, between 1992 and 2003, to a nonresidential forensic Child and Adolescent Mental Health Service (CAMHS), specialising in sexually abusive behaviour. Referrals were predominantly from Local Authority Social Services departments, and, while the upper age limit for referrals is 21 , there is no lower age limit. As a designated fourth tier CAMH service referrals tended to be children and young people presenting with long-standing or serious sexual and non-sexual anti-social behaviour.

\section{Data collection}

Data were collected from two sources: the service's clinical files and the Offenders Index. The clinical files held various reports from multiple informants across a range of domains, including family history, education, and health. The Offenders Index provided a discrete amount of information about the convictions gained by the sample up to December 2003. The clinical files were also used to score the Psychopathy Checklist - Youth Version (PCLYV: Forth, Kosson, and Hare, 2003). The PCL-YV is a 20-item measure for rating psychopathy traits in young people aged between 12 and 18 years.

\section{Data analysis procedure}

- The psychosocial characteristics, psychiatric diagnoses, sexually abusive behaviours, and conviction profiles of the whole sample $(\mathrm{N}=280)$ were described.

- $\quad$ Two groups were identified, presenting with either an Early Onset $(n=93)$ or a Late Onset $(n=120)$ of sexually abusive behaviour. Early Onset sexually abusive behaviour began before the eleventh birthday, and Late Onset began after the eleventh birthday. Age 11 was chosen as the cut-off because it conforms to the DSM-IV cut-off for childhood and adolescent onset conduct disorder, and was used by Moffitt and colleagues to differentiate Early and Late Onset antisocial behaviour. The groups were compared, using Chi-Square analysis, on psychosocial characteristics, sexually abusive behaviours, non-sexual anti-social behaviours, and conviction profiles. In 67 cases the age of onset could not be identified, therefore, they were excluded from the analysis. Logistic regression was used to explore the psychosocial predictors of an Early Onset of SAB. 
- A group of young people were identified as having ESPD traits on the basis of presenting with higher than sample average numbers of conduct disorder behaviours, and a higher than sample average level of personality traits, as measured by the PCL-YV. Fifty-four cases presented with ESPD traits, and were compared, using Chi Square analysis, to the remaining $n=149$ cases (non-ESPD) in relation to psychosocial characteristics, sexually abusive behaviours, non-sexual anti-social behaviours, and conviction profiles. Seventy-seven cases were excluded from the analysis because they were too young to be assessed with the PCL-YV or because was insufficient file information to score the PCL-YV.

- $\quad$ Exploratory comparisons, using Chi-Square analysis, were made between cases with ESPD traits on the Early $(n=32)$ and Late $(n=18)$ Onset trajectories in relation to psychosocial and sexually abusive behaviour characteristics.

\section{Findings}

1. Juveniles who start sexually abusive behaviour before 11 years of age (childhood), can be distinguished from those who start after 11 years of age (adolescence).

Those with an Early Onset differ, to a statistically significant degree, from those with a Late Onset by having higher rates of adverse psychosocial characteristics in relation to: difficult temperaments; exposure to inadequate parenting; inadequate family sexual boundaries; high levels of abuse and neglect; and high levels of insecure attachments.

Using regression analysis, four psychosocial predictors (inadequate family sexual boundaries, lack of parental supervision, early difficult temperament, and insecure attachment) were identified as independently predictive of an Early Onset of sexually abusive behaviour. In terms of their behaviour, those in the Early Onset group had higher rates of anti-social behaviour in childhood, and were more likely to sexually abuse a variety of victims.

For the Late Onset group the only distinguishing psychosocial risk factor was in relation to higher levels of substance misuse. They were also more likely to: sexually abuse specific groups of victims including much younger children; to use verbal coercion with their victims; and to be convicted of sexual offences in adolescence.

2. A subgroup of juvenile sexual abusers with Emerging Severe Personality Disorder traits can be identified, and they differ from JSAs without ESPD traits on a range of factors.

Those with ESPD traits were found to differ from the non-ESPD group on a range of psychosocial factors. Specifically, they had: higher rates of parents with mental health problems; difficult temperaments in infancy; exposure to inconsistent parenting; higher levels of insecure attachment; and higher levels of placement disruption.

In relation to anti-social behaviour, the ESPD group tended to show a very early onset of antisocial behaviours, persistent anti-social behaviour across developmental periods, and sexual and physical cruelty to animals.

In relation to sexually abusive behaviour, those with ESPD traits tended to display higher rates of 'predatory' behaviour (e.g. abusing more strangers, abusing child and adult victims), higher rates of grooming prior to the abuse, more excessive force, and verbal coercion.

When the conviction rates of the ESPD group were compared to those of the non-ESPD group, and amount of time 'available to reconvict' was controlled for, their overall conviction rate of 67 per cent was nearly twice that of the non-ESPD group (37\%), and they were shown to present with significantly higher rates of violent and non-sexual/non-violent convictions. 


\section{Implications}

The primary policy implication concerns the provision of specialist services for juvenile sexual abusers. The findings indicate that juvenile sexual abusers are a heterogeneous population. Important differences are associated with the age of onset of the SAB, and whether or not ESPD traits are present. Therefore, services for juvenile sexual abusers cannot adopt a 'one size fits all' approach to treatment and hope to meet all the needs of their clients. A wide range of services are needed, and strategic thought is required to clarify how these will be realised. The types of services required include: primary prevention services; assessment and treatment services for pre-adolescent sexual abusers; and assessment and treatment services for adolescent sexual abusers, including those with emerging personality disorders.

Clinically, there are cost benefits to the public purse from early intervention with children presenting with conduct disordered behaviour (Scott, Knapp, Henderson and Maughan, 2001), and children presenting with sexually abusive behaviour (Borduin, Schaeffer and Heiblum, 2004). Therefore, investment in preventative and treatment resources for local child and adolescent services are likely to have long-term benefits.

\section{Recommendations}

\section{Clinical recommendations}

Early intervention is recommended if there is evidence of Early Onset sexually abusive behaviour, or emerging personality disorder traits. This should be preceded by a developmental assessment, including assessment of psychiatric disorders and personality disorder traits.

\section{Policy recommendations}

As a range of individual and family risk factors are associated with the later emergence of serious and diverse patterns of offending, a 'one size fits all' approach is unlikely to be effective. Therefore, a three-part solution is proposed.

- $\quad$ First, establishing primary prevention services in the form of multi-agency support and skills-based training for parents and young people.

- Second, establishing local, community teams to assess and treat children and adolescents presenting with sexually abusive behaviour.

- $\quad$ Third, establishing a network of regional specialist teams to provide consultation, teaching, and management in complex cases. There is also need for a small number of specialist residential treatment facilities for juvenile sexual abusers.

These recommendations are best achieved by establishing a standing, inter-departmental government committee, with representation from the Youth Justice Board, Department of Health, and Department for Education and Skills, to oversee their implementation.

\section{Research recommendations}

In relation to JSAs, research in the following areas is required.

- Understanding why some juvenile delinquents perpetrate sexually abusive behaviours while others do not.

- $\quad$ Long-term outcome studies with JSAs.

- A large-scale evaluation of treatments for JSAs. 
In relation to young people presenting with ESPD traits the following research is required.

- $\quad$ Retrospective studies with adults with severe personality disorders to help identify the childhood and adolescent developmental trajectories pursued by those with ESPD traits.

- $\quad$ Prospective studies with children and adolescents at risk of developing ESPD traits to improve understanding of the resilience factors that might help some children move off the severe personality disorder trajectory.

- $\quad$ Studies to develop and evaluate developmentally sensitive measurement tools for assessing ESPD traits in young people. 


\section{Introduction}

Young people presenting with sexually abusive behaviour (SAB) are referred to in this study as juvenile sexual abusers (JSAs). Sexually abusive behaviour refers to any act of sexual behaviour perpetrated against a non-consenting victim; it is not restricted to convicted offences. The term 'juvenile' is used in this study to refer to the range of children and adolescents included in the sample. As such, it includes pre-adolescent children, and young people up to the age of 21. Finally, the term 'anti-social behaviour' refers to a broad range of behaviours including delinquent acts such as running away from home or school truancy, as well as behaviours that could be prosecuted within the criminal justice system, such as arson or assault.

Anti-social juveniles are a heterogeneous population, and increasingly research has focused on identifying the characteristics of subgroups of anti-social youth. This programme of research is driven, in part, by the need to improve knowledge about the small group of persistent, seriously anti-social juveniles who are considered 'at risk' of becoming adult dangerous offenders. The research has identified numerous subgroups of anti-social juveniles, classified according to the developmental trajectories they appear to pursue (Broidy et al., 2003; Loeber and Stouthamer-Loeber, 1998; Moffitt and Caspi, 2001). These trajectories are associated with both differential psycho-bio-social correlates and risk markers, and differential outcomes in late adolescence and early adulthood. Such identification supports the heterogeneous view of anti-social juveniles, and indicates that risk management with members of this population should take account of their differing levels of risk and their differing needs when it comes to intervention.

Most anti-social juveniles display behaviours associated with the diagnostic label 'conduct disorder' (CD) (American Psychiatric Association, 1994), for example, aggression to people and animals, property destruction, and serious violation of rules. However, a small group of juveniles exhibit a 'severe' type of conduct disorder as defined by the number of conduct disorder behaviours they displayed, and/or by the degree of harm they cause. Conduct disordered behaviour in childhood and adolescence is a mandatory criteria for a diagnosis of anti-social personality disorder (APD) in adults. It is also one of the behavioural traits associated with psychopathic personality disorder (PPD). Both of these personality disorders are overrepresented in offender populations, particularly among adult dangerous offenders, and together they represent a type of severe personality disorder (SPD). Although current diagnostic tools preclude diagnosis of anti-social personality disorder before 18 years of age, both APD and PPD traits are unlikely to first arise at the age of 18; their emergence has a developmental component. The emerging traits are therefore likely to be observable among anti-social juveniles, particularly those displaying persistent or serious anti-social behaviour such as violent or sexual offending behaviour.

To date, the research on juvenile sexually abusive behaviour is unclear as to whether those who perpetrate such behaviour are a distinct subgroup of anti-social juveniles, or whether such behaviour is perpetrated by a wide range of anti-social youth. This debate centres on whether juvenile sexual abusers are on a developmental trajectory towards becoming adult sex offenders, or if they will desist from the behaviour in adulthood. Although recent research has led to a better understanding of the characteristics of juvenile sexual abusers and the abuse they commit (Boyd, Hagan and Cho, 2000; Hunter, Figueredo, Malamuth and Becker, 2003; Veneziano and Veneziano, 2002), there has been relatively little empirical investigation into the possible subgroups of juvenile abusers, and the developmental trajectories they follow. 
In the following sections the evidence in relation to developmental trajectories for anti-social behaviour, emerging severe personality disorder traits, and sexually abusive behaviour is explored. This review forms the basis for two main proposals explored in the current study. Firstly, it is proposed that there are distinguishable developmental trajectories for juveniles presenting with sexually abusive behaviour. Secondly, it is proposed that a subgroup of juveniles with sexually abusive behaviour will display emerging severe personality disorder traits. To date, neither of these propositions has been extensively explored, and the current study begins to address this gap. 


\section{Developmental trajectories of juvenile anti-social behaviour}

Juveniles who engage in anti-social behaviour are a heterogeneous group in terms of their background characteristics, anti-social and offending behaviour, and adult outcomes. Researchers have sought to identify the developmental trajectories that characterise antisocial juveniles to improve prevention and intervention programmes, and ultimately reduce recidivism. Much of this work has been based on prospective, longitudinal cohort studies. Researchers have tended to use the concept of age of onset, e.g. early (childhood) vs late (adolescent) onset, as a primary basis on which to identify distinct trajectories (Patterson, DeBaryshe and Ramsey, 1989). However, as research design and analysis techniques have become more complex, the possibilities of multiple trajectories towards anti-social behaviour have been explored (Loeber and Stouthamer-Loeber, 1998). Developmental psychopathologists have argued that for some individuals anti-social behaviour appears to be a stable developmental trait with an early onset, persisting through subsequent developmental periods into adulthood (Patterson et al., 1989; Skilling, Quinsey and Craig, 2001). While for others, it is a transient state associated with specific developmental periods, particularly adolescence and early adulthood.

The theoretical taxonomy incorporating these ideas was developed by Moffitt (1993) who identified a dual taxonomy: a 'life course persistent' (LCP) trajectory and an 'adolescence limited' (AL) trajectory. Moffitt hypothesised that the LCP trajectory was an Early Onset trajectory triggered by the interaction between a child's neuropsychological deficits and his/her criminogenic environments, to produce a 'pathological personality'. For example, the Early Onset group were expected to have been exposed to neuropsychological risk factors such as peri-natal problems and early childhood abuse/neglect. They were also likely to have been born to parents who exhibited traits such as hyperactivity and irritability, which are known to be heritable (Plomin, Chipuer and Loehlin, 1990).

Conversely, those on the adolescence limited or Late Onset trajectory were defined as displaying anti-social behaviour only during the adolescent developmental stage, and were believed to have experienced less adverse early histories, and fewer early neuropsychological deficits. It was also believed that the majority of young people on this trajectory would desist from anti-social behaviour by early adulthood. Further differentiations between the trajectories were proposed. In particular, it was hypothesised that the antisocial behaviour of those on the AL trajectory was likely to be more influenced by delinquent peer associations than the behaviour of those on the LCP trajectory.

Moffitt and her colleagues have reported empirical support for these two trajectories. Results from the Dunedin longitudinal study indicate that ten per cent of the males in the cohort were on the LCP trajectory, while 26 per cent were on the AL trajectory (Moffitt, Caspi, Harrington and Milne, 2002). As hypothesised, the two groups were distinguishable on early childhood factors with those in the Early Onset, LCP group characterised by higher rates of neuropsychological risk factors (such as abuse and neglect in early childhood), higher rates of neuropsychological deficits (such as expressive speech and language problems), as well as inattention and impulsivity. The difficult temperament in early childhood, exhibited by those on the LCP trajectory, was found to interact with the criminogenic environments produced by parents with anti-social and offending histories who lacked the ability to provide consistent discipline (Moffitt and Caspi, 2001).

Further empirical investigations between the trajectories revealed that those on the LCP trajectory were at greater risk of developing personality disorder traits, of engaging in a wide variety of anti-social behaviours, and of engaging in more violence than those on the AL trajectory (Moffitt, Caspi, Dickson, Silva and Stanton, 1996). However, it was noted that during adolescence the two trajectories could not be discriminated on markers of anti-social behaviour. Even by 26 years of age the two groups continued to be distinguishable, with the LCP group presenting with higher rates of severe hyperactivity, violent behaviour, and 
psychopathic personality disorder traits, as well as elevated mental health problems, and substance misuse (Moffitt et al., 2002).

Recently, Moffitt and colleagues identified an additional third trajectory now labelled 'low level chronic'. At an earlier stage of data collection this trajectory was labelled the 'recovery group' (Moffitt et al., 2002). However, data collection during the early adult period revealed this to be misleadingly optimistic since these young people were showing a long-term offending pattern that closely resembled the 'low level chronic offenders' first identified by Nagin, Farrington, and Moffitt (1995). This 'new' trajectory shares many characteristics with the LCP group during the childhood phase, but, in adolescence and early adulthood they engage in a persistent low level of anti-social behaviour, rather than the persistent high level associated with the LCP trajectory. Hence, Moffitt (2003) now suggests that the original dual taxonomy should be extended to include this third trajectory.

Other researchers have also argued that more than two trajectories for anti-social behaviour exist, although there is a general consensus that age of onset is a crucial discriminating factor. For example, Loeber and his colleagues hypothesised the existence of subgroups within the broad LCP and AL trajectories, accounting for the variety of outcomes they observed in their samples during late adolescence and adulthood (Loeber and StouthamerLoeber, 1998; Loeber et al., 1993). Two LCP subtypes were suggested. The first was characterised by a pre-school onset of aggression together with the co-morbid presence of Attention Deficit Hyperactivity Disorder (ADHD) symptoms, while the second was characterised by a middle-childhood onset of aggression and no ADHD symptoms. Two types of limited duration trajectories were also suggested. Both were characterised by high levels of aggression, but the first was believed to desist in elementary school, while the second was likely to desist in late adolescence or early adulthood. Loeber and StouthamerLoeber (1998) also proposed a fifth trajectory of Late-Onset offenders characteristic of people who did not display any aggression in childhood or adolescence, but, developed anti-social behaviour problems in late adolescence/early adulthood.

Recent developments in statistical analysis techniques such as growth modelling (Muthén, 2001) have given rise to studies that have aimed to identify anti-social behaviour developmental trajectories (Broidy et al., 2003; White, Bates and Buyske, 2001; Wiesner and Capaldi, 2003). Comparisons between these studies are problematic because different measures of anti-social behaviour are used. In particular, some use a measure of frequency while others use a measure of severity. While both measures are valid they are not readily comparable since a measure of frequency may miss those juveniles who engage in more serious but less frequent anti-social behaviours. In addition, the time periods over which the trajectories are 'followed' often vary considerably. Despite these methodological differences the general pattern of results has been surprisingly similar. Within studies, multiple trajectories have been identified, including 'escalating', 'desisting', 'de-escalating', and 'persistent/chronic' trajectories. Across studies the 'persistent/chronic' trajectory has been consistently observed, characterising a subgroup of approximately six per cent of juveniles with an Early Onset of anti-social behaviour that persists across childhood, adolescence, and in some studies into adulthood.

There is substantial agreement among researchers that trajectories of juvenile anti-social behaviour, defined according to age of onset of the behaviour, e.g. early or late, can distinguish between subgroups of juveniles with regard to psychosocial characteristics, antisocial behaviour, and criminal outcomes. There is also increasing evidence that a 'persistent/chronic' subgroup of anti-social juveniles exists, and, on the basis of their childhood and adolescent profile are 'at risk' of becoming adult persistent/chronic offenders (Skilling et al., 2001). However, one limitation of these studies is that they tended to investigate antisocial behaviour in general, rather than particular subtypes of anti-social behaviour. Specifically, it is not known whether age of onset defined trajectories are relevant for differentiating among juvenile sexual abusers.

In this study the concepts of childhood and adolescent onset sexually abusive behaviour were used as definitions of the 'Early' and 'Late' Onset trajectories. The anti-social trajectory literature enables some hypotheses to be made about the differences likely to be observed 
between the two sexually abusive behaviour trajectories. For example, it is predicted that those with a childhood onset will have higher rates of difficult temperament in infancy, will be more likely to experience adverse parenting and maltreatment in childhood, and display higher rates of impulsive, anti-social behaviour in childhood. However, both trajectories are predicted to have similar rates of anti-social behaviour in adolescence. It also follows from the literature that those with an Early Onset of sexually abusive behaviour are likely to have biological parents with their own neuropsychological risk factors, and histories of childhood abuse. Finally, the findings of Moffitt et al., (2002) that those with an Early Onset of anti-social behaviour are at the greatest risk of developing anti-social personality disorder traits in adulthood suggests that those on the Early Onset sexually abusive behaviour trajectory are most likely to have emerging severe personality disorder traits. 


\section{Emerging severe personality disorder (ESPD) traits in young people}

Personality disorder traits reflect interpersonal functioning deficits, emotional processing/regulation difficulties, and behavioural control problems. A variety of clinical personality disorders are outlined in the Diagnostic and Statistical Manual of Mental Disorders (DSM: American Psychiatric Association, 1994) and the International Classification of Mental and Behavioural Disorders (World Health Organisation, 1992). However, such disorders are rarely applied to children and adolescents; indeed, according to DSM-IV, anti-social personality disorder (APD) cannot be officially diagnosed until an individual reaches the age of 18. The diagnosis of conduct disorder (CD) is commonly applied to juveniles displaying persistent behavioural problems including aggression to people and animals, destruction of property, deceitfulness, theft, and serious rule violation. However, CD cannot be viewed as a childhood personality disorder because it is diagnosed solely on the basis of behavioural criteria without reference to interpersonal and affective criteria.

A personality disorder not currently defined in either DSM or ICD is psychopathic personality disorder (PPD). The criteria for identifying those with high levels of PPD traits are operationalised by Robert Hare in the Psychopathy Checklist - Revised (PCL-R: Hare, 2004), and include: interpersonal traits (manipulation); deficient affect (callousness); and behavioural traits (impulsivity). Within offender populations certain personality disorders are overrepresented. For example, the prevalence rate of APD among adult offenders is between 50 and 80 per cent, while between 10 and 25 per cent are likely to display high levels of PPD traits (Vaughan and Howard, 2005).

In a recent initiative between the Home Office, Department of Health, and HM Prison Service (the Dangerous and Severe Personality Disorder [DSPD] Programme) a series of assessment and treatment services have been piloted for individuals suffering from severe personality disorders. These services are specifically for adults whose severe personality disorders are functionally related to a high risk of committing further serious violent and/or sexual offences. Diagnoses of anti-social and psychopathic personality disorder are two of the primary admission criteria for these services.

While these diagnoses are rarely applied to children and adolescents, it is unlikely that the traits associated with these personality disorders only emerge when an individual reaches adulthood. Indeed, developmental models have been proposed within which the emergence of APD and PPD traits might be understood (Salekin and Frick, 2005; Vizard, French, Hickey and Bladon, 2004). Importantly, the model proposed by Vizard et al., (2004) includes potential for resilient children, and those who receive appropriate intervention, to move off the trajectory towards these personality disorders. Nonetheless, ethical, methodological and developmental concerns exist about extending the constructs of APD and PPD to children and young people (Marsee, Silverthorn and Frick, 2005). PPD is consistently highly correlated with poor treatment prognosis, and it is currently possible for clinicians to refuse adults with personality disorders admission to mental health services on the grounds of untreatability of their personality disorder. Therefore, the consequent negative effects of labelling children and young people as suffering from these disorders is raised as the primary deterrent to the downward extension of the constructs (Seagrave and Grisso, 2002). In addition, considerably more research is needed to identify valid and reliable methods of assessing the traits in young people. This is a key issue given that 'normal' adolescents express traits such as impulsivity. Therefore clear, developmentally appropriate definitions of the traits must be developed.

Despite these concerns the clinically acknowledged existence of a small group of children and young people displaying developmentally persistent, severe forms of anti-social behaviour has led to research extending the constructs to young people. A considerable body of research exists that identifies the childhood markers of these personality disorders (Bernstein, Cohen, Skodol, Bezirganian and Brook, 1996; Farrington and Coid, 2003; Lahey and Waldman, 2003; Simonoff, Elander, Holmshaw, Pickles and Murray, 2004). This research 
clearly identifies the developmental links between conduct disorder and anti-social personality disorder. For example, Loeber, Green and Lahey (2003) note that 30 to 40 per cent of juveniles with CD go on to develop APD in adulthood.

However, juvenile conduct disorder is neither a necessary, nor sufficient, risk predictor for developing APD in adulthood. Numerous additional factors have been identified (Moran and Hagell, 2001), including genetic influences; temperament; parenting practices and family environment; childhood anti-social behaviour; peer group influences; and environmental factors. Gene-environment correlations and interactions have been identified in the research literature (Mason and Frick, 2004), indicating that while genetics play a role in the development of some personality disorders, the exact nature of the role is yet to be fully explored. Results from twin studies have indicated stronger genetic influence for the antisocial behaviour of conduct disordered children who also display callous and unemotional traits, compared to conduct disordered children who lack these traits (Viding, Blair, Moffitt and Plomin, 2005).

Childhood temperament is another early indicator of later 'personality' (Shiner and Caspi, 2003). For example, Caspi et al., (1994) reported positive associations between early childhood 'high impulsivity', 'weak constraint' and 'negative emotionality' and adolescent/adult crime. Similarly, Tremblay, Phil, Vitaro, and Dobkin (1994) reported 'impulsivity' in preschoolers to be the best predictor of delinquency at the age of 13. Lahey and Waldman (2003) also proposed that variations along the following three dimensions of temperament 'negative emotionality', 'daring' and 'prosociality' are important in the prediction of later conduct problems.

A number of specific factors relating to parenting and family environment are known to be associated with the later emergence of anti-social behaviour and APD, including: psychiatric disorder in parents (especially personality disorder); criminality in parents; marital discord; violence between parents; inadequate parental supervision; harsh parental discipline; inconsistent parenting; maltreatment; lack of structured care in the family environment; loss of parents; one-parent families; large family size with little space between successive children; and institutional care of the child (Coid, 1999; Egelund and Sroufe, 1981; Farrington, 1995; McCord, 1979; Royal College of Psychiatrists, 1999). However, in a series of studies on the interactions between social and biological factors and the outcomes of arrest, or psychiatric disorder, by 18 years old, Werner and colleagues (Werner and Smith, 1982; Werner,1985) noted that, despite a socially deprived upbringing, some children had sufficient protective factors both within themselves (positive self-concept, affectionate disposition, internal locus of control), and, within the care-giving environment (mother in steady employment, structure and rules in household, close peer friends), to be able to develop without adverse outcome.

Finally, isolation or rejection from pro-social peers, as a result of peer rejection and/or seeking out other anti-social young people has also been associated with an increased risk of later anti-social behaviour and delinquency (Coie, Terry, Zakriski and Lochman, 1995; Dodge and Coie, 1987).

In comparison to research on the developmental trajectories of APD, research on the developmental trajectories of psychopathic personality disorder is in its infancy (Farrington, 2005). However, Bowlby (1951), in his pioneering observations, identified prolonged maternal deprivation as a precursor to the development of an 'affectionless character' in a group of juvenile delinquents. He concluded that insecure attachment to care-givers could precede the development of callousness and lack of empathy in young people. In addition, there has been empirical support for the role of anti-social parents, parental rejection, poor parental supervision, and erratic discipline (Campbell, Procter and Santor, 2004; Farrington, in press; McCord and McCord, 1964). While the Psychopathy Checklist Youth Version (PCL-YV; Forth, Kosson and Hare, 2003) has only recently been published, Paul Frick and his colleagues have been investigating the childhood manifestations of traits associated with PPD for a number of years. Their work aimed to explore the relationships between conduct disordered behaviour and the callous/unemotional traits associated with PPD. They hypothesised that among children displaying CD behaviour there would be a subgroup who also displayed callous/unemotional traits, and these young people would present in a manner similar to 
adults with psychopathic personality disorder (Barry et al., 2000; Christian, Frick, Hill, Tyler and Frazer, 1997).

Within a 'high risk' sample of children Frick and his colleagues identified a subgroup with both $\mathrm{CD}$ and callous/unemotional traits and observed that individuals within this group presented with deficits consistent with those seen in adults with PPD (Frick, O'Brien, Wootton and McBurnett, 1994). As such they might be regarded as presenting with some of the emerging traits associated with the severe personality disorders. For example, young people with CD and callous/unemotional traits had higher scores on measures of thrill seeking; lower sensitivity thresholds for punishment cues; and impaired abilities to accurately recognise and respond to fearful and sad facial expressions (Frick, 2004; Frick et al., 2003).

They also reported that these same young people exhibited greater variation in their antisocial behaviour, than other conduct disordered juveniles (Christian et al., 1997). Finally, those juveniles with both $C D$ and callous/unemotional traits tended to be more 'predatory' in their aggression, that is, they engaged in premediated, instrumental violence rather than simply reacting to provoking situations, and displayed less empathy for the suffering of others (Frick et al., 2003; Pardini, Lochman and Frick, 2003).

Frick and his colleagues noted weaker associations between the dysfunctional parenting practices and anti-social behaviour of those with both CD and callous/unemotional traits, compared to other anti-social juveniles. This implies that factors in addition to dysfunctional parenting, such as genetic influences and neuropsychological deficits, may play a greater role in the emergence of anti-social behaviour in young people with $C D$ and callous/unemotional traits.

Finally, in a study exploring the existence of a taxon for serious anti-sociality in boys, Skilling et al., (2001) reported that measures of both DSM conduct disorder criteria and psychopathic traits were capable of identifying a distinct subgroup of anti-social boys who, they concluded, were on a trajectory towards lifelong anti-social behaviour.

Current consensus among researchers suggests that neuro-cognitive abnormalities may underlie the psychopathy profile in both young people and adults (Blair, 2002; Vaughn and Howard, 2005; Viding, 2004), though further testing is required. Similarly, although the genetic influence on the presence of callous/unemotional traits is strong, more research is needed to explore the gene-environment interactions that determine which young people with these traits develop psychopathic personality disorder in adulthood. There are as yet no long-term follow-up studies of children and adolescents displaying PPD traits, therefore the full developmental trajectory of this particular personality disorder remains unclear.

Anti-social and psychopathic personality disorder traits emerge along a developmental pathway, and their strong association with serious violent and/or sexual offending in adulthood suggests that a subgroup of juvenile sexual abusers will display emerging severe personality disorder traits in childhood and adolescence. Predictions, based on the existing literature, about the characteristics likely to be observed in this subgroup include: parents with personality disorders; difficult early temperament in infancy; insecure attachment; persistent impulsivity from early childhood; diverse anti-social behaviours; and predatory and instrumental aggression. 


\section{Juvenile sexual abusers and juvenile sexually abusive behaviour}

Juvenile sexual abusers (JSA) comprise a small but significant subgroup of anti-social children and adolescents. Official statistics indicate that 20 per cent of those convicted of sexual offences are under 20 years of age (Home Office, 2003), while victim surveys report that 30 to 50 per cent of child sexual abuse is perpetrated by other children and adolescents (Davis and Leitenberg, 1987). However, much of the research on juvenile sexual abusers is limited by small sample sizes, heterogeneous samples, and the over representation of nonUK samples. Research in this field has tended to focus on the background characteristics of these young people, and describing the nature of their abuse. By contrast, research on recidivism and the possible typologies within this population has been limited.

\section{Abuser characteristics}

The families of many JSAs can be characterised as unstable or dysfunctional (Hsu and Strazynski, 1990; Veneziano and Veneziano, 2002). The parents have often experienced their own chaotic or disturbed childhoods, and therefore bring a legacy of inadequate parenting models and insufficient ability to cope with raising a family. Separation or divorce between biological parents early in the life of young abusers is common (Fehrenbach, Smith, Monastersky and Deisher, 1986) and often results in a consequently unstable home life due to constant family 'reorganisations' created by the appearance of multiple step fathers. Exposure to domestic violence is also frequently reported (Lewis, Shankok and Pincus, 1979; Van Ness, 1984), and prevalence rates for experiencing or witnessing abuse (physical, emotional or sexual), and physical neglect are high.

A feature of the family backgrounds of many JSAs is exposure to inappropriate or deviant sexuality (Richardson, Graham and Bhate, 1995). This can take the form of childhood sexual abuse within the family, inadequate family boundaries about viewing sexually explicit material (for example, through television or print media), and exposure to other adult family members engaging in consenting and/or non-consenting sexual activity. Given these experiences it is not surprising that a large proportion of JSAs are placed in the care of local authorities for substantial periods of their childhoods. However, even when this happens stability is not guaranteed as many children subsequently experience multiple changes in placement. Such experiences within the family increase the likelihood of insecure attachment bonds, and studies with adult sexual offenders have indeed reported high levels of insecure attachment (Hudson and Ward, 1997).

Non-sexual anti-social behaviour is also a feature of most young sexual abusers (Prentky, Harris, Frizell and Righthand, 2000). For example, disruptive behaviour in school is often reported, some of which can begin as early as primary school, and truancy and expulsion follow for a substantial proportion. Examples of the types of non-sexual anti-social behaviours exhibited by young sexual abusers include stealing, fire-setting, and physical aggression to people or animals. It is therefore consistent with these findings that high levels of diagnosed conduct disorder are reported within this population.

Learning difficulties as a result of inherent intellectual disabilities and/or emotional and behavioural problems feature in the profiles of a considerable number of young sexual abusers (Kahn and Chambers, 1991). For example, between a third and a half of the samples in six UK studies (Dolan, Holloway, Bailey and Kroll, 1996; James and Neil, 1996; Manocha and Mezey, 1998; O'Halloran et al., 2002; Richardson et al., 1995; Taylor, 2003) were subject to the provisions of a Statement of Educational Need (SEN). 


\section{Abuse characteristics}

With regard to the sexually abusive behaviour (SAB) perpetrated by juvenile sexual abusers, empirical investigation indicates considerable similarity with the behaviours perpetrated by adult sexual offenders (Groth, 1977; Wasserman and Kappel, 1985), although research has not yet determined whether the behaviours carry the same meaning for juveniles as they do for adults. Juvenile abusers are capable of committing contact (including penetration) and non-contact sexual offending behaviours, as well as offending against a range of victims including, younger children, peers and adults (Awad and Saunders, 1991; Boyd et al., 2000). Although juveniles may abuse male or female victims, females tend to be the more prevalent victims. Juvenile abusers also tend to victimise those they know, including family members or friends/acquaintances, rather than strangers, and therefore, they carry out much of the abusive behaviour in their own homes (Fehrenbach et al., 1986). Some juveniles also use verbal and/or physical coercion to ensure their victim's compliance, or to prevent the victim's disclosure after the abuse.

Some differences in the sexually abusive behaviours perpetrated by juveniles have been noted, particularly between those abusing younger children and those abusing peers or adults. For example, those who victimise peers/adults have a somewhat higher rate of using verbal or physical coercion (Becker, Cunningham-Rathner and Kaplan, 1986). They are also more likely to exclusively abuse female victims, and are more likely to abuse strangers, than those who abuse younger children (Boyd et al., 2000; Richardson et al., 1995).

\section{Recidivism}

Despite research indicating that as many as a half of adult sex offenders report an adolescent onset of sexual deviance (Abel, Osborn and Twigg, 1993), it does not necessarily follow that a half of juvenile sexual abusers will become adult sex offenders. However, very few studies have examined the recidivism rates of JSAs in adulthood, most have only looked at recidivism rates during the adolescent period (Smith and Monastersky, 1986). The results of these studies indicate that within the adolescent period approximately a quarter of juveniles who have been convicted of one sexual offence in adolescence will be convicted of another sexual offence. However, in studies that examined recidivism in adulthood the rates for sexual offences range from nine per cent to 37 per cent, depending on the sample type and length of follow-up (Nisbet, Wilson and Smallbone, 2004; Rubinstein, Yeager, Goodstein and Lewis, 1993; Sipe, Jensen and Everett, 1998; Worling and Curwen, 2000), although, sexual offences are likely to be disproportionately underestimated by officially recorded conviction data as such offences are notoriously difficult to detect and successfully prosecute (Lussier, 2005). With this caveat in mind, it may be assumed that reported recidivism rates are likely to be an underestimate of the true rate of sexual recidivism.

Of equal, and perhaps of more importance, are the rates of non-sexual recidivism observed in these studies. In adolescence, JSAs who recidivate are six times more likely to be arrested for non-sexual than sexual offences (Caldwell, 2002), and, in adulthood the prevalence rates for non-sexual recidivism varies from 37 to 89 per cent, again depending on sample type and length of follow-up. So, while only a minority of young people presenting with sexually abusive behaviour are likely to be convicted of sexual offences in adulthood, a high proportion are likely to be convicted of non-sexual offences. This indicates that sexually abusive behaviour in childhood may represent an important marker for the emergence of a generally anti-social profile in adulthood. Caldwell (2002) makes precisely this point, suggesting that the recidivism data indicates the well known link between an Early Onset of offending and subsequent chronic offending may not be offence specific. In other words, young people with an Early Onset of sexually abusive behaviour may be at high risk for future chronic non-sexual offending.

\section{Typologies}

To date the possibility that clinically relevant typologies of juvenile sexual abusers might be identified using personality factors has been relatively neglected. Smith, Monastersky and 
Deisher (1987) and Worling (2001) represent two exceptions to this trend. Using different methodologies both studies identified four personality-based subgroups within their populations of juvenile sexual abusers: anti-social/impulsive; unusual/isolated; overcontrolled/reserved; and confident/aggressive (Worling, 2001). Worling was also able to successfully discriminate between the subgroups on factors such as 'removal from home', 'parental marital status', and 'criminal charges' indicating that JSAs with different personality profiles display differential relationships with known risk factors for anti-social outcomes. The 'antisocial/impulsive' subgroup showed particularly strong positive associations between these risk factors and criminal behaviour.

Sexual aggression is one type of anti-social behaviour and studies with adult sex offenders have revealed that some display a stable and persistent pattern of sexual offending (often referred to as 'specialists'), while others only sexually offend occasionally as part of a wider repertoire of other offending behaviours (often referred to as 'generalists') (Gebhard, Gagnon, Pomeroy and Christenson, 1965; Soothill, Francis, Sanderson and Ackerley, 2000). This suggests that trajectories for sexual offending behaviour may exist, although they have not been extensively explored among a juvenile population.

In an early attempt to explore trajectories, Becker and Kaplan (1988) suggested a three-path model. They labelled the first path 'dead end' because no further sexual offences occurred after the first; the second path they referred to as 'the delinquent path' because further acts of sexual abuse were committed, but, only as part of a wider repertoire of offending and delinquency. The final path they labelled 'the sexual interest path', and hypothesised that it would characterise those who continued to sexually abuse to the predominant exclusion of other non-sexual offending. They also hypothesised that those on the third path would be most likely to develop paraphilic arousal patterns such as, paedophilia.

Among adult rapists, Seto and Barbaree (1997) hypothesised the existence of two distinct developmental pathways. One group was believed to have an Early Onset of anti-social behaviour, to be persistently anti-social, and to offend both sexually and non-sexually. The second group was thought to have less extensive non-sexual offending histories and more sexual offences, as well as being more opportunistic in their sexual offending. In the only test of such pathways among adolescent sexual abusers Butler and Seto (2002) compared two subgroups, categorised according to their non-sexual offence history, i.e. 'sex-only' and 'sexplus'. The sex-only group displayed few conduct disorder problems, revealed more pro-social attitudes, and had an estimated low risk for future delinquency. While the sex-plus group displayed a varied and criminally versatile pattern of offending, high levels of conduct disorder problems, and endorsed many pro-criminal beliefs and attitudes.

\section{Sexually abusive behaviour and emerging severe personality disorder traits}

The importance of understanding the influence of personality disorder traits on offending behaviour is increasingly recognised (Frick et al., 2003). Severe personality disorders such as APD and PPD are consistently identified as conferring a high risk for future recidivism, particularly for serious violent and/or sexual offending. Empirical investigations of the relationship between sexually abusive behaviour and psychopathy traits are limited, but among adult sex offenders, a minority of child abusers (10\% to $15 \%)$, are estimated to have high levels of PPD traits, while a greater proportion of rapists (40\% to $50 \%)$, are estimated to be high scoring psychopaths (Gretton, Catchpole, McBride, Hare and Regan, 2005). Brown and Forth (1997) also reported that in a sample of adult rapists, PPD traits had no significant association with the 'age of onset of sexual offending', 'relationship to the victim', or 'number of prior sexual offences'. However, there was a significant association with the 'number of victims' and 'extent of previous non-sexual offending'. These findings suggest that PPD traits are not specifically associated with an increased risk of sexual offending per se, but they are associated with high frequency offending behaviours involving multiple victims.

In a sample of incarcerated juvenile sexual offenders, Gretton, McBride, Hare, O'Shaughnessy and Kumka (2001) reported 13 per cent had high levels of PPD traits; similarly Langstrom and Grann (2000) reported a prevalence rate for PPD traits of 20 per cent in their incarcerated sample. Of particular interest in Gretton et al.'s (2001: 2005) work was 
the finding that the presence of PPD traits was associated with increased risk for both 'violent' and 'non-violent' recidivism, but not for 'sexual' recidivism. Consistent with the findings from the adult literature the authors concluded that juvenile sex offenders with PPD traits are more likely to engage in a variety of offending behaviours, than 'specialising' in sex offending.

Juvenile sexual abusers share many psychosocial characteristics with non-sexually abusing juvenile delinquents. Their conviction profiles also suggest that the majority have a generally anti-social profile, as non-sexual offences predominate in both adolescence and early adulthood. The type of sexually abusive behaviour exhibited by juveniles is relatively well documented, although it is known to differ between subgroups. This indicates the need for better conceptualisations of JSA subgroups to enable clinical profiles of the behaviours characteristic of different types of juvenile sexual abusers to be devised.

Preliminary work on identifying subgroups of young people presenting with sexually abusive behaviour has been promising, although the clinical utility of such distinctions has yet to be explored. Given their similarity to non-sexually abusing delinquents it is likely that the Early and Late Onset trajectories will be a useful method of discriminating between subgroups of JSAs. The finding that PPD traits among sexual abusers have more predictive validity for nonsexual offending behaviour is also important. It suggests that those juveniles who present with sexually abusive behaviour and PDD traits may represent the group most likely to go on to engage in a generic pattern of serious offending in adulthood. 


\section{Conclusions from the evidence base}

The concept of age of onset trajectories has proved very useful for distinguishing between subgroups of anti-social youth, but has not yet been evaluated with a population of juvenile sexual abusers. The literature on age of onset enables hypotheses to be made about the likely characteristics of JSAs on the Early and Late Onset trajectories. For example, on the basis of the findings reported by Moffitt and colleagues (1996) it would be expected that young people on the Early Onset trajectory are likely to have higher rates of difficult temperament in infancy, and experience poorer parenting, including abuse and neglect during childhood, compared to their peers on a Late Onset trajectory. Individuals on the Early Onset trajectory would also be expected to have higher rates of non-sexual anti-social behaviour in childhood, but it is likely that in adolescence both trajectories would present with similar rates. By late adolescence and early adulthood, however, it would be expected that individuals on the Early Onset trajectory would continue to engage in anti-social behaviour, consistent with the notion of a life course persistent or chronic trajectory (Moffitt et al., 2002). By contrast, those on the Late Onset trajectory would be expected to show reduced levels of such behaviour. Conviction data are likely to reflect this pattern.

Some of Moffitt and colleagues' findings also provide a basis for hypothesising about the different kinds of sexually abusive behaviour likely to be observed by the two trajectories. For example, the finding that juveniles with an Early Onset of anti-social behaviour were more likely to have been exposed to higher rates of varied abuse and neglect early in childhood (Moffitt et al., 1996) leads to the expectation that JSAs with an Early Onset of SAB would have been exposed to higher rates of varying kinds of abuse, including inappropriate sexualisation, physical abuse, and neglect from an early stage in development. Meanwhile, those with a Late Onset of SAB would be expected to be less likely to have been exposed to abusive experiences and inappropriate sexualisation in early childhood. Differences in early experience, such as these, are likely to influence the nature of any SAB observed in the trajectories. For those on an Early Onset trajectory, SAB is likely to occur in the context of a young child externalising his/her response to multiple sexual and non-sexual traumatic stressors and unpredictable environments. This is not necessarily the case for the Late Onset trajectory, where explanations for SAB are more difficult to extrapolate from Moffitt's theory of anti-social behaviour. However, the previously published characteristics of the abuse perpetrated by adolescents (Boyd et al., 2000; Richardson et al., 1995) suggest that their SAB may be motivated by difficulty initiating intimate peer relationships, or by difficulty in expressing anger or power conflicts, leading to a tendency to dominate and exert control over others.

Emerging severe personality disorder traits are only exhibited by a small group of anti-social individuals. However, this small group are known to be responsible for a disproportionate number of violent and/or sexual offences, and for engaging in persistent anti-social behaviour across the developmental trajectory from childhood to adulthood. The study of juvenile sexual abusers with ESPD traits is in its infancy, and most of the research has focused on the effect of ESPD traits on recidivism rates. As a result, little is known about the psychosocial or sexually abusive behaviour characteristics of young people presenting with sexually abusive behaviour, who also present with emerging severe personality disorder traits. Nonetheless, the existing literature enables some hypotheses to be made. For example, it is likely that those with ESPD traits will have parents with mental health problems from whom some genetic traits may have been inherited (Viding et al., 2005). They are also likely to exhibit difficult temperaments in infancy and childhood (Shiner and Caspi, 2003), though they may not necessarily have experienced more adverse family backgrounds than their non-ESPD counterparts.

Behaviourally, it would be expected that those young people with ESPD traits would be likely to exhibit a diverse range of anti-social behaviours, beginning in early childhood and persisting across subsequent developmental periods (Christian et al., 1997; Frick, 2004; Skilling et al., 2001). In particular they would be expected to be highly impulsive, and engage 
in behaviours reflecting callousness such as cruelty to animals, predatory aggression, and recklessness (Frick, 2004). In the context of SAB, one would expect higher levels of predatory and instrumental sexual aggression, such as grooming victims, abusing a diversity of victims, and using excessive force. It would also be expected that such serious anti-social behaviour would result in these young people obtaining higher rates of conviction, particularly for violent offences, although not necessarily for sexual offences (Gretton et al., 2001; 2005).

Finally, in view of the fact that Moffitt et al., (2002) noted that those with an Early Onset of anti-social behaviour are at increased risk of developing ESPD traits, an interaction between these two concepts would be expected. Specifically, it would be predicted that young people with an Early Onset of SAB would be more likely to have ESPD traits. If this were found to be the case it would indicate that JSAs with ESPD traits do not represent a homogeneous group, and raises the possibility that there may be distinct subgroups of juvenile sexual abusers with ESPD traits, each associated with different aetiological factors.

The current study was designed to investigate the hypotheses relating to both age of onset and ESPD traits, with the primary aim of informing clinical practice in relation to prevention, assessment and risk management for young people presenting with sexually abusive behaviour. 


\section{Aims and hypotheses}

\section{Aims}

1. The first aim was to describe a UK cohort of children and young people presenting with sexually abusive behaviour, in relation to their psychosocial, psychiatric and sexually abusive behaviour characteristics, as well as describing their conviction profiles.

2. The second aim of the study was to explore the degree to which 'age of onset' trajectories could be used to identify distinct subgroups within a population of juvenile sexual abusers, in relation to psychosocial characteristics, anti-social behaviour and conviction profiles.

3. The third aim of the study was to explore the degree to which high levels of emerging severe personality disorder (ESPD) traits could be used to identify a distinct trajectory of juvenile sexual abusers, in relation to psychosocial characteristics, anti-social behaviour and conviction profiles.

4. The fourth aim of the study was to determine whether those on the Early Onset trajectory were more likely to have ESPD traits, and to explore the possibility that the ESPD group may be further differentiated.

5. The fifth aim of the study was to provide practical guidance for clinicians, policy makers and researchers in relation to the implications of any findings by outlining:

- the characteristics of Early Onset juvenile sexual abusers, Late Onset juvenile sexual abusers, and juvenile sexual abusers with ESPD traits, to help inform clinicians about early identification and intervention;

- the resource implications and service provision requirements for policy makers developing services to meet the needs of different groups of juvenile sexual abusers;

- the research priorities with regard to juvenile sexual abusers and juveniles with ESPD traits.

\section{Hypotheses}

1. Sexually abusive behaviour in childhood/adolescence is indicative of a generally antisocial profile. Therefore, a cohort of juvenile sexual abusers would be predicted to have convictions for both sexual and non-sexual offences, with a greater proportion of the latter.

2. The developmental trajectories of those with Early and Late Onset of sexually abusive behaviour are predicted to be distinguished in relation to the following:

- Psychosocial characteristics

- $\quad$ The Early Onset trajectory is predicted to have higher rates of early difficult temperament and abuse/neglect.

- Sexually abusive behaviour

- $\quad$ The Early onset trajectory is predicted to have higher rates of victimising both male and female, and both child and adult victims. The Late onset trajectory is predicted to have higher rates of victimising specific victim groups such as only much younger children.

- Non-sexual anti-social behaviour

- $\quad$ The Early onset trajectory is predicted to have higher rates of antisocial behaviour in childhood. 
In relation to their convictions, both trajectories were expected to have similar rates of conviction by adolescence.

3. Those with ESPD traits will be distinguished from those without ESPD traits in relation to the following:

- Psychosocial characteristics

- $\quad$ Those with ESPD traits are predicted to have higher rates of parents with mental health problems.

- $\quad$ Those with ESPD traits are predicted to have higher rates of early difficult temperament.

- Sexually abusive behaviour

- $\quad$ Those with ESPD traits are predicted to have higher rates of predatory $\mathrm{SAB}$ for example, prior grooming, abusing strangers, abusing both males and females, and both children and adults.

- Non-sexual anti-social behaviour

- $\quad$ Those with ESPD traits are predicted to exhibit a variety of nonsexual anti-social behaviours throughout childhood and adolescence.

- $\quad$ Those with ESPD traits are predicted to exhibit cruelty to animals and reckless behaviour throughout childhood and adolescence.

- Conviction profile

- $\quad$ Those with ESPD traits are predicted to have higher rates of convictions, particularly for violent and non-violent offences.

4. Those on the Early Onset trajectory are predicted to be more likely to present with ESPD traits. 


\section{Method}

\section{Sample}

The sample consists of a cohort of children and adolescents referred to The Young Abusers Project (YAP) between 1992 and 2003 inclusive. During this period 325 cases were referred to the YAP clinical team. However, the referring agencies for 36 cases did not pursue the referral, and because there was insufficient information in the files to conduct a valid file review they were excluded from the analysis. Nine further cases were referred for an assessment, as a result of perpetrating non-sexual violent offences including murder, but because the primary presenting problem was not sexually abusive behaviour they were also excluded from the study.

The final sample comprised 280 cases referred for an assessment of their sexually abusive behaviour.

\section{The Young Abusers Project (YAP)}

The Young Abusers Project is a specialist fourth tier, National Health Service (NHS) forensic child and adolescent service, co-managed by the National Society for the Prevention of Cruelty to Children (NSPCC) and the local Primary Care Trust. Fourth tier NHS services cater for clients with complex, persistent problems that have proved resistant to previous interventions in third tier, community-based services (such as local Child and Adolescent Psychiatry Services), and instead require specialist input from highly trained multi-disciplinary teams. YAP is a non-residential service that accepts nationwide referrals to assess and, where geographically viable, provide treatment to children and young people displaying sexually abusive behaviour. Referrals are predominantly received from Local Authority Social Services departments, though criminal justice and health service referrals are also accepted. The upper age limit for referrals is 21 , but there is no lower age limit.

As a designated fourth tier NHS service the young people who are referred tend to present with long-standing, persistent sexual and non-sexual anti-social behaviour, and a wide range of co-morbid (co-occurring) psychiatric and developmental disorders. The YAP service has lengthy experience of some of the most complex cases in the country. It has also made a substantial contribution to the evidence base in this field, and consulted on the development of specialist services for children and young people with sexually harmful behaviour. As a result the YAP service continues to provide consultation to service developers and policy makers

\section{Data collection and coding}

The data was collected from the YAP clinical files and the Offenders Index.

\section{YAP clinical files}

These contain copies of the pre-assessment documents obtained by the referring agencies. They can include: medical histories; Social Services family assessment reports; minutes of Child Protection Meetings; scholastic reports; previous psychiatric or psychological reports; and witness statements. They also contain the YAP assessment reports including a Specialist Risk Assessment Report, a Psychological Report, and a Psychotherapy Assessment Report.

In some cases the referrers were only able to provide a limited number of pre-assessment reports, therefore not every case had the same number or type of reports containing background information. However, all cases included in the study had reports from more than one informant, thereby ensuring that multiple sources of information were available, and single sources were not relied upon. As each referral had to have an allocated Social Worker 
before being accepted by YAP, all cases were subject to a Social Services family assessment. This ensured that, as a minimum, the parents' backgrounds and the early childhood of each case had been assessed. A developmentally sensitive coding schedule was developed by the first author to enable data to be extracted from the files (see the glossary in Appendix 1 for the definitions used to rate the variables). Information was coded across the following domains:

Demographics

Referral details

Biological parents' history

Family functioning

Educational achievement

Cognitive assessment

Local Authority placement history
Physical and Mental Health

Sexual abuse victimisation

Physical abuse victimisation

Emotional abuse victimisation

Physical Neglect victimisation

Sexually abusive behaviour

Non-sexual Aggression/violence

Given that the type of pre-assessment reports provided were not identical in each case, there was variability in the information available for coding. Consequently, it was necessary to rate items as 'don't know' if the file did not contain an explicit statement that the item was absent in the case. Given that this was a sample of chronically and seriously anti-social young people, the authors were confident that if the variable had been a concern in the case it would have been referred to. However, as many of the variables resulted in being coded as either yes or don't know we acknowledge the results are a likely underestimate of the true prevalence of the items, and that some cases will have been falsely coded as negative when in fact the item was present, but not recorded in the file. This was unlikely to affect the outcome of the between-group comparisons because the same issue was relevant for all cases.

At the time of data collection the researcher coding the data was blind to both the age of onset and ESPD status of the cases.

The Psychopathy Checklist Youth Version (PCL-YV)

The Psychopathy Checklist Youth Version (Forth et al., 2003) was scored on the basis of information contained in the YAP files. This is a 20-item rating scale for assessing psychopathy traits in young people aged from 12 to 18 years (see Appendix 2 for a list of the items). This measure should only be used by those who have received accredited training on the PCL-R or PCL-YV. The researcher who rated the case files had completed Psychopathy Checklist training delivered by Robert Hare and Adelle Forth. Attempting to score the items without the use of the standardised manual will result in an invalid and unreliable assessment. Ideally, the items should be scored following a semi-structured interview in addition to a file review. However, for the purposes of research a file review alone is acceptable, as long as sufficient information is provided and is sourced from multiple informants across different domains (Forth et al., 2003; Grann, Langstrom, Tengstrom and Stalenheim, 1998; Wong, 1988). These stipulations were adhered to when rating the YAP case files.

The 20 items on the PCL-YV are conceptually consistent with those of the adult measure (PCL-R; Hare, 2004), although some items are altered to reflect the developmental differences between adults and juveniles. For example, the adult items regarding 'promiscuity' and 'many marital relationships' were altered to reflect 'impersonal sexual behaviour' and 'unstable interpersonal relationships'. Adequate internal consistency for this measure has been reported across settings with Cronbach's alphas of .85, .87, and .94 reported in institutional, probation and clinic/community samples respectively (Forth et al., 2003). Interrater reliabilities, using file only assessment procedures, have also revealed good intraclass correlation coefficients (ICC) of .85 (McEachran, 2001), and .93 (Jack, 2000). Inter-rater reliabilities were not available in this study as only one researcher rated the case files. However, an alpha coefficient of .85 for the PCL-YV scores, and a mean inter-item correlation of .22 (range -.05 to .82 ) indicate satisfactory reliability and homogeneity. 


\section{The Offenders Index}

The Offenders Index is a database administered by the Home Office Research and Statistics Directorate. It contains specific amounts of information about convictions for instance, date of conviction, disposal, and the offences charged with, for standard list offences recorded in England and Wales. These offences include all indictable offences, and the more serious non-indictable offences. Data from this resource are accessed by 'matching' details such as name and date of birth provided by the external research team to the information on the database. If the matching is successful a list of convictions accrued by each individual is produced. Unfortunately, many offence details including the age of the victim and what happened in the offence are not included on the Offenders Index. Successful matching between the sample and the Offenders Index was achieved for 96 per cent $(n=268)$ of the cases.

The data obtained by the YAP Research Unit covered all convictions recorded up to December 2003. Three conviction profiles were analysed in this study: lifetime conviction profile; pre-YAP conviction profile; and post-YAP conviction profile. The lifetime conviction profile was based on convictions that occurred between the age of ten years (age of criminal responsibility in UK) and December 2003. The pre-YAP conviction profile was based on convictions that occurred before the original YAP assessment, but also included any offences that were part of the YAP assessment. The post-YAP conviction profile was based on any new convictions that occurred after the YAP assessment up to December 2003. Within each profile three mutually exclusive categories of offences were examined: sexual offences; violent offences; and non-sexual and non-violent offences.

For each of these conviction profiles the time spent 'at risk' of being convicted was calculated, that is, the time when individuals were not in custody and were, therefore, able to be convicted. All calculations of the time at risk began on the individual's tenth birthday. Due to the wide age range of cases referred to YAP, and the period during which cases were collected (1992 - 2003), the times spent 'at risk' varied considerably across individual cases.

\section{Ethical considerations}

The information used in this study was gathered as part of the YAP's routine clinical assessment. All referrers were informed, at the time of referral, that the data would be used for anonymised descriptive research. They gave informed consent for the data to be used for research. Following an independent review of the study protocol, the local Primary Care Trust's (PCT's) Research Ethics Committee approved this study. In accordance with that approval, all cases were anonymised, and only identifiable by a unique research number, and no individual cases are identifiable from the results.

\section{Data analysis procedure}

Figure 7.1 outlines the four separate groups of analysis undertaken in this study.

The first aim of the study was to describe the characteristics of the cohort. As indicated in Figure 7.1, N=280 cases were included in the analysis. Frequencies of the psychosocial characteristics, psychiatric diagnoses and sexually abusive behaviour were calculated, as well as the prevalence of convictions in each of the three conviction profiles.

The second aim of the study was to compare the psychosocial characteristics, sexually abusive behaviour, non-sexual anti-social behaviour, and conviction profiles of the Early and Late Onset SAB trajectories. As indicated in Figure 7.1, $\mathrm{n}=213$ cases were available for this analysis. In 67 cases (24\%) the age at which SAB had begun could not be confirmed, and therefore these were excluded. This left $n=93$ on the Early Onset trajectory that is, the SAB had begun before the individual's eleventh birthday and continued after the eleventh birthday into adolescence, and $n=120$ on the Late Onset trajectory that is, the SAB had only begun after the eleventh birthday. The cut-off age of 11 years was chosen as the discriminator between childhood and adolescence because the same cut-off is used in the Diagnostic and 
Statistical Manual of Mental Disorders -IV, and by Moffitt et al., (1996). It must be stressed that although those on the EO trajectory began their SAB in childhood, the reality of child and adolescent services meant that, with the exception of one case, all those on the Early Onset trajectory were not referred to YAP until they had reached adolescence. Chi-Square analysis (using Cramer's $V$ test for categorical variables) was used to compare the psychosocial characteristics, $\mathrm{SAB}$, non-sexual anti-social behaviour, and conviction profiles of the two trajectories. The 95 per cent confidence intervals for the percentages are given where significant differences were identified. Chi-Square analysis only tests the association between the characteristics and subgroups; it is not a test of cause and effect.

Figure 7.1: Overview of the analysis undertaken in the study

\begin{tabular}{|c|c|c|c|}
\hline 1 & $\begin{array}{l}\text { Characteristics of the } \\
\text { sample } \\
\mathrm{N}=280\end{array}$ & $\mathrm{~N}=280$ & $\begin{array}{l}\text { Descriptive analysis: } \\
\text { - Psychosocial } \\
\text { characteristics and } \\
\text { psychiatric diagnoses } \\
\text { - SAB characteristics } \\
\text { - Conviction profiles }\end{array}$ \\
\hline 2 & $\begin{array}{l}\text { Age of onset trajectories for } \\
\text { juvenile sexually abusive } \\
\text { behaviour } \\
n=213 \\
(n=67 \text { not classifiable })\end{array}$ & $\begin{array}{l}n=93 \text { Early Onset } \\
n=120 \text { Late Onset }\end{array}$ & 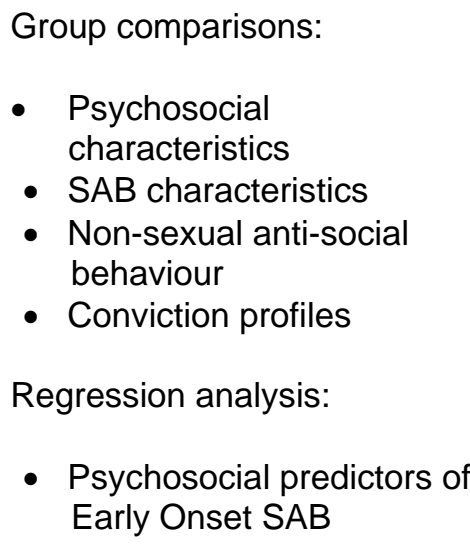 \\
\hline 3 & $\begin{array}{l}\text { Emerging severe personality } \\
\text { disorder traits } \\
\mathrm{n}=203 \\
(n=77 \text { not classifiable })\end{array}$ & $\begin{array}{l}n=54 \text { ESPD traits } \\
n=149 \text { non-ESPD } \\
\text { traits }\end{array}$ & $\begin{array}{l}\text { Group comparisons: } \\
\text { - Psychosocial } \\
\text { characteristics } \\
\text { - SAB characteristics } \\
\text { - Non-sexual anti-social } \\
\text { behaviour } \\
\text { - Conviction profiles }\end{array}$ \\
\hline 4 & $\begin{array}{l}\text { The relationship between } \\
\text { age of onset trajectories for } \\
\text { SAB and ESPD traits } \\
n=187\end{array}$ & $\begin{array}{l}\mathrm{n}=32 \text { Early Onset }+ \\
\text { ESPD traits } \\
\mathrm{n}=18 \text { Late Onset }+ \\
\text { ESPD traits }\end{array}$ & $\begin{array}{l}\text { Group comparisons: } \\
\text { - Psychosocial } \\
\text { characteristics } \\
\text { - SAB characteristics }\end{array}$ \\
\hline
\end{tabular}

Conviction prevalence rates were calculated for the lifetime, pre-YAP, and post-YAP periods, taking account of the 'time at risk' in each period. In addition, Kaplan-Meier analysis was used to compare the survival rates for the first sexual and violent convictions post-YAP. The Kaplan-Meier procedure provides a graphical depiction of how many and how quickly 
individuals 'fail', that is, are convicted during the follow-up period. The Kaplan-Meier analysis also takes account of 'censored cases'; these are cases in which convictions do not occur before the end of the follow-up period. It should be noted, however, that these censored cases may 'fail' after the end of the follow-up period, but these convictions will not be included in the analysis.

The third aim of the study was to identify a subgroup of JSAs with emerging severe personality disorder traits, and compare them with a non-ESPD group, in relation to their psychosocial characteristics, sexually abusive behaviour, non-sexual anti-social behaviour, and conviction profiles. As indicated in Figure 7.1 only $n=203$ cases were included in this analysis. This is because the PCL-YV (one of the measures used to define the construct of ESPD traits) is not recommended for use with young people under 12 years of age. Consequently, all those aged under 12 at the time of the original YAP assessment $(n=54)$ were excluded from the analysis. In addition, cases where there was insufficient file information to provide a valid PCL-YV score $(n=23)$ were also excluded. This left a total of $n=203$ cases with valid PCL-YV scores. The ESPD and non-ESPD groups were compared, as above, using Chi-Square and Kaplan-Meier analysis.

The final aim of the study was to explore the prevalence of cases presenting with ESPD traits on the Early and Late Onset trajectories. As indicated in Figure 7.1, n=187 cases were available for this analysis. Only those on the age of onset trajectories with valid PCL-YV scores were included, and not all members of the ESPD subgroups could be categorised according to the age at which their $S A B$ began. Exploratory comparisons were also conducted between those with ESPD traits on the Early and Late Onset trajectories in relation to psychosocial and $S A B$ characteristics. For these comparisons only $n=50$ cases were available for analysis ( $n=32$ ESPD on the Early Onset trajectory, and $n=18$ ESPD on the Late Onset trajectory). Again, Chi-Square analysis was used to compare the groups.

All data analysis was conducted using SPSS for windows (v.11). 


\title{
8. Characteristics of the sample $(\mathrm{N}=280)$
}

\author{
Demographics
}

The 280 juvenile sexual abusers in the sample were predominantly male (91\%), Caucasian (83\%), and born in the UK (93\%). The other ethnicities represented include Black (8\%), Black Mixed race (7\%), Bangladeshi or Indian (1\%), with the final one per cent having no recorded ethnicity. At the time of the original YAP assessment the average age of the sample was 13.9 years old (sd 3.0), though their ages ranged from $5.5-21.11$ years old. The majority (81\%) were aged between 11 and 17 years when they were assessed, but 14 per cent were under ten years old. Intellectual disability, defined as an IQ of $\leq 70$, was present in 24 per cent of the sample. This was measured using either the Wechsler Intelligence Scale for Children (WISCIII) (The Psychological Corporation, 1992), or on the basis of clinical judgement.

Referral to the Young Abusers Project occurred through a number of routes: the majority (63\%) were referred by Social Services departments, 21 per cent were referred through a health route, and 14 per cent through the criminal justice service. A third of those referred through Social Services were subject to child protection legislation including Interim and Full Care Orders.

\section{Psychosocial characteristics and psychiatric diagnoses}

Data on a range of psychosocial characteristics were collected from the case files, and the clinical diagnoses were made as part of the YAP specialist risk assessment. As outlined in Table 8.1, detrimental parenting practices such as harsh parental discipline, lack of parental supervision, and inconsistent parenting were characteristic of the family environments of many young people in the sample. The parents of these young people may have been illequipped to provide good parenting as a result of their own childhood experiences. For example, as children the parents of 40 per cent of the sample had been victims of abuse or neglect, and 24 per cent had spent time in Local Authority Care. Many (41\%) were also judged to be suffering from mental disorders in adulthood.

At the time of the YAP assessment, over a third of the sample had parents with criminal records, and only 23 per cent were living with both their biological parents. Five types of maltreatment were examined in this study (physical abuse, sexual abuse, emotional abuse, physical neglect, and exposure to domestic violence). Nearly every young person (92\%) had experienced at least one type of maltreatment, and in most cases this had begun before they reached seven years of age. A significant minority of the sample (25\%) had experienced all five forms of maltreatment.

Over three-quarters of the sample had been removed from their families to Local Authority Care. The removal occurred at an average age of 9.5 years old (sd 4.0). Discontinuity of care, either as a result of being moved by the Local Authority, or being moved between family members, was a common experience for the majority, that is, only 14 per cent remained in their original family unit at the time of the YAP assessment. Of those with more than one move in placement, 31 per cent had moved between six to twenty times. In addition to sexually abusive behaviour, many in the sample also displayed non-sexual anti-social behaviour, including, physical aggression (70\%), stealing (55\%), fire-setting (27\%), and physical cruelty to animals (19\%), as well as being generally hyperactive/impulsive. However, only 18 per cent were reported as misusing alcohol or drugs.

Also outlined in Table 8.1 are the psychiatric disorders exhibited by the sample. The figures cited refer to the prevalence of those reaching the threshold for a diagnosis. As indicated, Conduct Disorder was the most prevalent diagnosis, although nearly a third of the sample also reached the threshold for a diagnosis of Post-traumatic Stress Disorder (PTSD). Just over a quarter of the sample also displayed clinically relevant levels of speech and language 
problems. In addition, some members of the sample displayed symptoms but not enough to reach the threshold for a diagnosis, therefore they were categorised as displaying 'subthreshold' levels of the disorder. Collecting this additional data revealed the full extent of the emotional and behavioural disturbance in the sample. For example, an additional 35 per cent had sub-threshold levels of CD, 37 per cent displayed sub-threshold levels of PTSD, and a total of 68 per cent displayed symptoms of hyperactivity, impulsivity, or inattention.

Table 8.1: Psychosocial characteristics and psychiatric diagnoses of the whole sample

\begin{tabular}{|c|c|c|}
\hline & & $\begin{array}{c}\text { Whole sample } \\
(\mathrm{n}=280) \\
\% \\
\end{array}$ \\
\hline $\begin{array}{l}\text { Parental and } \\
\text { family factors }\end{array}$ & $\begin{array}{r}\text { Parental criminality } \\
\text { Parental childhood abuse } \\
\text { Parental mental health problems } \\
\text { Inconsistent parenting } \\
\text { Lack of parental supervision } \\
\text { Inadequate family sexual boundaries } \\
\text { Marital separation/divorce }\end{array}$ & $\begin{array}{l}35 \\
40 \\
41 \\
64 \\
49 \\
44 \\
73\end{array}$ \\
\hline $\begin{array}{l}\text { Attachment } \\
\text { related factors }\end{array}$ & $\begin{array}{r}\text { Early difficult temperament } \\
\text { Removal to Local Authority Care } \\
6+\text { changes in home placement } \\
\text { Insecure attachment }\end{array}$ & $\begin{array}{l}28 \\
76 \\
35 \\
53\end{array}$ \\
\hline Child factors & $\begin{array}{r}\text { Peri natal problems } \\
\text { Hyperactive/impulsive behaviour } \\
\text { Excluded from school } \\
\text { Any substance misuse } \\
\text { Socially isolated } \\
\text { Ever on the Child Protection Register } \\
\text { Statement of Educational Need }\end{array}$ & $\begin{array}{l}26 \\
68 \\
42 \\
18 \\
58 \\
64 \\
45\end{array}$ \\
\hline Trauma factors & $\begin{array}{r}\text { Childhood sexual abuse } \\
\text { Physical abuse } \\
\text { Emotional abuse } \\
\text { Physical neglect } \\
\text { Exposure to domestic violence } \\
\text { Experienced any of the above maltreatment } \\
\text { Experienced all five of the above maltreatments }\end{array}$ & $\begin{array}{l}71 \\
66 \\
74 \\
59 \\
49 \\
92 \\
25\end{array}$ \\
\hline $\begin{array}{l}\text { Psychiatric } \\
\text { disorders }\end{array}$ & $\begin{array}{r}\text { DSM-IV Conduct Disorder } \\
\text { DSM-IV Post Traumatic Stress Disorder } \\
\text { DSM-IV Attention Deficit Hyperactivity disorder } \\
\text { DSM-IV Reactive Attachment Disorder } \\
\text { Speech and language problems }\end{array}$ & $\begin{array}{r}50 \\
29 \\
2 \\
17 \\
26\end{array}$ \\
\hline
\end{tabular}

\section{Sexually abusive behaviour (SAB)}

Characteristics of the SAB perpetrated by the sample are outlined in Table 8.2. More of the sample abused females than males, and abusing child victims was more likely than abusing 
adults. Using the age differential of a minimum of five years between abuser and victim, at least 59 per cent of the sample had abused a much younger child. Indeed, 16 per cent of the sample had only abused much younger children. A small group (9\%) had also engaged in sexual activity with animals. The most likely victims of the abusive behaviour were relatives or friends/acquaintances. Siblings predominated in the former, and other schoolchildren in the latter. The abuser's home or school were the most common locations for the abuse, with 83 per cent abusing in either, and 31 per cent abusing in both venues.

Table 8.2: Sexually abusive behaviour characteristics of the whole sample

\begin{tabular}{|c|c|c|}
\hline & & $\begin{array}{c}\text { Whole sample } \\
(\mathrm{n}=280) \\
\%\end{array}$ \\
\hline \multirow{12}{*}{ Victims } & Abused female victims & 88 \\
\hline & Abused male victims & 57 \\
\hline & Abused child victims ( $\leq 17 \mathrm{yrs})$ & 94 \\
\hline & Abused adult victims ( $\geq 18 \mathrm{yrs})$ & 31 \\
\hline & Abused male and female victims & 47 \\
\hline & Abused child and adult victims & 28 \\
\hline & Abused relatives & 63 \\
\hline & Abused friends or acquaintances & 74 \\
\hline & Abused strangers & 11 \\
\hline & Raped adult women & 6 \\
\hline & Any victims $\geq 5$ yrs younger than abuser & 59 \\
\hline & Only victims $\geq 5 y r s$ younger than abuser & 16 \\
\hline \multirow{9}{*}{ Abuse } & Any penetration (anal or vaginal) & 58 \\
\hline & Sexual/genital fondling & 83 \\
\hline & Oral-genital contact with victim & 21 \\
\hline & Masturbation of victim & 14 \\
\hline & Indecent exposure & 41 \\
\hline & Verbal coercion & 36 \\
\hline & Physical coercion & 8 \\
\hline & Prior grooming & 34 \\
\hline & Abused with co-abusers at any time & 13 \\
\hline
\end{tabular}

Direct physical contact between the abuser and victim was more prevalent than non-contact abusive behaviour, though 29 per cent of the sample had also engaged in non-contact behaviours such as indecent exposure. In this sample the prevalence rate of penetrative acts is likely to represent an underestimate, due to the lack of detail provided by referrers and their use of euphemistic terminology. Therefore, a proportion of those engaging in 'sexual/genital fondling' may have actually penetrated the victim. Few abusers used physical coercion against their victims, but 35 per cent used verbal coercion to obtain the victim's compliance and/or silence following the abuse. Grooming techniques, such as inviting the victim to play on a computer or to go up to their bedroom to play, were used on at least one occasion by 34 per cent of the sample. Such techniques often lacked the sophistication of those used by adult sex offenders, but were still a means of isolating the victim from other people. A minority of the sample also engaged in more serious types of sexually abusive behaviour, for example eight per cent used excessive force, four per cent abducted their victims, three per cent used a weapon, and one per cent tied up their victim.

The sample predominantly acted on their own to commit the abuse, however, three per cent $(n=8)$ only acted with a co-abuser, while ten per cent had a history of acting both on their own and with others on different occasions. In addition to the sexual behaviours cited above, five 
per cent of the sample had previously exhibited examples of frotteurism, six per cent had stalked a victim; seven per cent had engaged in sadistic sexual behaviour, and five per cent had exhibited fetishistic sexual behaviour with objects such as female clothing or nappies.

\section{Conviction profiles}

A successful matching process between the sample details and Offender's Index database was achieved for 96 per cent $(n=268)$ of the cases.

Table 8.3: Conviction profiles of those matched on the Offenders Index $(n=268)$

\begin{tabular}{cc}
\hline & $\begin{array}{c}\text { Whole sample } \\
(\mathrm{n}=268) \\
\%\end{array}$ \\
\hline
\end{tabular}

Lifetime conviction profile
Any convictions

Sexual convictions

Violence convictions

Non-sex/non-violence convictions
40

15

23

33

$\begin{array}{lrr}\text { Pre-YAP } & \text { Sexual convictions } & 11 \\ \text { conviction } & \text { Violence convictions } & 6 \\ \text { profile } & \text { Non-sex/non-violence convictions } & 10\end{array}$

Post-YAP

Sexual convictions

\section{Lifetime conviction profile}

Between the age of ten years old and December 2003 the 268 cases spent an average of 9.4 years (sd 4.1) 'at risk' of being convicted. As outlined in Table 8.3, a total of 40 per cent were convicted of an offence during this time frame. As predicted, the largest proportions of those convicted were convicted of violent and non-sex/non-violent offences. Only 15 per cent of those who spent time at risk were convicted of sexual offences.

\section{Pre-YAP conviction profile}

During the pre-YAP period the sample spent an average of 4.5 years (sd 2.5) at risk of conviction, and, as shown in Table 8.3, convictions for sexual offences were more prevalent than convictions for violent offences. This is perhaps not surprising, given the specialist nature of the YAP service.

\section{Post-YAP conviction profile}

Between the YAP assessment and December 2003 the sample spent an average of 4.9 years (sd 2.7) at risk. As indicated in Table 8.3, over three times as many cases were convicted of violent offences, and five times as many were convicted of non-sexual/non-violent offences, compared to sexual offences. 
The results of the Kaplan-Meier analysis of the survival rates for the first sexual and violent convictions post-YAP are presented in Figures 8.1 and 8.2 (see Appendix 4). They indicate that the first sexual convictions post-YAP did not occur until at least two years following the YAP assessment. The data also indicate that for some members of the cohort the first postYAP sexual conviction did not occur until some six years after the original YAP assessment. In contrast, the first convictions for post-YAP violent offences began occurring almost immediately, and although some were not convicted for the first time until six years after the YAP assessment, the period during which the most rapid rate of first violent convictions occurred was $0-4$ years post-YAP.

\section{Sexual offending in adulthood}

By the time the Offenders Index data were collected $n=181$ of the sample had entered adulthood, i.e. reached 18 years of age, therefore it was possible to examine how many juvenile sexual abusers were also convicted of a sexual offence in adulthood. Over an average period of 3.7 years (sd 2.9) at risk in early adulthood only nine cases (5\%) were convicted of a sexual offence, while 15 (8\%) were convicted of violent offences, and $34(19 \%)$ were convicted of non-sexual/non-violent offences.

Among those who were convicted of sexual offences $n=7$ were convicted between 18 and 20 years of age, while $n=2$ were convicted between 21 and 25 years of age. They were convicted of a total of 14 sexual offences. The majority of offences were for contact sexual offences, such as rape or indecent assault, while only one offence of indecent exposure was recorded. Five offences were against females under 16 years old, while six were against females over 16 years old.

With only nine cases of adult sexual offending there were too few cases to conduct valid or reliable comparisons in an effort to identify possible aetiological precursors to later adult sexual offending. Such analysis will be possible in a future follow-up study if the Offenders Index is examined in several years time, as this will increase the 'time at risk' period, and in all probability, the number of identified adult sexual offenders.

\section{Summary}

This cohort of juvenile sexual abusers is characterised by extensive histories of maltreatment, parental separation, and inadequate parenting. Most had been removed from their original families to live in a variety of other settings, although stability in these placements was not guaranteed. Not surprisingly, over half were considered insecurely attached to their primary care-givers. Rates of emotional and behavioural mental health problems were considerable in the sample, and nearly half had been in contact with the criminal justice system at least once in adolescence or early adulthood. Notably, most of these contacts were for non-sexual/nonviolent or violent offending rather than sexual offending.

The generally low rate of sexual convictions may have several explanations. Firstly, it is possible that JSAs sexually reoffend at a lower rate than for non-sexual offences. Secondly, low rates of conviction may also reflect reluctance on the part of the criminal justice system to proceed against juveniles with prosecutions for sexual offences. Thirdly, the fact that sexual offences are often harder to detect and successfully prosecute than non-sexual offences may be part of the explanation. Finally, research with adult sex offenders has also shown that long follow-up periods are required to capture the extent of sexual convictions (Cann, Falshaw and Friendship, 2004). The low conviction figure also indicates how many juveniles displaying SAB do not appear in officially recorded statistics. Overall, the conviction profile of this cohort corroborates findings from previous studies, indicating that juvenile sexual abusers tend to have a generally anti-social profile, rather than specialising in sexual offences.

The characteristics of the SAB perpetrated by the sample are also similar to those reported by numerous other samples, that is victims tended to be known to the abuser, and most frequently female, while contact sexual behaviours were very common. 


\section{Early and Late Onset trajectories of juvenile sexually abusive behaviour $(n=213$ )}

The construct of 'age of onset' of sexually abusive behaviour was used to define two trajectories. The sample was categorised as either 'Early Onset' that is, the SAB had begun before the eleventh birthday, or 'Late Onset' that is, the SAB had begun after the eleventh birthday. In 67 cases the age at which the SAB began could not be identified, and to avoid inappropriate categorisation these cases were excluded. In total, the Early Onset (EO) trajectory comprised $n=93$ cases, while the Late Onset (LO) trajectory comprised $n=120$ cases.

As only $n=213$ cases were included in the analyses comparing the Early and Late Onset trajectories it was necessary to ensure that there were no significant differences between those included and excluded in the analyses. Therefore, the included $(n=213)$ were compared to the excluded $(n=67)$ on the following key variables (gender, ethnicity, intellectual disability, maltreatment, marital separation/divorce, and removal to Local Authority Care). The results (see Table A.1 in Appendix 4) reveal no significant differences between the groups on any of these variables, indicating that those included in the analyses are representative of the whole sample.

The aim of the analysis was to compare the two trajectories on a number of domains in order to establish whether there was sufficient support for the view that these trajectories are distinct and separable.

\section{Psychosocial characteristics and psychiatric diagnoses}

Comparisons between the trajectory groups on a range of psychosocial characteristics are outlined in Table 9.1. The results support the hypothesis that, in general, individuals on the EO trajectory were more likely to have experienced greater levels of abuse, and were more likely to have presented with a difficult early temperament. In addition, it was found that they experienced poorer parenting, higher levels of inappropriate sexualisation and demonstrated higher levels of childhood behavioural problems.

With respect to parenting, the EO trajectory was associated with parents with mental health problems or, who had themselves spent time in care as children. Individuals on the EO trajectory were found to have experienced higher levels of inconsistent parenting, lack of supervision, and the odds ratio indicates they were over four times more likely than those on the LO trajectory to have been judged as insecurely attached to their care-givers. In relation to early temperament, the odds ratio indicates that those on the EO trajectory were twice as likely as those on the LO trajectory to have presented as oppositional, aggressive or hyperactive in infancy. Those on the EO trajectory were also significantly more likely to have experienced multiple changes in home placement, although as the confidence intervals suggest the extent to which the trajectories differ could be very small.

As predicted, those on the EO trajectory were also more likely to have been abused (sexual, physical, emotional) and/or physically neglected, though both trajectories were associated with similar levels of domestic violence. Higher rates of both childhood sexual abuse (CSA) and inadequate family sexual boundaries were associated with the EO trajectory, indicating perhaps part of the causal mechanism for the early exhibition of SAB. With respect to childhood behavioural problems the odds ratio indicates that those on the EO trajectory were nearly twice as likely as those on the LO trajectory to display symptoms of hyperactivity, impulsivity or poor concentration. Their non-sexual behavioural problems were also exhibited early, with nearly two-thirds of the EO trajectory identified as disruptive in primary school. Physical and/or sexual cruelty to animals are often considered characteristics of more disturbed young people, and, as noted in Table 9.1, both trajectories were more likely to 
engage in physical cruelty than sexual cruelty, although, those on the EO trajectory were more likely to have displayed sexual and physical cruelty to animals. Notably, none of those on the Late Onset trajectory engaged in both sexual and physical cruelty to animals. Only in relation to substance misuse did those on the LO trajectory present with a higher prevalence, being twice as likely to have misused alcohol and/or drugs.

Table 9.1: Comparisons between the Early and Late Onset trajectories on psychosocial characteristics

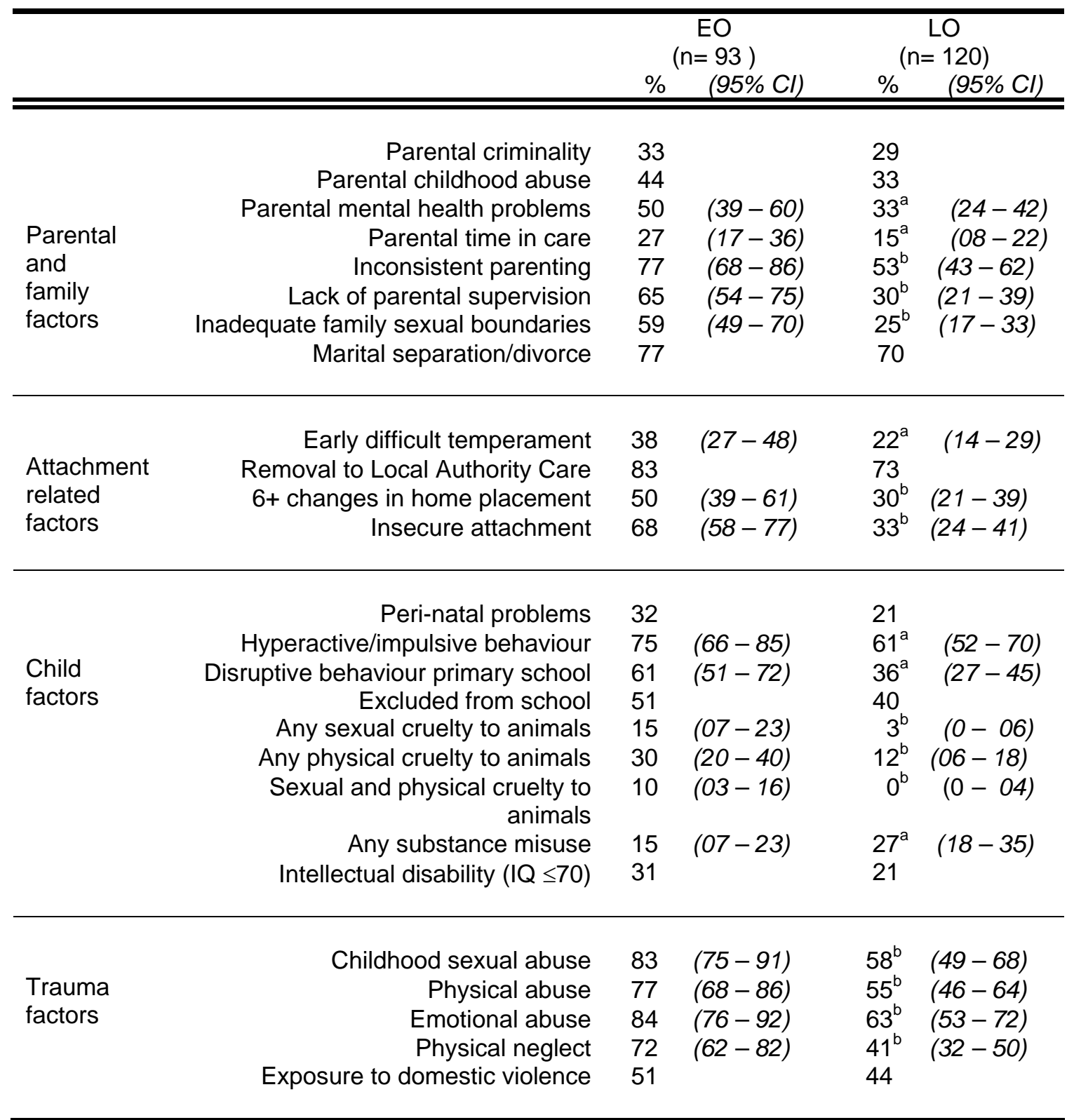

Note: ${ }^{\mathrm{a} p} p .05,{ }^{\mathrm{b} p} \mathrm{p} .01$

The EO and LO trajectories tended to present with similar levels of psychiatric disorder. For example, 52 and 51 per cent of the EO and LO trajectories respectively were diagnosed with Conduct Disorder. Similarly, when those exhibiting sub-threshold levels of $C D$ were included in the figures, 94 per cent and 86 per cent respectively of the EO and LO trajectories were affected. Approximately a quarter of both trajectories were diagnosed with Post-Traumatic Stress Disorder. However, the EO trajectory (25\%: Cl $15-34 \%)$ was significantly $(p=.000)$ more likely than the LO trajectory $(6 \%$ : $\mathrm{Cl} 1-10 \%)$ to be diagnosed with reactive attachment disorder, although the extent to which the two trajectories could differ could be as small as 
five per cent. In addition, a greater proportion of the EO trajectory (28\%) presented with speech and language problems, compared to the LO trajectory (15\%).

\section{Psychosocial predictors of Early Onset sexually abusive behaviour}

Having identified the psychosocial characteristics associated with the EO trajectory, logistic regression, using the forward stepwise method, was used to model the characteristics predictive of an early onset of sexually abusive behaviour. Only variables on which the EO and LO trajectories differed significantly, and which were likely to have occurred developmentally prior to the onset of the SAB were entered into the equation (parental mental health problems, parental removal to care, inconsistent parenting, inappropriate family sexual boundaries, poor parental supervision, difficult early temperament, sexual abuse, physical abuse, emotional abuse, physical neglect, multiple changes of care placement, and insecure attachment). The results presented in Table 9.2 indicate that only four of these developmental factors: inappropriate family sexual boundaries; poor parental supervision; difficult early temperament; and insecure attachment were independently, significantly predictive of an Early Onset of SAB. Together they accounted for 37 per cent of the variance, and successfully predicted 72 per cent of the sample $(66 \%$ of the EO, and $76 \%$ of the LO trajectories).

Table 9.2: Psychosocial predictors of an Early onset of juvenile sexually abusive behaviour

\begin{tabular}{lcccccc}
\hline & B & S.E & df & Sig & $\operatorname{Exp(B)}$ & $\begin{array}{c}95 \% \mathrm{Cl} \text { for } \\
\operatorname{Exp}(\mathrm{B})\end{array}$ \\
\hline \hline $\begin{array}{l}\text { Inadequate family sexual } \\
\text { boundaries }\end{array}$ & 1.153 & .349 & 1 & .001 & 3.168 & $1.60-6.27$ \\
\hline Lack of parental supervision & 1.216 & .349 & 1 & .001 & 3.373 & $1.70-6.69$ \\
\hline Early difficult temperament & .803 & .374 & 1 & .032 & 2.232 & $1.07-4.65$ \\
\hline Insecure attachment & 1.35 & .343 & 1 & .000 & 3.856 & $1.97-7.55$ \\
\hline
\end{tabular}

\section{Sexually abusive behaviour (during adolescence)}

By virtue of being on the EO trajectory, those juveniles had begun their abusive behaviour much earlier than those on the LO trajectory. Developmentally, the sexually abusive behaviour of those on the EO trajectory may have changed as the individual got older, and perhaps, became more 'skilled' at sexually abusing. The effect of this potential heterotypic continuity means that comparing the sexual behaviour of the EO trajectory committed at 'any time' to the behaviour of the LO trajectory committed during adolescence is not developmentally comparable. To overcome this problem the trajectories were compared on the SAB they both committed during the adolescent period, i.e. between 11 and 17 years of age.

It was hypothesised that those on the EO trajectory would have a more indiscriminate pattern of victim selection. The results, presented in Table 9.3, provide some support for this view. Those on the EO trajectory were significantly more likely to abuse both male and female victims, and both child and adult victims, although, as indicated by the confidence intervals, the extent to which the EO and LO differ could in fact be quite small. Those on the EO 
trajectory were also more likely to abuse male victims. This unexpected result may imply the re-enactment of their own sexual victimisation, but as the abusers rather than victim. By contrast, it was expected that those on the LO trajectory would present with more targeted victim selection. If was found that those on the LO trajectory were indeed significantly more likely to only abuse much younger children, that is children at least five years younger than them. In addition, they had an odds ratio of being three times more likely than those on the EO trajectory to only abuse female victims. As shown in Table 9.3, on many other characteristics the trajectories did not differ, particularly in relation to the nature of the abuse itself. One exception to this pattern is the higher levels of verbal coercion by those on the LO trajectory which may suggest a higher level of verbal functioning in this group, consistent with Moffitt's hypothesis that those on the EO trajectory are characterised by higher levels of neuro-cognitive deficits.

Table 9.3: Comparisons between the Early and Late Onset trajectories on sexually abusive behaviour during adolescence (11 - 17 years)

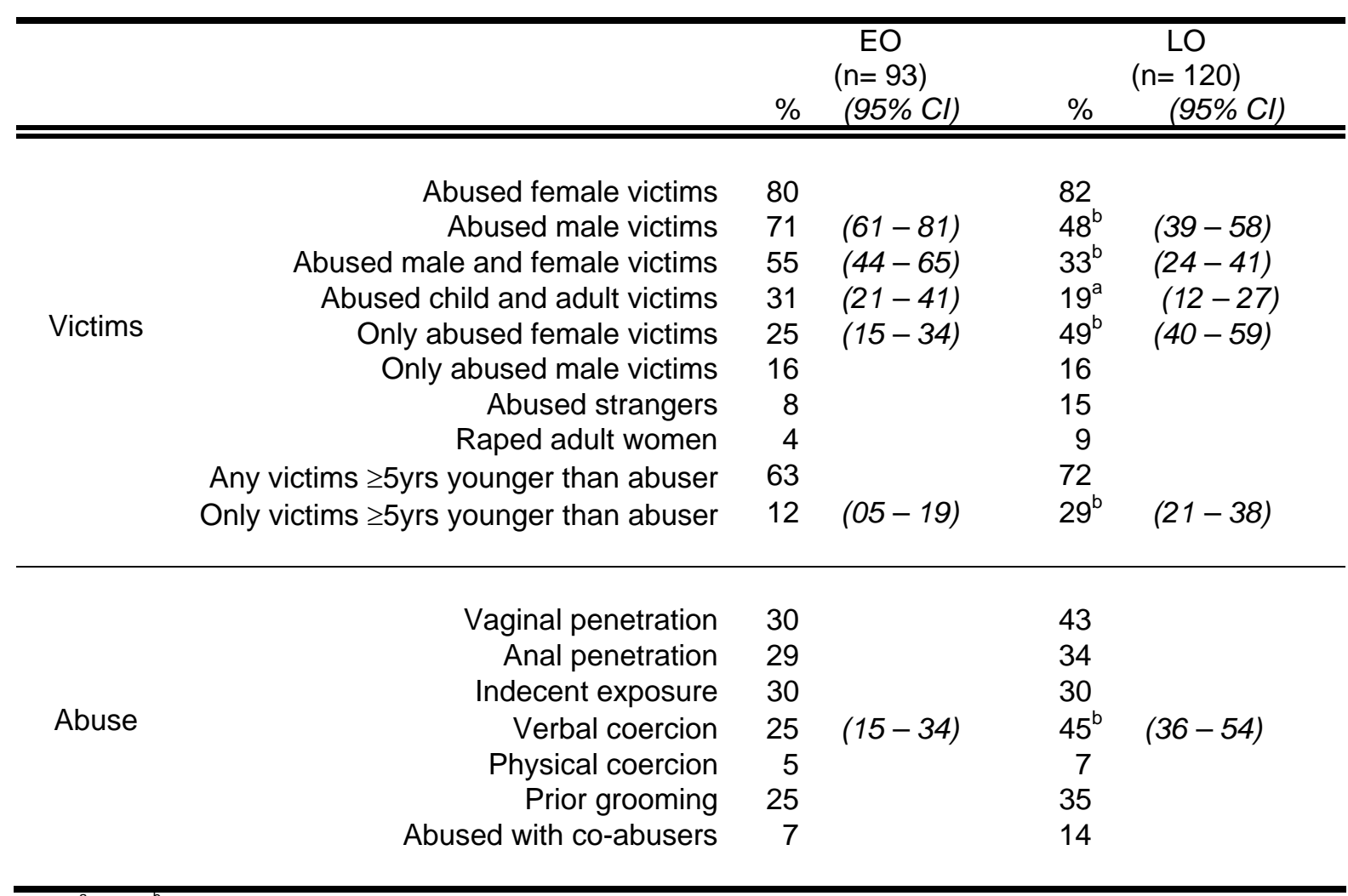

Note: ${ }^{\mathrm{a} p} p .05,{ }^{\mathrm{b}} p .01$

\section{Non-sexual anti-social behaviour}

The standardised developmental method of data collection used in this study enabled information on anti-social behaviour in each of four discrete developmental periods (i.e. 0-3 years, $4-6$ years, $7-10$ years, $11-17$ years) to be examined. As a result, it was possible to 'map' the progression of behavioural problems in the form of a developmental sequence, and compare the sequences of the Early and Late Onset trajectories. The results, presented in Table 9.4, provide support for the hypothesis that those on the EO trajectory would have higher rates of anti-social behaviour than the LO trajectory throughout childhood, but similar rates in the adolescent period. However, some exceptions to this pattern were observed. During adolescence those on the EO trajectory continued to be significantly more insecurely attached, and more likely to engage in reckless behaviour. However, it is notable from an examination of the confidence intervals that the extent to which the trajectories differed is quite considerably for insecurity but not for reckless behaviour. The findings across the developmental periods also highlight how early those on the EO trajectory begin to exhibit 
anti-social behaviour, for example, nearly half were displaying persistent physical aggression between the ages of four and six years. 
Table 9.4: Comparisons between the Early and Late Onset trajectories for non-sexual anti-social behaviour across developmental periods

\begin{tabular}{|c|c|c|c|c|c|c|c|c|}
\hline & \multicolumn{2}{|c|}{$0-3 y r s$} & \multicolumn{2}{|c|}{$4-6 y r s$} & \multicolumn{2}{|c|}{$7-10 y r s$} & \multicolumn{2}{|c|}{$11-17 y r s$} \\
\hline & $\begin{array}{l}E O \\
(n=93) \\
\%\end{array}$ & $\begin{array}{l}\text { LO } \\
(n=120) \\
\%\end{array}$ & $\begin{array}{l}E O \\
(n=93) \\
\%\end{array}$ & $\begin{array}{l}\text { LO } \\
(n=120) \\
\%\end{array}$ & $\begin{array}{l}\text { EO } \\
(n=93) \\
\%\end{array}$ & $\begin{array}{l}\text { LO } \\
(n=120) \\
\%\end{array}$ & $\begin{array}{l}E O \\
(n=93) \\
\%\end{array}$ & $\begin{array}{l}\text { LO } \\
(n=120) \\
\%\end{array}$ \\
\hline Difficult temperament ${ }^{a}$ & $\begin{array}{l}26 \\
(16-35)\end{array}$ & $\begin{array}{l}13^{\mathrm{c}} \\
(07-20)\end{array}$ & - & - & - & - & - & - \\
\hline Oppositional & 8 & 3 & $\begin{array}{l}19 \\
(11-28)\end{array}$ & $\begin{array}{l}8^{c} \\
(03-14)\end{array}$ & $\begin{array}{l}36 \\
(25-46)\end{array}$ & $\begin{array}{l}13^{\mathrm{d}} \\
(07-20)\end{array}$ & 47 & 41 \\
\hline Insecure attachment & $\begin{array}{l}13 \\
(06-20)\end{array}$ & $\begin{array}{l}3^{d} \\
(01-05)\end{array}$ & $\begin{array}{l}36 \\
(25-46)\end{array}$ & $\begin{array}{l}4^{d} \\
(0-08)\end{array}$ & $\begin{array}{l}52 \\
(41-62)\end{array}$ & $\begin{array}{l}17^{\mathrm{d}} \\
(10-24)\end{array}$ & $\begin{array}{l}61 \\
(51-72)\end{array}$ & $\begin{array}{l}28^{c} \\
(20-37)\end{array}$ \\
\hline Physically aggressive & $\begin{array}{l}24 \\
(14-33)\end{array}$ & $\begin{array}{l}11^{\mathrm{c}} \\
(05-17)\end{array}$ & $\begin{array}{l}41 \\
(30-51)\end{array}$ & $\begin{array}{l}18^{\mathrm{d}} \\
(10-25)\end{array}$ & $\begin{array}{l}70 \\
(60-80)\end{array}$ & $\begin{array}{l}32^{\mathrm{d}} \\
(23-40)\end{array}$ & 72 & 64 \\
\hline Physical cruelty to animals ${ }^{b}$ & - & - & $\begin{array}{l}5 \\
(01-10)\end{array}$ & $\begin{array}{l}0^{\mathrm{C}} \\
(0-0)\end{array}$ & $\begin{array}{l}14 \\
(06-22)\end{array}$ & $\begin{array}{l}1^{d} \\
(01-03)\end{array}$ & 18 & 9 \\
\hline Fire-setting ${ }^{b}$ & - & - & $\begin{array}{c}8 \\
(02-13)\end{array}$ & $\begin{array}{l}2^{c} \\
(01-04)\end{array}$ & 15 & 8 & 26 & 18 \\
\hline Stealing $^{b}$ & - & - & 5 & 4 & $\begin{array}{l}29 \\
(20-39)\end{array}$ & $\begin{array}{l}13^{d} \\
(07-20)\end{array}$ & 48 & 55 \\
\hline Excluded from school ${ }^{b}$ & - & - & $\begin{array}{l}11 \\
(04-18)\end{array}$ & $\begin{array}{l}2^{d} \\
(01-04)\end{array}$ & $\begin{array}{l}24 \\
(14-33)\end{array}$ & $\begin{array}{l}7^{d} \\
(02-12)\end{array}$ & 34 & 37 \\
\hline Impulsivity $^{b}$ & - & - & $\begin{array}{l}19 \\
(11-28)\end{array}$ & $\begin{array}{l}9^{c} \\
(04-15)\end{array}$ & $\begin{array}{l}32 \\
(22-42)\end{array}$ & $\begin{array}{l}11^{d} \\
(05-17)\end{array}$ & 51 & 39 \\
\hline Reckless behaviour $^{b}$ & - & - & 1 & 0 & 7 & 2 & $\begin{array}{l}16 \\
(08-24)\end{array}$ & $\begin{array}{l}5^{d} \\
(01-09)\end{array}$ \\
\hline Socially isolated ${ }^{b}$ & - & - & 9 & 5 & $\begin{array}{l}26 \\
(16-35)\end{array}$ & $\begin{array}{l}15^{c} \\
(08-22)\end{array}$ & 63 & 55 \\
\hline
\end{tabular}

Note: a difficult temperament was only collected for the 0 - 3yrs period; $b$ these items were not collected in the $0-3 y r s$ period; ${ }^{c} p .05,{ }^{d} p .01 .95 \% \mathrm{Cl}$ for $\%$ in parentheses. 


\section{Conviction profiles}

\section{Lifetime conviction profile}

The LO trajectory spent significantly longer at risk during this period, therefore it was necessary to identify comparable groups, based on time spent at risk, in order to compare the conviction profiles. As presented in Table 9.5, the groups comprised EO $n=58$, and LO $n=50$, and spent an average of eight years (sd 1.5) at risk. There were no significant differences between the trajectories in relation to prevalence for each type of conviction although, twice as many on the LO trajectory were convicted of sexual offences. As the majority of these convictions occurred during adolescence, the hypothesis that the trajectories would have similar rates was supported.

Table 9.5: Conviction profiles of the Early and Late Onset trajectories

\begin{tabular}{|c|c|c|c|}
\hline & & $\begin{array}{ll} & \mathrm{EO} \\
\% & (95 \% \mathrm{Cl}) \\
\end{array}$ & $\begin{array}{cl} & \mathrm{LO} \\
\% & (95 \% \mathrm{Cl}) \\
\end{array}$ \\
\hline \multirow{5}{*}{$\begin{array}{l}\text { Lifetime } \\
\text { conviction } \\
\text { profile }\end{array}$} & & $\overline{(n=58)}$ & $(n=50)$ \\
\hline & Any convictions & 45 & 56 \\
\hline & Sexual convictions & 9 & 18 \\
\hline & Violence convictions & 33 & 34 \\
\hline & Non-sex/non-violence convictions & 40 & 46 \\
\hline \multirow{5}{*}{$\begin{array}{l}\text { Pre-YAP } \\
\text { conviction } \\
\text { profile }\end{array}$} & & $(n=61)$ & $(n=103)$ \\
\hline & Sexual convictions & \multirow{2}{*}{$7(01-13)$} & $19^{a}(11-28)$ \\
\hline & Violence convictions & & 9 \\
\hline & Non-sex/non-violence convictions & 10 & 18 \\
\hline & & $(n=69)$ & $(n=92)$ \\
\hline \multirow{3}{*}{$\begin{array}{l}\text { Post-YAP } \\
\text { conviction } \\
\text { profile }\end{array}$} & Sexual convictions & \multirow{2}{*}{$\begin{aligned} 3 & (0-07) \\
23 & \end{aligned}$} & \multirow{2}{*}{$13^{a}(06-20)$} \\
\hline & Violence convictions & & \\
\hline & Non-sex/non-violence convictions & 23 & $\begin{array}{l}26 \\
38\end{array}$ \\
\hline
\end{tabular}

Note: ${ }^{a} p .05$

\section{Pre-YAP conviction profile}

The trajectories spent significantly different periods at risk pre-YAP, therefore comparable subgroups were identified ( $E O \mathrm{n}=61$, and $\mathrm{LO} n=103$ ) who spent an average of 5.7years (sd 1.5) at risk. As indicated in Table 9.5, similar proportions were convicted of violent and nonsexual/non-violent offences, but, at the time of the YAP assessment, the odds of the LO trajectory already having convictions for sexual offences was three times greater than for the EO group.

\section{Post-YAP conviction profile}

Again, differences in the time spent at risk in this period necessitated the identification of comparable subgroups ( $E O n=69$, and LO $n=92$ ), who spent an average of 5.1years (sd 1.8) at risk. As with the pre-YAP period the trajectories had similar rates of violent and nonsexual/non-violent convictions, while the odds of the LO trajectory were nearly five times greater than for the EO trajectory for being convicted of sexual offences. However, for both trajectories the overall rates of sexual convictions were much lower than those for the other types of conviction. 
The differences and similarities between the trajectories are further illustrated in the results of the survival rate comparisons for sexual and violent offending post-YAP (see Figures 9.1 and 9.2 in Appendix 3). The sexual conviction graph depicts that both trajectories had similar survival rates for the first sexual offence over the first two years post-YAP, but after this period more of the LO trajectory were convicted of sexual offences, although the first offence may have occurred up to six years after the YAP assessment. Throughout the post-YAP period both trajectories had virtually identical survival rates for violent offending.

\section{Summary}

The results indicate that the constructs of Early and Late Onset trajectories, based on age of onset of the sexually abusive behaviour, have relevance for distinguishing between subgroups of juvenile sexual abusers. The hypotheses in relation to psychosocial characteristics, SAB, non-sexual anti-social behaviour and conviction profiles were supported, suggesting preliminary evidence for distinct juvenile sexual abuser trajectories. However, validation studies are required.

To summarise, the Early Onset trajectory appears to be characterised by high rates of: early difficult temperament; inadequate parenting; childhood maltreatment; multiple changes of home placement; and insecure attachment. Non-sexual anti-social behaviours displayed by this trajectory also begin early and tend to persist through childhood and adolescence. In adolescence and early adulthood those on this trajectory are more likely to be convicted of violent or non-sexual/non-violent offences than sexual offences. Those on the EO trajectory were also characterised by high rates of $S A B$ against a diverse range of victims. This trajectory was also associated with the highest rate of abusing male victims.

In contrast, those on the Late Onset trajectory were characterised by lower rates of poor parenting, maltreatment, and non-sexual anti-social behaviour in childhood. However, by adolescence high rates of non-sexual anti-social behaviour were evident, as were high rates of substance misuse. Convictions during adolescence and early adulthood were more likely to have been obtained for violent or non-sexual/non-violent offences, although this trajectory appears to be associated with a relatively higher risk of being convicted of sexual offences. The SAB of those on this trajectory was characterised by more targeted victim selection in relation to female and child victims, and a greater use of verbal coercion. 


\title{
10. Emerging severe personality disorder traits in young sexual abusers $(n=203)$
}

\author{
Emerging severe personality disorder traits (ESPD)
}

In this study two dimensions were used to define the construct of 'emerging severe personality disorder traits': conduct disorder traits and psychopathic personality disorder traits.

\section{Conduct disorder traits}

On the basis of the file data, ten out of the 15 DSM-IV behavioural criteria of Conduct Disorder could be directly identified including: any bullying; initiating fights; any use of a weapon; any physical cruelty to humans; any physical cruelty to animals; any forced sexual cruelty; any fire setting; any property destruction; any lying; and any truancy. Because of insufficient detail in relation to the remaining criteria two further combined categories were created. The first, 'any stealing', incorporated 'stealing while confronting a victim', 'stealing while not confronting a victim' and 'breaking into property'. The second, 'any staying out or running away from home' incorporated 'staying out at night' and 'running away from home overnight'. This produced a list of 12 behavioural criteria in total. Each item was scored one if there was evidence of the behaviour occurring at any time during childhood or adolescence; otherwise it was scored zero. The full cohort displayed an average score of 5.3 items (s.d. 2.7). For the purposes of this study those scoring at or above the mean score of five were categorised as showing high levels of conduct disorder traits.

\section{Psychopathic personality disorder traits}

File data were also used to score the Psychopathy Checklist Youth Version (PCL-YV). Scoring is based on the persistent exhibition of the trait over time and across different domains. Scores of zero for not apparent, one for somewhat apparent, and two for definitely apparent were applied. This measure is designed for use with young people between the ages of 12 and 18. Those below 12 years of age at the time of the original assessment, and those cases for which there was insufficient data to derive a valid score $(n=77)$ were excluded. This produced a group of 203 valid cases. Scores on the PCL-YV can range from zero to 40. The mean score for this sample was found to be 8.8 (s.d. 6.6). There is no recommended cut-off for this measure, thus, for the purposes of this study, the mean score again acted as a cut-off to categorise the sample. Those scoring nine or above were categorised as displaying high psychopathic personality disorder traits (36\%).

The results of a one-tailed Pearson correlation between the total conduct disorder and PCLYV scores $(r=.58, p=.000)$ indicated that, although moderately correlated, the constructs were not measuring the same thing. Previously, Frick et al., (2003) identified a subgroup of children displaying behaviours and traits representative of psychopathy who had high levels of both CD problems and psychopathic traits. Skilling et al., (2001) also found that the construct of 'serious anti-sociality' was indexed by high scores on measures of DSM conduct disorder symptoms and the PCL-YV. Given these findings the authors constructed a measure of emerging severe personality disorder traits (ESPD) comprising above average scores on both the conduct disorder traits and the PCL-YV. A total of $n=54$ individuals scored above average on both measures and constituted the ESPD group. The remaining cases, n=149 that did not reach this threshold comprised the non-ESPD group comparison group.

As only $n=203$ cases were included in the analyses comparing the ESPD and non-ESPD groups it was necessary to ensure that there were no significant differences between those included and excluded in the analyses. Therefore, the included $(n=203)$ were compared to the excluded $(n=77)$ on the following key variables (gender, ethnicity, intellectual disability, maltreatment, marital separation/divorce, and removal to Local Authority Care). The results (see Table A.2 in Appendix 4) reveal no significant differences between the groups on any of 
these variables, indicating that those included in the analyses are representative of the whole sample. In the following analyses the ESPD group was compared to the non-ESPD group to test the hypotheses that they would differ in relation to psychosocial characteristics, sexually abusive behaviour, non-sexual anti-social behaviour, and conviction profiles.

\section{Psychosocial characteristics}

The results presented in Table 10.1 indicate that, as predicted, the ESPD group had significantly higher rates of parental mental health problems and early difficult temperament. As indicated by the confidence intervals, the extent to which the two groups differed on these variables was greater for parental mental health problems than for difficult temperament. In addition, the ESPD group had higher rates of parental childhood abuse, and odds ratios of being twice as likely to have experienced inconsistent parenting, and over three times as likely to have insecure attachments than the non-ESPD group. The results also indicate that the ESPD group had experienced significantly higher rates of removal into care, and multiple changes of home placement, although the extent to which the groups differed varied.

Table 10.1: Comparisons between the ESPD trait groups on psychosocial characteristics

\begin{tabular}{|c|c|c|c|c|c|}
\hline & & \multicolumn{2}{|r|}{$\begin{array}{l}\text { ESPD } \\
(n=54)\end{array}$} & \multicolumn{2}{|c|}{$\begin{array}{c}\text { Non-ESPD } \\
(n=149)\end{array}$} \\
\hline & & $\%$ & $(95 \% \mathrm{Cl})$ & $\%$ & $(95 \% \mathrm{Cl})$ \\
\hline $\begin{array}{l}\text { Parental } \\
\text { and } \\
\text { family } \\
\text { factors }\end{array}$ & $\begin{array}{r}\text { Parental criminality } \\
\text { Parental childhood abuse } \\
\text { Parental mental health problems } \\
\text { Parental time in care } \\
\text { Inconsistent parenting } \\
\text { Lack of parental supervision } \\
\text { Inadequate family sexual boundaries } \\
\text { Marital separation/divorce }\end{array}$ & $\begin{array}{l}35 \\
54 \\
69 \\
24 \\
76 \\
46 \\
39 \\
70\end{array}$ & $\begin{array}{l}(39-68) \\
(55-82) \\
(64-88)\end{array}$ & $\begin{array}{l}34 \\
34^{\mathrm{b}} \\
32^{\mathrm{b}} \\
22 \\
58^{\mathrm{a}} \\
46 \\
42 \\
74\end{array}$ & $\begin{array}{l}(26-41) \\
(24-40) \\
(50-67)\end{array}$ \\
\hline $\begin{array}{l}\text { Attachment } \\
\text { related } \\
\text { factors }\end{array}$ & $\begin{array}{r}\text { Early difficult temperament } \\
\text { Removal to Local Authority Care } \\
6+\text { changes in home placement } \\
\text { Insecure attachment }\end{array}$ & $\begin{array}{l}46 \\
93 \\
62 \\
72\end{array}$ & $\begin{array}{l}(32-61) \\
(85-100) \\
(47-76) \\
(59-85)\end{array}$ & $\begin{array}{l}21^{b} \\
74^{b} \\
30^{b} \\
44^{b}\end{array}$ & $\begin{array}{l}(14-28) \\
(66-81) \\
(22-38) \\
(35-52)\end{array}$ \\
\hline $\begin{array}{l}\text { Child } \\
\text { factors }\end{array}$ & $\begin{array}{r}\text { Peri natal problems } \\
\text { Hyperactive/impulsive behaviour } \\
\text { Disruptive behaviour primary school } \\
\text { Excluded from school } \\
\text { Any sexual cruelty to animals } \\
\text { Any physical cruelty to animals } \\
\text { Sexual and physical cruelty to animals } \\
\text { Any substance misuse } \\
\text { Intellectual disability }(\mathrm{IQ} \leq 70)\end{array}$ & $\begin{array}{l}35 \\
87 \\
63 \\
67 \\
20 \\
35 \\
15 \\
32 \\
35\end{array}$ & $\begin{array}{l}(77-97) \\
(49-77) \\
(53-80)\end{array}$ & $\begin{array}{l}27 \\
62^{\mathrm{b}} \\
40^{\mathrm{b}} \\
40^{\mathrm{b}} \\
6 \\
11 \\
1^{\mathrm{b}} \\
20 \\
22\end{array}$ & $\begin{array}{l}(54-70) \\
(32-48) \\
(31-48)\end{array}$ \\
\hline $\begin{array}{l}\text { Trauma } \\
\text { factors }\end{array}$ & $\begin{array}{r}\text { Childhood sexual abuse } \\
\text { Physical abuse } \\
\text { Emotional abuse } \\
\text { Physical neglect } \\
\text { Exposure to domestic violence }\end{array}$ & $\begin{array}{l}69 \\
72 \\
83 \\
54 \\
52\end{array}$ & & $\begin{array}{l}72 \\
66 \\
71 \\
58 \\
51\end{array}$ & \\
\hline
\end{tabular}

Note: ${ }^{\mathrm{a}} p .05,{ }^{\mathrm{b}} p .01$ 
Behaviourally, the ESPD group had significantly higher rates of hyperactive/impulsive behaviour, and school exclusion; indeed, their school-based anti-social behaviour began very early with nearly two-thirds considered disruptive in the early primary school years (e.g. 4-6 years). Finally, the ESPD group was significantly more likely to have engaged in sexual or physical cruelty to animals, and displayed an odds ratio of over twelve times greater likelihood of being sexually and physically cruel to animals.

\section{Sexually abusive behaviour}

It was hypothesised that the ESPD group would have higher rates of predatory SAB, prior grooming, abusing strangers, and abusing both males and females and child and adult victims. The results in Table 10.2 indicate support for each of these predictions. In addition, the ESPD group had significantly higher rates of using excessive force, and employing verbal coercion. Notably, however, the non-ESPD group were significantly more likely to have only abused much younger children. Despite these significant differences, as indicated by the confidence intervals, the extent to which the two groups differ could be very small.

Table 10.2: Comparisons between the ESPD trait groups on sexually abusive behaviour characteristics

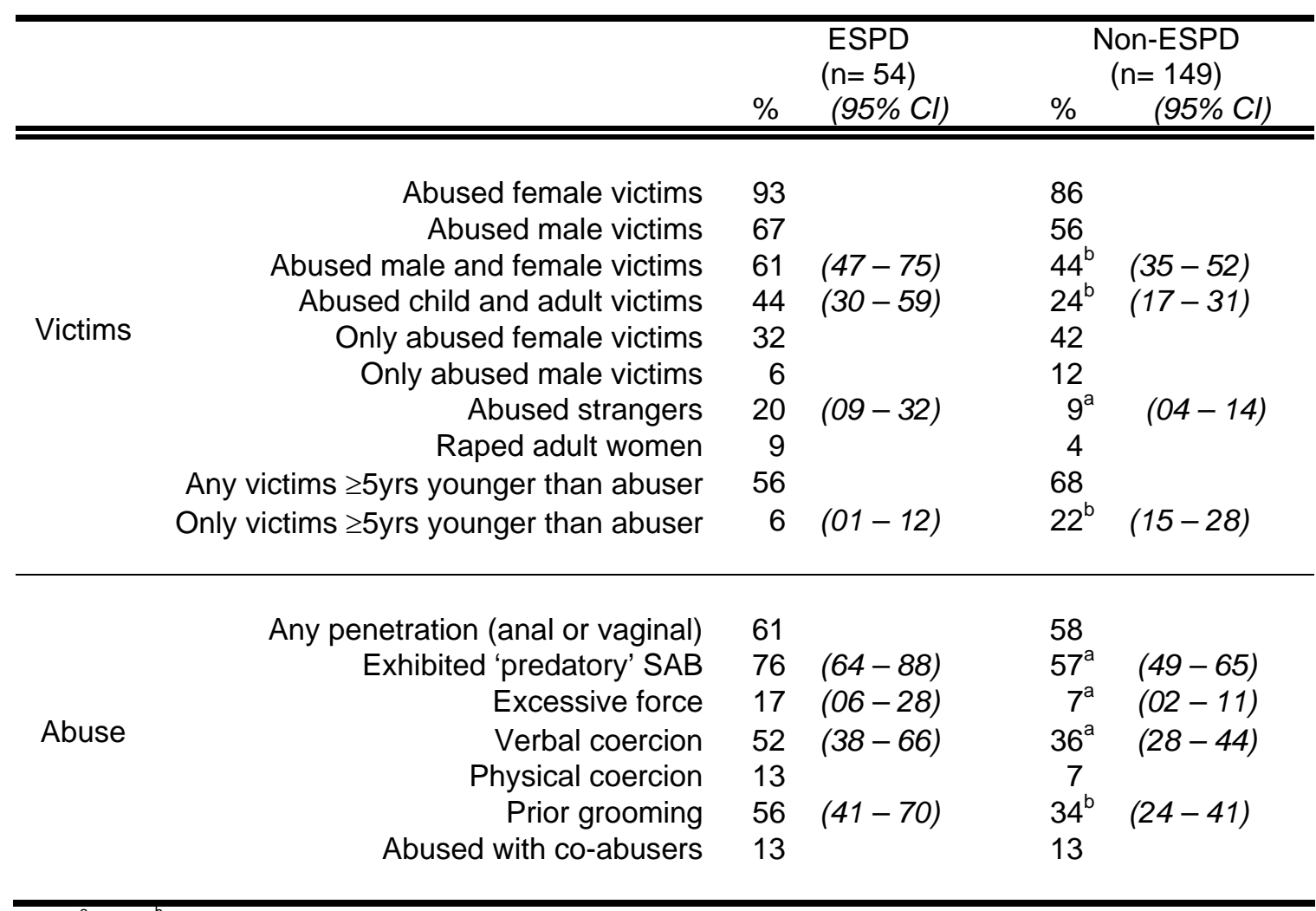

Note: ${ }^{\mathrm{a} p} p .05,{ }^{\mathrm{b}} p .01$

\section{Non-sexual anti-social behaviour}

As indicated in Table 10.3 the presentation of non-sexual anti-social behaviour over time differed significantly for the two groups on the majority of behavioural problems. It is also notable that in the middle childhood and adolescent periods the extent to which the two groups differ are quite considerable, as well as being significantly different.

As predicted, the ESPD group displayed higher rates of anti-social behaviour throughout childhood and adolescence, while the non-ESPD group only tended to show elevated rates in adolescence. The results also indicate how early in development the ESPD group begin to display serious anti-social behaviour. For example, by early childhood (4-6 years of age) nearly half of the ESPD group exhibited physical aggression to others, and just over a quarter 
were highly impulsive. By middle childhood (7-10 years of age) at least 24 per cent were setting fires, 32 per cent were excluded from school, and 13 per cent were putting themselves in danger by engaging in reckless behaviour. By adolescence (11-17 years of age) most of the ESPD group was engaging in anti-social behaviours, with just over a quarter engaging in very serious anti-social behaviour including physical cruelty to animals and reckless behaviour that endangered themselves. The hypothesis that the ESPD group would engage in animal cruelty and reckless behaviour throughout childhood and adolescence was supported, and the results also indicate that such behaviour is far more characteristic of those with ESPD traits than those without. 
Table 10.3: Comparisons between the ESPD trait groups for non-sexual anti-social behaviour across developmental periods

\begin{tabular}{|c|c|c|c|c|c|c|c|c|}
\hline & \multicolumn{2}{|c|}{$0-3 y r s$} & \multicolumn{2}{|c|}{$4-6 y r s$} & \multicolumn{2}{|c|}{$7-10 y r s$} & \multicolumn{2}{|c|}{$11-17 y r s$} \\
\hline & $\begin{array}{l}\text { ESPD } \\
(n=54) \%\end{array}$ & $\begin{array}{l}\text { Non-ESPD } \\
(n=149) \%\end{array}$ & $\begin{array}{l}\text { ESPD } \\
(n=54) \%\end{array}$ & $\begin{array}{l}\text { Non-ESPD } \\
(n=149) \%\end{array}$ & $\begin{array}{l}\text { ESPD } \\
(n=54) \%\end{array}$ & $\begin{array}{l}\text { Non-ESPD } \\
(n=149) \%\end{array}$ & $\begin{array}{l}\text { ESPD } \\
(n=54) \%\end{array}$ & $\begin{array}{l}\text { Non-ESPD } \\
(n=149) \%\end{array}$ \\
\hline Difficult temperament $^{a}$ & $\begin{array}{l}33 \\
(20-47)\end{array}$ & $\begin{array}{l}11^{\mathrm{c}} \\
(05-16)\end{array}$ & - & - & - & - & - & - \\
\hline Oppositional & $\begin{array}{l}11 \\
(02-20)\end{array}$ & $\begin{array}{l}2^{\mathrm{c}} \\
(01-04)\end{array}$ & $\begin{array}{l}26 \\
(13-39)\end{array}$ & $\begin{array}{l}9^{c} \\
(04-14)\end{array}$ & $\begin{array}{l}48 \\
(34-62)\end{array}$ & $\begin{array}{l}13^{\mathrm{C}} \\
(07-18)\end{array}$ & $\begin{array}{l}69 \\
(55-82)\end{array}$ & $\begin{array}{l}36^{c} \\
(28-44)\end{array}$ \\
\hline Insecure attachment & $\begin{array}{l}15 \\
(04-25)\end{array}$ & $\begin{array}{l}4^{c} \\
(01-07)\end{array}$ & 28 & 17 & $\begin{array}{l}56 \\
(41-70)\end{array}$ & $\begin{array}{l}26^{c} \\
(18-33)\end{array}$ & $\begin{array}{l}67 \\
(53-80)\end{array}$ & $\begin{array}{l}38^{c} \\
(30-46)\end{array}$ \\
\hline Physically aggressive & $\begin{array}{l}30 \\
(17-43)\end{array}$ & $\begin{array}{l}11^{\mathrm{c}} \\
(05-16)\end{array}$ & $\begin{array}{l}46 \\
(32-61)\end{array}$ & $\begin{array}{l}19^{c} \\
(12-25)\end{array}$ & $\begin{array}{l}76 \\
(64-88)\end{array}$ & $\begin{array}{l}38^{c} \\
(29-46)\end{array}$ & $\begin{array}{l}89 \\
(80-98)\end{array}$ & $\begin{array}{l}64^{c} \\
(56-72)\end{array}$ \\
\hline Physical cruelty to animals ${ }^{b}$ & - & - & $\begin{array}{c}7 \\
(01-14)\end{array}$ & $\begin{array}{c}0^{\mathrm{C}} \\
(0-0)\end{array}$ & $\begin{array}{l}13 \\
(03-23)\end{array}$ & $\begin{array}{l}2^{c} \\
(01-04)\end{array}$ & $\begin{array}{l}28 \\
(15-41)\end{array}$ & $\begin{array}{l}9^{c} \\
(04-14)\end{array}$ \\
\hline Fire-setting $^{b}$ & - & - & 7 & 3 & $\begin{array}{l}24 \\
(12-36)\end{array}$ & $\begin{array}{l}5^{c} \\
(01-09)\end{array}$ & $\begin{array}{l}46 \\
(32-61)\end{array}$ & $\begin{array}{l}14^{c} \\
(08-20)\end{array}$ \\
\hline Stealing ${ }^{\mathrm{b}}$ & - & - & $\begin{array}{l}13 \\
(03-23)\end{array}$ & $\begin{array}{l}2^{\mathrm{c}} \\
(01-04)\end{array}$ & $\begin{array}{l}32 \\
(18-45)\end{array}$ & $\begin{array}{l}14^{\mathrm{c}} \\
(08-20)\end{array}$ & $\begin{array}{l}80 \\
(68-91)\end{array}$ & $\begin{array}{l}47^{c} \\
(39-55)\end{array}$ \\
\hline Excluded from school $^{b}$ & - & - & $\begin{array}{l}13 \\
(03-23)\end{array}$ & $\begin{array}{l}3^{c} \\
(0-05)\end{array}$ & $\begin{array}{l}32 \\
(18-45)\end{array}$ & $\begin{array}{l}9^{c} \\
(04-14)\end{array}$ & $\begin{array}{l}56 \\
(41-70)\end{array}$ & $\begin{array}{l}32^{c} \\
(24-39)\end{array}$ \\
\hline Impulsivity $^{b}$ & - & - & $\begin{array}{l}26 \\
(13-39)\end{array}$ & $\begin{array}{l}9^{c} \\
(04-14)\end{array}$ & $\begin{array}{l}43 \\
(28-57)\end{array}$ & $\begin{array}{l}13^{\mathrm{c}} \\
(07-18)\end{array}$ & $\begin{array}{l}74 \\
(61-87)\end{array}$ & $\begin{array}{l}34^{c} \\
(26-41)\end{array}$ \\
\hline Reckless behaviour $^{b}$ & - & - & 0 & 1 & $\begin{array}{l}13 \\
(03-23)\end{array}$ & $\begin{array}{l}0^{\mathrm{C}} \\
(0-0)\end{array}$ & $\begin{array}{l}28 \\
(15-41)\end{array}$ & $\begin{array}{l}4^{c} \\
(01-07)\end{array}$ \\
\hline Fighting and stealing $^{b}$ & - & - & $\begin{array}{l}9 \\
(01-17)\end{array}$ & $\begin{array}{l}1^{\mathrm{c}} \\
(01-03)\end{array}$ & $\begin{array}{l}24 \\
(12-36)\end{array}$ & $\begin{array}{l}7^{c} \\
(02-11)\end{array}$ & $\begin{array}{l}69 \\
(55-82)\end{array}$ & $\begin{array}{l}34^{c} \\
(26-42)\end{array}$ \\
\hline Socially isolated ${ }^{b}$ & - & - & 7 & 8 & 24 & 20 & $\begin{array}{l}74 \\
(61-87)\end{array}$ & $\begin{array}{l}54^{c} \\
(45-62)\end{array}$ \\
\hline
\end{tabular}

Note: a) difficult temperament was only collected for the $0-3 y r s$ period; $b$ ) these items were not collected in the $0-3 y r s$ period. ${ }^{c} p .01$. Cl for $\%$ in parentheses. 


\section{Conviction profiles}

\section{Lifetime criminal profile}

The ESPD and non-ESPD groups were comparable in relation to the time they spent at risk of conviction during their lifetime, having spent an average of 10.3 years (sd 3.5) at risk. As indicated in Table 10.4, the ESPD group had significantly higher rates for each type of conviction except sexual convictions, although as indicated by the confidence intervals the extent to which the two groups differ is relatively small. The odds of being convicted of any offence was nearly three times greater in the ESPD group, and over three times greater for being convicted of a violent offence. These results provide clear support for the hypothesis that those with ESPD traits are at a much higher risk of conviction, particularly for violent offences.

Table 10.4: Conviction profiles of the ESPD trait groups

\begin{tabular}{|c|c|c|c|c|c|}
\hline & \multirow{2}{*}{\multicolumn{2}{|c|}{$\begin{array}{l}\text { ESPD } \\
(n=54) \\
(95 \% \text { Cl) }\end{array}$}} & \multicolumn{2}{|c|}{$\begin{array}{l}\text { Non-ESPD } \\
(n=142)\end{array}$} \\
\hline & & & & $\%$ & $(95 \%$ CI) \\
\hline \multirow{4}{*}{$\begin{array}{l}\text { Lifetime } \\
\text { conviction } \\
\text { profile }\end{array}$} & Any convictions & 63 & $(49-77)$ & $37^{a}$ & $(29-46)$ \\
\hline & Sexual convictions & 20 & & 17 & \\
\hline & Violence convictions & 44 & $(30-59)$ & $19^{a}$ & $(12-26)$ \\
\hline & Non-sex/non-violence convictions & 54 & $(39-68)$ & $31^{a}$ & $(23-39)$ \\
\hline
\end{tabular}

Pre-YAP conviction profile
Sexual convictions

Violence convictions Non-sex/non-violence convictions

\section{0}

$19(07-30)$

26 (13-39)
11

$4^{\mathrm{a}} \quad(01-07)$

$9^{\mathrm{a}}(04-14)$

$\begin{array}{lrrrrr}\text { Post-YAP } & \text { Sexual convictions } & 4 & 8 & \\ \text { conviction } & \text { Violence convictions } & 39 & (25-53) & 17^{\mathrm{a}} & (10-23) \\ \text { profile } & \text { Non-sex/non-violence convictions } & 46 & (32-61) & 28^{\mathrm{a}} & (20-36)\end{array}$

Note: ${ }^{a} p .01$

\section{Pre-YAP conviction profile}

The ESPD and non-ESPD groups were comparable in relation to the time they spent at risk of conviction during the pre-YAP period, having spent an average of 5.3 years (sd 1.9) at risk. At the time of the original YAP assessment both groups were equally likely to have been convicted of a sexual offence, although, there was a trend for higher rates in the ESPD group. However, the odds of already having a conviction for a violent offence was over six times greater in the ESPD group, and three and a half times greater for being convicted of a nonviolent/non-sexual offence.

\section{Post-YAP conviction profile}

The ESPD and non-ESPD groups were comparable in relation to the time they spent at risk of conviction during the post-YAP period, having spent an average of 4.9 years (sd 2.5) at risk. The results presented in Table 10.4 indicate that, following the YAP assessment, the ESPD group continued to be significantly more likely to be convicted of both violence and non- 
sexual/non-violent offences, while neither group was significantly more likely to gain a sexual conviction. Notably, the percentage of sexual convictions was lower in the ESPD group, and, for both groups it was much lower than for either violent or non-sexual/non-violent convictions.

The survival rates for the first sexual and violent convictions post-YAP plotted in Figures 10.1 and 10.2 (see Appendix 3) indicate that the groups had similar (non-significantly different) survival rates for sexual conviction. However, the groups differed significantly in their survival rates for the first violent conviction. The graph indicates that post-YAP, more of the ESPD group were convicted of a violent offence, and their first convictions tended to occur early in the post-YAP period, that is, the majority of the first violent convictions occurred within the first three years post-YAP, while for some in the non-ESPD group the first violent conviction did not occur until six years post-YAP.

\section{Summary}

The results indicate that a subgroup of juvenile sexual abusers with emerging severe personality disorder traits can be identified, and that they can be distinguished from other juvenile sexual abusers in relation to psychosocial characteristics, SAB, non-sexual antisocial behaviour, and conviction profiles.

The factors on which the ESPD group differed from the non-ESPD group suggests that those with ESPD traits are characterised by having parents with their own abuse histories, as well as mental health problems including anti-social personalities. As infants this group is characterised by difficult early temperaments, oppositional and aggressive behaviour, and are likely to experience inconsistent parenting from their care-givers. The latter may be one source of the high level of insecure attachment to their care-givers. During early childhood, oppositional and aggressive behaviour is evident in conjunction with other anti-social behaviours such as stealing, impulsive and reckless behaviour. By middle childhood this group is characterised by diverse, persistent anti-social behaviour including fire-setting, cruelty to animals, stealing and reckless behaviour. The level of impulsivity in this group is notable, and many will have already been permanently excluded from at least one primary school. In adolescence, their anti-social behaviour persists, along with significant levels of social isolation. Finally, JSAs with ESPD traits are likely to have begun sexually abusing early, like their other anti-social behaviour, but over time it becomes apparent that their SAB contains elements of predation such as grooming and excessive force, as well as instrumental aggression such as abusing strangers, and the use of verbal coercion. 


\section{The relationship between Early and Late Onset trajectories of juvenile sexually abusive behaviour and emerging severe personality disorder traits $(n=187)$}

The final aim of the study was to explore the relationship between the age of onset trajectories and the presence of emerging severe personality disorder traits. As depicted in Figure 11.1, the prediction that the Early Onset trajectory was more likely to have high rates of ESPD traits was supported. Indeed, 64 per cent of those with ESPD traits had an Early Onset of SAB, while 36 per cent had a Late Onset.

Figure 11.1: Number of cases with ESPD and non-ESPD traits on the Early and Late Onset trajectories

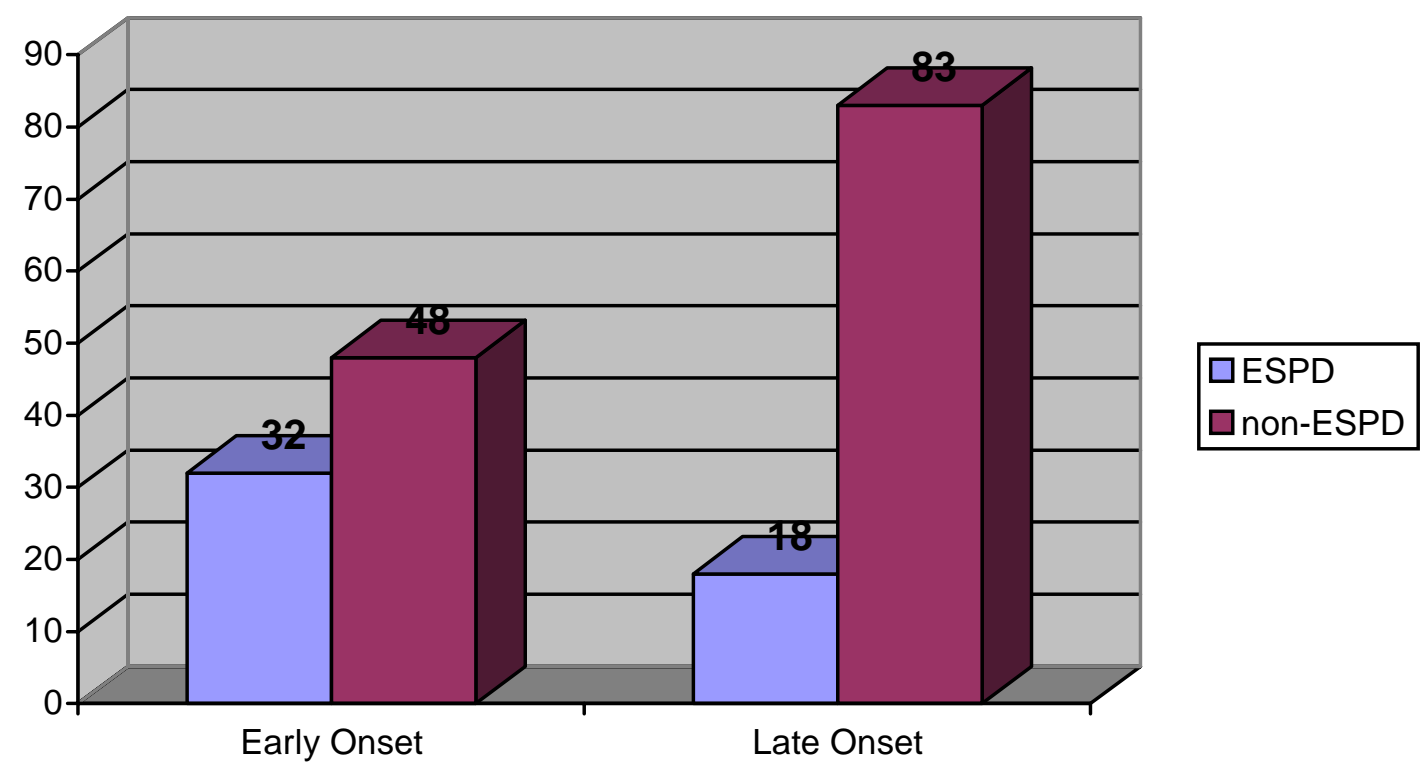

Having established that although the majority of those with ESPD traits are on the Early Onset SAB trajectory, the results indicate a small number on the Late Onset trajectory. Exploratory comparisons were therefore conducted to investigate the differences and similarities, in relation to psychosocial and SAB characteristics, between the ESPD groups on the Early and Late Onset trajectories.

As only $n=187$ cases were included in the analyses it was necessary to ensure that there were no significant differences between those included and excluded in the analyses. Therefore, the included $(n=50)$ were compared to the excluded $(n=137)$ on the following key variables: gender; ethnicity; intellectual disability; maltreatment; and marital separation/divorce. The results (see Table A.3 in Appendix 4) reveal no significant differences between the groups on any of these variables, indicating that those included in the analyses are representative of the whole sample. 


\section{Psychosocial characteristics}

The results presented in Table 11.1 indicate that on the majority of psychosocial characteristics the two groups are similar. The only significant differences between them suggest that the ESPD group on the EO trajectory are more likely to have experienced lack of parental supervision, inappropriate family sexual boundaries, CSA, physical neglect, and multiple changes in home placement. Those on the EO trajectory were also significantly more likely to have engaged in sexual activity with animals, and combined sexual and physical cruelty to animals. The only characteristic that was significantly more likely for those with ESPD traits on the LO trajectory was the misuse of alcohol and/or drugs. In addition to these significant differences there was a trend for the ESPD traits group on the EO trajectory to have higher rates of parental criminality, and peri natal problems.

Table 11.1: Comparisons between the ESPD trait groups on the Early and Late Onset trajectories on psychosocial characteristics

\begin{tabular}{|c|c|c|c|c|c|}
\hline & & \multirow{2}{*}{\multicolumn{2}{|c|}{$\begin{array}{cc} & \text { ESPD on EO } \\
\text { trajectory } \\
(n=32) \\
\% \quad(95 \% \mathrm{Cl})\end{array}$}} & \multicolumn{2}{|c|}{$\begin{array}{c}\text { ESPD on LO } \\
\text { trajectory } \\
(n=18)\end{array}$} \\
\hline & & & & $\%$ & $(95 \% \mathrm{Cl})$ \\
\hline $\begin{array}{l}\text { Parental } \\
\text { and } \\
\text { family } \\
\text { factors }\end{array}$ & $\begin{array}{r}\text { Parental criminality } \\
\text { Parental childhood abuse } \\
\text { Parental mental health problems } \\
\text { Parental time in care } \\
\text { Inconsistent parenting } \\
\text { Lack of parental supervision } \\
\text { Marital separation/divorce }\end{array}$ & $\begin{array}{l}41 \\
53 \\
72 \\
28 \\
81 \\
63 \\
50 \\
72\end{array}$ & $\begin{array}{l}(44-80) \\
(31-69)\end{array}$ & $\begin{array}{l}22 \\
56 \\
72 \\
17 \\
72 \\
17^{b} \\
17^{b} \\
67\end{array}$ & $\begin{array}{l}(0-36) \\
(0-36)\end{array}$ \\
\hline $\begin{array}{l}\text { Attachment } \\
\text { related } \\
\text { factors }\end{array}$ & $\begin{array}{r}\text { Early difficult temperament } \\
\text { Removal to Local Authority Care } \\
6+\text { changes in home placement } \\
\text { Insecure attachment }\end{array}$ & $\begin{array}{l}50 \\
94 \\
77 \\
78\end{array}$ & $(60-93)$ & $\begin{array}{l}50 \\
89 \\
39^{b} \\
56\end{array}$ & $(14-64)$ \\
\hline $\begin{array}{l}\text { Child } \\
\text { factors }\end{array}$ & $\begin{array}{r}\text { Peri natal problems } \\
\text { Hyperactive/impulsive behaviour } \\
\text { Disruptive behaviour primary school } \\
\text { Excluded from school } \\
\text { Any sexual cruelty to animals } \\
\text { Any physical cruelty to animals } \\
\text { Sexual and physical cruelty to } \\
\text { animals } \\
\text { Any substance misuse } \\
\text { Intellectual disability (IQ } \leq 70)\end{array}$ & $\begin{array}{l}44 \\
88 \\
59 \\
69 \\
31 \\
44 \\
22 \\
22 \\
41\end{array}$ & $\begin{array}{l}(14-49) \\
(06-38) \\
(06-38)\end{array}$ & $\begin{array}{c}17 \\
89 \\
67 \\
67 \\
0^{\mathrm{b}} \\
22 \\
0^{\mathrm{a}} \\
\\
50^{\mathrm{a}} \\
17\end{array}$ & $\begin{array}{l}(0-0) \\
(0-0) \\
(27-73)\end{array}$ \\
\hline $\begin{array}{l}\text { Trauma } \\
\text { factors }\end{array}$ & $\begin{array}{r}\text { Childhood sexual abuse } \\
\text { Physical abuse } \\
\text { Emotional abuse } \\
\text { Physical neglect } \\
\text { Exposure to domestic violence }\end{array}$ & $\begin{array}{l}81 \\
75 \\
81 \\
66 \\
50\end{array}$ & $(66-96)$ & $\begin{array}{l}44^{\mathrm{b}} \\
61 \\
83 \\
28^{\mathrm{a}} \\
56\end{array}$ & $(19-70)$ \\
\hline
\end{tabular}

Note: ${ }^{\mathrm{a} p} p .05,{ }^{\mathrm{b}} p .01$ 


\section{Sexually abusive behaviour}

In relation to the SAB exhibited by the ESPD groups on the EO and LO trajectories, the results in Table 11.2 indicate predominantly similar behaviours with the exceptions that those on the EO trajectory were significantly more likely to have abused male victims, and to have abused both male and female victims. However, the majority of significant differences between the groups indicate that those on the LO trajectory had higher rates of only abusing females, abusing strangers, using verbal or physical coercion, and raping adult women.

Table 11.2: Comparisons between the ESPD trait groups on the Early and Late Onset trajectories on sexually abusive behaviour characteristics

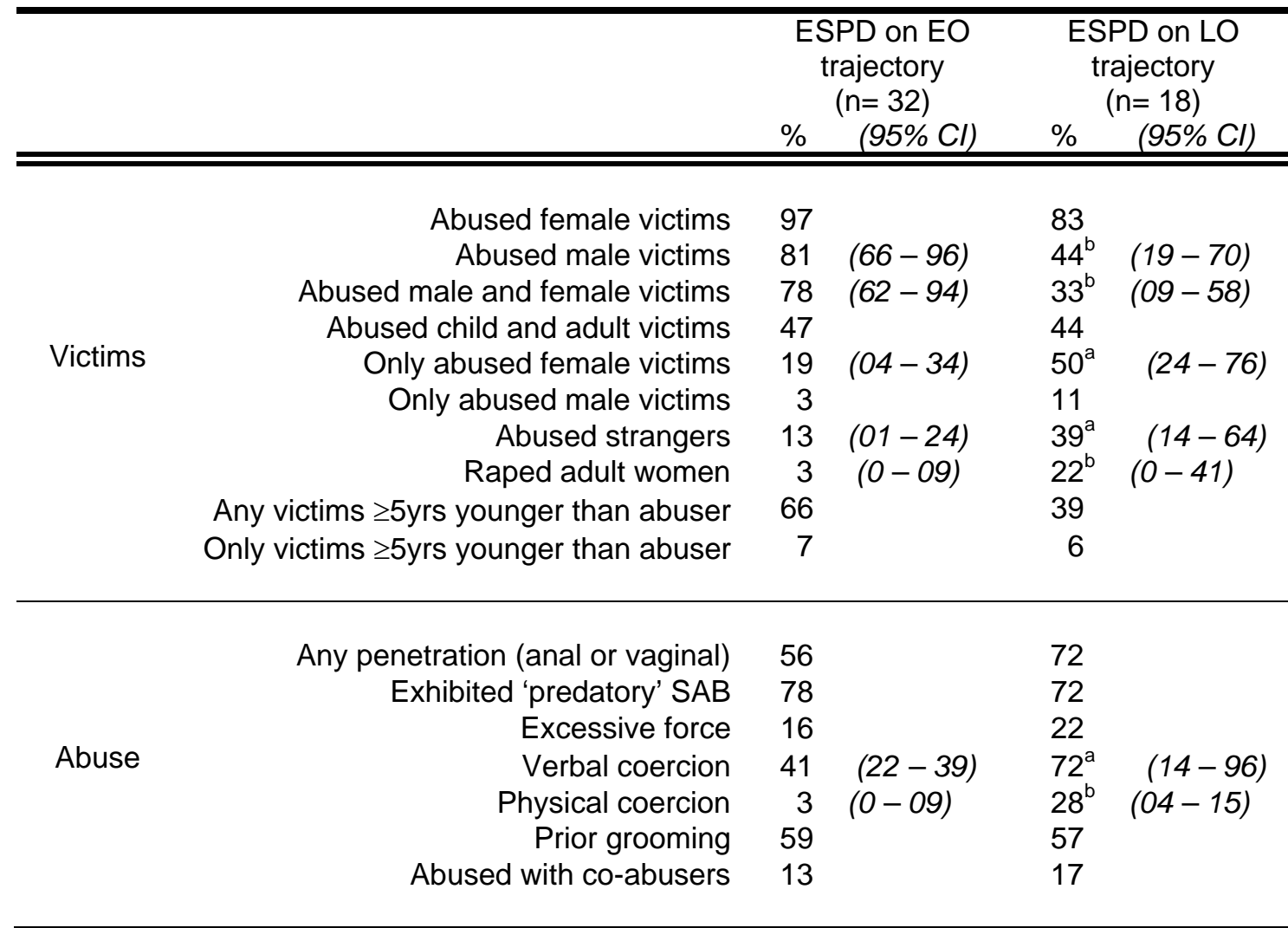

Note: ${ }^{\mathrm{a} p} p .05,{ }^{\mathrm{b}} p .01$

\section{Summary}

The exploratory group comparisons suggest that juvenile sexual abusers with ESPD traits are not a homogeneous population, and that those on different $S A B$ age of onset trajectories experience some different psychosocial risk factors, and display some differences in the sexually abusive behaviour they perpetrate. The differences are in the directions observed in the age of onset trajectory comparisons (see Chapter 9), indicating that the age at which SAB begins is an important differentiator of subgroups of juvenile sexual abusers, and can even differentiate between those with ESPD traits. However, the small numbers used in these exploratory comparisons preclude definitive, generalisable conclusions. It is also likely that the small numbers are responsible for the fact that the extent to which the two groups could differ are negligible, despite the existence of significant differences. Further empirical investigations with appropriate sample sizes are required. 


\section{Discussion}

The sample in this study was a naturally occurring, clinical cohort of high-risk children and adolescents referred to a community based assessment and treatment service for young sexual abusers. The characteristics of the sample reveal that it is similar to other published samples in terms of psychosocial characteristics and sexually abusive behaviour. However, the sample also differs in important ways. For example, it includes pre-adolescent children and the assessment of clinical disorders, which is not a routine part of all JSA services. Coming from a fourth tier service that predominantly receives referrals from Social Services departments, the sample also has higher rates of maltreatment, and emotional and behavioural disturbance than some other samples. The conviction profile of this sample concurs with previous studies in that it displays a generally anti-social profile, rather than a 'specialist' sex offending profile. However, the authors acknowledge that the conviction data for sexual offences are likely to be an underestimate of the actual prevalence of sexual offending behaviour.

The sexual behaviours exhibited by this sample are very similar to those perpetrated by adult sexual offenders. However, such behavioural similarity may stem from a different set of cognitive and psychological factors. For example, as Caldwell (2002) points out JSAs are heterogeneous, and the behaviours they commit are so varied that for the majority "offences against young children committed by younger teens serve as a poor proxy for pedophilic deviance" (p. 296). Therefore, risk assessments with JSAs need to explore the meaning of the $S A B$ for each individual to determine the risk of recidivism, and not simply rely on adult sex offender risk assessment variables.

Given the relatively modest period of follow-up into adulthood the conviction data in this study were unable to shed light on the relationship between juvenile sexually abusive behaviour and adult sexual offending. However, Loeber and Stouthamer-Loeber's (1998) fifth trajectory of Late Onset offenders may be useful for understanding adult sexual offending. That is, research indicates that very few JSAs are convicted of sexual offences in adulthood, while approximately half of adult sex offenders begin in adolescence, therefore, at least half of adult sex offenders must be Late Onset offenders.

The characteristics of this sample categorise it as 'high risk' for persistent anti-social behaviour and enduring mental health problems, including personality disorders. Both of which make it ideal for exploring the constructs of age of onset trajectories and emerging severe personality disorder traits.

\section{Age of onset trajectories of juvenile sexual abusers}

One aim of the study was to explore the value of age of onset trajectories for discriminating between subgroups of juvenile sexual abusers. The results suggest preliminary support for the hypothesis that JSAs with childhood or adolescent onsets of sexually abusive behaviour differ with respect to certain psychosocial and SAB characteristics, and with respect to the developmental sequences of their non-sexual anti-social behaviour. The conviction data in this study predominantly cover the adolescent period, with only a minority of early adulthood convictions. As a result, there was not enough data to evaluate the adult conviction outcomes of the trajectories. However, the adolescent conviction profiles of the Early and Late Onset trajectories were not expected to differ significantly, and this was reflected in the results.

The finding that those on Early Onset trajectory were characterised by significantly higher rates of difficult temperament, inadequate parenting, maltreatment and insecure attachment provides some support for Moffitt's (1993) contention that those with an Early Onset of antisocial behaviour are triggered by an interaction between neuropsychological deficits such as difficult temperament, and adverse environments such as inadequate parenting. Further support for the utility of the age of onset trajectories as discriminators between subgroups of JSAs comes from the finding that the EO trajectory had higher rates of abuse and neglect, impulsivity and hyperactivity, and speech and language problems, all of which Moffitt 
predicted should differentiate between Early and Late Onset trajectories. Even the finding that the EO trajectory had higher rates of non-sexual anti-social behaviour in childhood, while both trajectories had similar rates in adolescence, is consistent with Moffitt's developmental model.

The high rates of childhood sexual abuse and inappropriate family sexual boundaries on the EO trajectory suggests potential 'causes' of non-developmentally appropriate sexual behaviour. For example, inappropriate sexualisation from an early age may irrevocably damage neurobiological emotional regulation mechanisms. Alternatively, inappropriate sexualisation may lead to sexually arousing behaviour becoming reinforced as a means of internal comfort, or as a means of coping with negative emotions. Finally, simple social learning principles may, in the case of those exposed to early sexualisation, explain the Early Onset of sexually abusive behaviour.

The reasons why those on the EO trajectory abuse such a range of victims remains unclear. One possibility is that high levels of early sexualisation in this group contribute to behavioural conditioning to more diverse and deviant sexual stimuli. A second possibility is that for these children the $S A B$ is secondary to sexual arousal. For instance, it may indicate that behavioural expressions of anger, jealousy or frustration have become sexualised as a result of multiple forms of abuse. A number of the young people indicated that their SAB was motivated by anger and frustration, rather than sexual arousal, and indicated that over time they shifted from sexual violence to non-sexual violence as a means of expressing these feelings. Finally, the finding that inadequate family sexual boundaries acts together with difficult temperament in the logistic regression offers support for the early sexualisation thesis.

In contrast, the Late Onset trajectory had lower rates of adverse family functioning, again supporting Moffitt's theory that the onset of anti-social behaviour in adolescence is less directly influenced by factors such as early inadequate parenting and maltreatment. With regard to sexual behaviour, many of those who only began to abuse in adolescence will have reached puberty, therefore it is possible that their behaviour was motivated, in part, by sexual arousal, or an inability to achieve developmentally appropriate sexual relationships. The characteristics of the SAB exhibited by those on the LO trajectory lends support to this hypothesis. For instance, there was evidence of more 'targeted' victim selection in the form of: abusing only females, perhaps indicating intended heterosexual interactions that were expressed in a sexually aggressive manner; or, only abusing much younger children, perhaps reflecting teenagers whose inability to establish intimate relationships with a peer motivates them to meet their sexual needs with someone they perceive as less likely to reject them, such as a younger child.

These suggested differences between the motivations for the SAB exhibited by those on the Early and Late Onset trajectories is consistent with the finding that both groups are equally likely to use penetration or predatory forms of SAB, but that the LO trajectory has higher rates of using verbal coercion, that is, they may need to use such methods to facilitate the abuse of younger children.

In terms of the developmental sequences of non-sexual anti-social behaviour, the current findings are consistent with those of previous studies indicating that anti-social behaviour peaks in adolescence, which makes it difficult to differentiate between the trajectories during this period. The non-sexual anti-social behaviour of the Early and Late Onset trajectories followed this principle. Due to the nature of the sample it was not possible to examine their adult developmental sequences; however, in line with previous research it is predicted that the majority of the Late Onset trajectory will considerably reduce their level of anti-social behaviour in adulthood, while many of the Early Onset group will continue to display high levels of anti-social behaviour in adulthood.

Two significant results that were not a priori predictions require consideration. Firstly, why did those on the EO trajectory display significantly higher rates of abusing male victims? It is known that the majority of those on the Early Onset trajectory were male, and were exposed to early sexualisation. Ryan (1989) has suggested that boys who are sexually abused and go on to perpetrate $S A B$, are more likely to abuse victims who resemble them, as a means of 'reenacting' the abuse, but in the role of the perpetrator. 
Secondly, why were those on the LO trajectory significantly more likely to have sexual convictions post-YAP? One possibility is that because more of those on the LO trajectory sexually abused peers/adults, there was a greater chance of obtaining reliable evidence and securing a conviction. Another possibility is that those on the LO trajectory were less likely to present with emotional and mental health problems than their EO counterparts. Therefore, they may have been dealt with through the criminal justice system, while those on the EO trajectory were diverted into mental health services. A third, more theoretically driven possibility, is that sexually abusive behaviour perpetrated in adolescence may reflect a greater level of sexual deviance than is the case in early childhood. Adolescents have had more opportunities to internalise social norms in relation to sexual behaviour, and have a greater cognitive capacity to assess the impact of their behaviour. As such, sexually harmful behaviour emerging at this time may be more predictive of difficulties specifically relating to sexual behaviour than might be the case in younger children.

\section{Emerging severe personality disorder traits}

A further aim of the study was to determine whether a subgroup of juvenile sexual abusers with emerging severe personality disorder traits could be identified. The results indicate that such a subgroup is identifiable, and that they can be differentiated from non-ESPD juvenile sexual abusers on a range of psychosocial, SAB, and non-sexual anti-social behaviour characteristics, as well as in relation to their conviction profiles. The results provided support for several specific predictions, consistent with the view that juvenile sexual abusers with ESPD traits present in a similar way to non-sexually abusing juvenile delinquents (Frick et al., 1994).

Like non-sexually abusing juveniles with ESPD traits, JSAs with emerging severe personality disorder traits are characterised by high rates of parental childhood abuse; parental mental health problems; difficult temperament in infancy; inconsistent parenting; and insecure attachment. They also exhibit high rates of persistent anti-social behaviour from an early age including impulsivity and hyperactivity, sexual and physical cruelty to animals, and reckless behaviour. Perhaps as a result of their anti-social behaviour they also have high rates of removal to Local Authority care, and multiple changes in home placement. Finally, in relation to SAB they are more likely to engage in predatory behaviour, to use verbal and physical coercion with their victims, and to abuse a variety of victims rather than just one type of victim. This profile of JSAs with emerging SPD traits conforms to what is already known about other juveniles with ESPD traits, but also extends one's knowledge by indicating that the criminally versatile, callous and manipulative traits associated with SPD are expressed by JSAs in the form of diverse victim selection, predatory SAB, and instrumental sexual aggression.

The finding that those with ESPD traits had high rates of parents with histories of abuse and mental health problems may indicate that the role of genetic heritability in SPD traits is consistent for both JSAs and non-JSAs. Although a gene-environment 'interaction' is likely, parents who have been abused may bring psychological deficits to their parenting that prevent them from interacting appropriately with their offspring. While those with ESPD traits exhibit difficult temperaments and oppositional and aggressive behaviour in infancy and early childhood, their exposure to inconsistent parenting at the same time makes it difficult to determine whether the child's behaviour pre-dates the adverse parenting or is in part triggered by it. Similarly, the need for early removal into care, and the subsequent multiple changes in home placement experienced by the ESPD group, may equally be a result of the emerging personality disorders in the child, that is serious anti-social behaviour, or the direct effect of adverse parenting or failures on the part of foster carers. Finally, it is possible that the high rates of insecure attachment displayed by the ESPD group may have developed as a result of the parents' difficulties interacting in a warm and loving manner with a child who lacks empathic abilities and interacts in a controlling way, rather than from the parents' deficient attachment behaviours.

Finally, although the conviction data in this study is largely limited to adolescence, the profiles of those with ESPD traits conform to previous studies, that is, those with ESPD traits are more prolific offenders and have high rates of violent offending in addition to high rates of 
non-violent offending. The results further strengthen the conclusion that the majority of JSAs are not on a pathway to becoming specialist sex offenders, as sexual offences were generally the least likely type of offences for which both the ESPD and non-ESPD groups were convicted. The adult conviction profile for the ESPD group is predicted to follow the post-YAP pattern with high rates of violent and non-sexual/non-violent convictions, and relatively low rates of sexual convictions. However, the small numbers of JSAs with ESPD traits who do persist in sexual offending require further research to try and identify the psychosocial predictors of such a profile.

\section{The relationship between age of onset trajectories for juvenile sexually abusive behaviour and emerging severe personality disorder traits}

The prediction that juvenile sexual abusers on the Early Onset trajectory would be more likely to have ESPD traits was supported. This suggests that JSAs with ESPD traits do not form a homogeneous group with regard to either their psychosocial or SAB characteristics. The subsequent exploratory comparisons between the ESPD groups on the Early and Late Onset trajectories provide tentative indications that the age of onset of the $S A B$ is an important factor for understanding the sexual behaviours of different subgroups of JSAs, even when ESPD traits are present. The differences observed between the ESPD groups on the two trajectories largely mirror those observed between those on the Early and Late Onset trajectories. Similar psychosocial factors such as lack of parental supervision, abuse, and multiple changes in the home placement, appear related to the development of an Early Onset of SAB and the development of ESPD traits. That these features differ for the ESPD group on the LO trajectory suggests differences in aetiology for those individuals who only begin displaying $\mathrm{SAB}$ in adolescence.

All these conclusions are tentative due to the small numbers involved in the exploratory analyses. More robust testing of hypotheses in relation to the interactions between ESPD traits and the age of onset trajectories of SAB are necessary with larger samples. 


\section{Conclusions}

This study explored the utility of both age of onset trajectories, and emerging severe personality disorder traits, as discriminating concepts within the heterogeneous population of juvenile sexual abusers. Both appear to have utility, although, the results need to be tested on larger, more representative samples of juvenile sexual abusers. Therefore, at this stage any conclusions are subject to further investigation. Table 13.1 contains a summary of the hypotheses explored in this study, together with the outcomes and supporting evidence.

Consideration of the constructs 'age of onset' and 'ESPD traits' would theoretically point to the possible existence of four subgroups or dimensions of JSA, as depicted in Figure 13.1. However, the results have been too exploratory to look at the interactions between these constructs in detail. In view of the theoretical focus of the study Chapter 11 presents preliminary data on those with ESPD traits and the interaction of this construct with age of onset of SAB. The interaction between the construct of age of onset and those without ESPD traits has not been explored. The primary focus of the current study has been to look at the constructs separately. The authors present in detail: the developmental profiles for JSAs with Early and Late Onsets of SAB irrespective of personality traits; and the developmental profiles of JSAs with emerging severe personality disorder traits, irrespective of age of onset of SAB (see Table 13.2 for a summary of these profiles). The items highlighted in each of these profiles refer to characteristics that differentiate them from their counterparts, but it should be stressed that they are not necessarily factors specific to that type of JSA. For example, the EO group and those with ESPD traits share many early developmental risk factors. Further research is required, not only to explore the interactions between age of onset and the presence of ESPD traits, but also to look in more detail at the nature of the early risk factors. For instance, while the EO trajectory was significantly more likely to be exposed to abuse and neglect, many of those on the LO trajectory were similarly exposed; it is therefore necessary to determine whether factors such as the age at which the abuse began, or who perpetrated the abuse, are clinically relevant discriminatory characteristics.

Figure 13.1: Subgroups of JSAs: Inter-relationships between age of Onset of SAB and ESPD traits

Age of Onset of SAB

\begin{tabular}{|c|c|c|}
\hline & $\begin{array}{l}\text { Early Onset } \\
\text { ESPD traits } \\
\quad(n=32)\end{array}$ & $\begin{array}{l}\text { Late Onset } \\
\text { ESPD traits } \\
\quad(n=18)\end{array}$ \\
\hline ל- & $\begin{array}{c}\text { Early Onset } \\
\text { Non-ESPD traits } \\
(n=48)\end{array}$ & $\begin{array}{l}\text { Late Onset } \\
\text { Non-ESPD traits } \\
(n=89)\end{array}$ \\
\hline
\end{tabular}

The fact that multiple psychosocial and behavioural characteristics differentiated the JSA subgroups indicates the need for further investigation into whether there is a 'dose' effect. That is, do a greater number of characteristics lead to an early onset of SAB, or the development of ESPD traits, or do interactions between certain characteristics at particular developmental stages convey increased risk? Current understanding with regard to the development of general anti-social behaviour or ESPD traits, suggests that adversity (in any form) experienced in infancy or early childhood creates vulnerability for subsequent development. That is, early childhood abuse makes children vulnerable to attention deficits and impulsive or withdrawn behaviour; as a result, they have difficulty concentrating and participating in 
primary school, which means that they often do poorly, which in turn, means they are less well equipped to cope at secondary school. Such an effect is sometimes referred to as the 'cumulative consequence' effect (Moffitt, 1993). Further research is required to explore the interactions and developmental effects of psychosocial risk factors to improve the ability to identify those at risk of developing SAB in childhood, and those at risk of developing emerging severe personality disorder traits. 
1. Sexually abusive behaviour in childhood/ adolescence is indicative of a generally anti-social profile. Therefore, a cohort of juvenile sexual abusers would be predicted to have convictions for both sexual and non-sexual offences, with a greater proportion of the latter.

2.i.a The Early Onset trajectory is predicted to have higher rates of early difficult temperament and abuse/neglect.

2.ii.a The Early Onset trajectory is predicted to have higher rates of victimising both male and female, and both child and adult victims.

2.ii.b The Late Onset trajectory is predicted to have higher rates of victimising specific victim groups such as only much younger children.

2.iii.a The Early Onset trajectory is predicted to have higher rates of anti-social behaviour in childhood.
Fifteen per cent of the cohort were convicted of sexual offences and 35 per cent were convicted of non-sexual offences (see Table 8.3).

The EO trajectory had significantly higher rates of difficult early temperament, childhood sexual abuse, physical abuse, emotional abuse, and neglect. There were no group differences in exposure to domestic violence (see Table 9.1)

The EO trajectory had significantly higher rates of abusing both male and female victims, as well as both child and adult victims (see Table 9.3).

The LO trajectory had significantly higher rates of only abusing female victims and only abusing much younger children. There was a non-significant trend for twice as many of the LO trajectory to rape adult women (see Table 9.3).

During childhood (0-10 years) the EO trajectory had significantly higher rates of a variety of anti-social behaviours, but during adolescence the group differences were non-significant (see Table 9.4).

The group differences on lifetime convictions were non-significant although there was a trend for greater convictions in the LO group (see Table 9.5).

The group difference was significant (see Table 10.1). 
Table 13.1 continued

Hypotheses

Evidence

3.i.b Those with ESPD traits are predicted to The group difference was in the have higher rates of early difficult predicted direction. (see Table 10.1).

temperament.

3.ii.a Those with ESPD traits are predicted to have higher rates of predatory $\mathrm{SAB}$ for example prior grooming, abusing strangers, abusing both males and females, and both children and adults.

3.iii.a Those with ESPD traits are predicted to exhibit a variety of non-sexual anti-social behaviours throughout childhood and adolescence.

The group differences were significant. (see Table 10.2).

The ESPD group exhibited significantly higher rates of a variety of anti-social behaviours in both childhood and adolescence but some specific behaviours (such as fire-setting) were at comparable levels to the non-ESPD group (see Table 10.3).

3.iii.b Those with ESPD traits are predicted to exhibit cruelty to animals and reckless behaviour throughout childhood and adolescence.

The ESPD group had significantly higher rates of both behaviours during childhood and adolescence. (see Table 10.3).

3.iv.a Those with ESPD traits are predicted to have higher rates of convictions, particularly for violent and non-violent offences.

The ESPD group compared to the nonESPD group had significantly higher conviction rates overall and for violent and non-violent offences. No differences were found, however, in relation to 'sexual convictions' (see Table 10.4).

4. Those on the Early Onset trajectory are predicted to be more likely to present with ESPD traits.

Sixty-four per cent of the EO trajectory had ESPD traits compared to only 36 per cent of the LO trajectory.

A clear finding throughout the study, that corroborates all previous JSA research, is that JSAs are more likely to engage in a wide range of anti-social and offending behaviours than in sexually abusive offending. Both the conviction and developmental sequence of anti-social behaviour reported in this study support this conclusion. These findings indicate that as a population, the majority of JSAs will desist from SAB by early adulthood. However, a minority, that are not yet able to be identified, are likely to continue to sexually abuse others. The results from the study corroborate previous studies with respect to the characteristics of JSAs, and highlights that they share many psychosocial and behavioural characteristics with nonsexually abusing delinquents. A salient question for future research is why, given the similarity in backgrounds, only some juvenile delinquents perpetrate SAB. 
Finally, despite the encouraging findings with respect to the utility of age of onsets trajectories and ESPD traits for differentiating between subgroups of JSAs, it must be remembered that they are the building blocks for a much needed wider programme of research on juvenile antisocial behaviour. This programme should aim to strengthen our understanding of: the motivations underlying $S A B$ by juveniles; why some juvenile delinquents commit $S A B$ and others do not; why some JSAs continue to commit sexual offences as adults; why some youth develop ESPD traits; whether all youth with ESPD traits continue to become adults with severe personality disorders; and what type of treatments work best with young people who display ESPD traits. 
Table 13.2: Preliminary developmental profiles of Early Onset JSAs, Late Onset JSAs, and JSAs with ESPD traits

\begin{tabular}{|c|c|c|c|}
\hline & Early Onset JSAs & Late Onset JSAs & $\begin{array}{l}\text { JSAs with ESPD } \\
\text { traits }\end{array}$ \\
\hline $\begin{array}{l}\text { Infancy/early } \\
\text { childhood } \\
(0-7 y r s)\end{array}$ & $\begin{array}{l}\text { Difficult temperament. } \\
\text { Physically aggressive. } \\
\text { Impulsive. } \\
\text { Insecure attachment. } \\
\text { Exposure to abuse and } \\
\text { neglect. } \\
\text { Exposure to inadequate } \\
\text { parenting. } \\
\text { Developmentally } \\
\text { inappropriate sexual } \\
\text { behaviour, e.g., } \\
\text { excessive masturbation. } \\
\text { SAB towards males, } \\
\text { females, children, } \\
\text { peers/adults, animals. }\end{array}$ & $\begin{array}{l}\text { Some exposure to } \\
\text { domestic violence. } \\
\text { Some exposure to } \\
\text { abuse/neglect. } \\
\text { Some exposure to } \\
\text { inadequate parenting. }\end{array}$ & $\begin{array}{l}\text { Difficult temperament. } \\
\text { Physically } \\
\text { aggressive. } \\
\text { Impulsive. } \\
\text { Insecure attachment. } \\
\text { Exposure to } \\
\text { inconsistent } \\
\text { parenting. }\end{array}$ \\
\hline $\begin{array}{l}\text { Middle } \\
\text { childhood } \\
\text { (7-10yrs) }\end{array}$ & $\begin{array}{l}\text { Removal from home. } \\
\text { Physical aggression, } \\
\text { impulsivity, and insecure } \\
\text { attachment. } \\
\text { Multiple changes in } \\
\text { placement. } \\
\text { Physical cruelty to } \\
\text { animals. } \\
\text { Non-sexual anti-social } \\
\text { behaviour. } \\
\text { Expulsion from school. } \\
\text { Social isolation. } \\
\text { Continuing SAB. }\end{array}$ & $\begin{array}{l}\text { Some physical } \\
\text { aggression and minor } \\
\text { anti-social behaviour. }\end{array}$ & $\begin{array}{l}\text { Removal from home. } \\
\text { Multiple changes in } \\
\text { placement. } \\
\text { Physical aggression, } \\
\text { impulsivity, insecure } \\
\text { attachment. } \\
\text { Non-sexual anti- } \\
\text { social behaviour. } \\
\text { Physical cruelty to } \\
\text { animals. } \\
\text { Expulsion from } \\
\text { school. } \\
\text { Social isolation. } \\
\text { SAB against range of } \\
\text { victims. }\end{array}$ \\
\hline
\end{tabular}

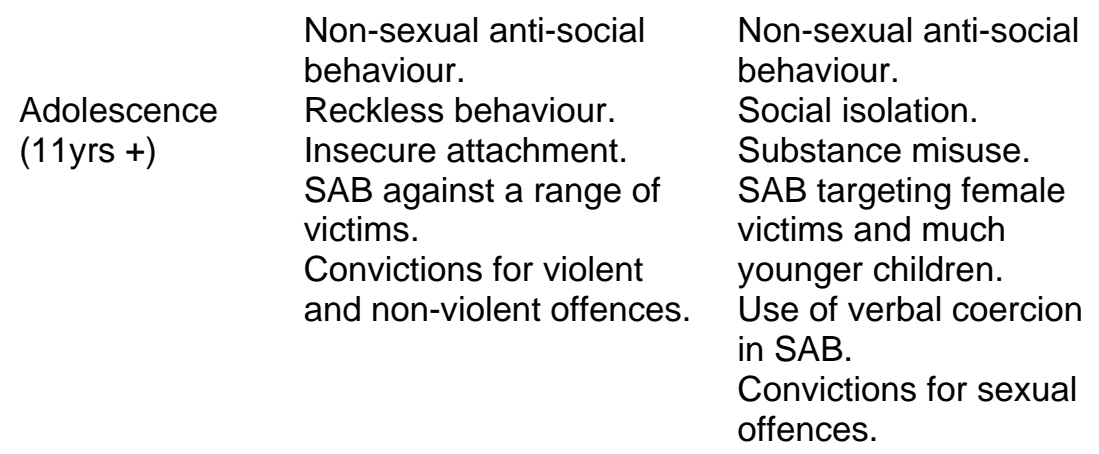

Chronic anti-social behaviour.

Social isolation. SAB against male and female victims; children and peers/adults; strangers. Predatory SAB, grooming, coercion. Convictions for violent and nonviolent offences. 


\section{Limitations}

A number of caveats must be borne in mind when interpreting the study findings. Firstly, the sample was obtained from a clinical rather than criminal justice setting. It was also obtained from a fourth tier NHS CAMH service, and as a result at the time of assessment the cases were presenting with chronic and persistent behavioural and emotional problems. Therefore, the sample may not be representative of all identified JSAs, particularly those with milder presentations, nor representative of undetected JSAs. As such the current findings require replication with more representative samples of JSAs.

Secondly, in respect of sample size the current study represents the largest and most detailed British study of juvenile sexual abusers. Nevertheless, a larger sample would increase power and allow more robust inferences to be drawn, reducing the likelihood of false positives and false negatives. This is particularly necessary for future studies exploring the interaction between the age of onset developmental trajectories and ESPD traits.

Thirdly, methodological limitations of the current design concern the reliance on file information in this study. The categorisation of cases into either EO or LO was made on the basis of information gathered from the pre-assessment files and the report of the YAP interview with the young person and the carers. Nonetheless, the secretive nature of $S A B$ means that there may have been acts of SAB that were undetected or undisclosed. As a result, the authors acknowledge the possibility that some of those categorised as LO may in fact have committed acts of SAB before the age of 11 years. As also noted in the Method there was a degree of variability in both the quantity and quality of information provided in each case. However, to address this concern the authors only rated cases with information from more than one source. Nevertheless, the absence of multiple sources and a lack of sufficient detail meant that a significant minority of cases were not classifiable in relation to both age of onset $(n=67)$ and the PCL-YV $(n=23)$, thereby reducing the sample sizes for those analyses. A further implication of the lack of detail, specifically the euphemistic nature of how $S A B$ was often described, is likely to have led to an under-specification of the abusive behaviours and possibly an underestimate of their seriousness.

Fourthly, this study aimed to employ existing operational definitions to investigate age of onset trajectories and ESPD traits. However, research on emerging personality disorders in childhood is in its infancy. ESPD traits were defined on the basis of conduct problems and personality functioning. While both these domains are relatively standardised with regard to measurement there is no consensus as to the cut-offs at which ESPD traits might be thought to exist. The current study employed an a priori hypothesis testing approach and identified those young people presenting with above average levels of both conduct problems and personality functioning. Although the findings provide some support for the view that individuals within this group present with emerging severe personality disorder traits, further developmental research and additional theoretical debate are required to derive a robust operationalised definition of ESPD traits in childhood, both for research purposes and clinical practice.

Fifthly, resilience factors within the child and protective factors within the care-giving environment are reasonably well documented in the literature in relation to delinquency and include high IQ, integrity of neurological systems and stable temperament, lack of thrill seeking behaviour, the presence of confiding peer relationships, and secure attachments. It has also been suggested that environmental protective factors may act as a counterbalance to risk factors, allowing a movement towards normal development (Royal College of Psychiatrists, 1999; Rutter, Giller and Hagell, 1998; Werner, 1985). This study was not designed to explore potential protective and resilience factors in relation to the development of Early and Late Onset sexually abusive behaviour or ESPD traits, although it could reasonably be argued that those children with fewer early childhood risk factors are likely to have fewer adverse outcomes. However, this proposition should be tested with further research. 
Sixthly, the authors' ability to examine the adult conviction outcomes of the sample was limited by the relatively short post-YAP period. However, the authors hope to be able to provide more robust conviction outcome data in the years to come as the sample ages naturally and more enter adulthood.

Finally, it will be noted that separate results for males and females were not presented. However, the authors' analyses revealed that gender was not a confounding factor for either age of onset or ESPD traits, therefore, separate results were not reported. Nevertheless, the authors acknowledge that other studies of JSA's have shown that while both genders commit very similar acts of $S A B$, they tend to differ on factors that may be aetiologically relevant (Robinson, 2005). For example, female abusers tend to have more severe histories of childhood sexual abuse compared to males. In relation to ESPD traits, although gender research is very limited, it indicates that the prevalence of psychopathy traits is similar for male and female juveniles, although the expression of general aggression differs (Marsee et al., 2005). That is, males are more overtly aggressive while females are more likely to engage in 'relational aggression'. 


\section{Implications}

There are clinical, policy and research implications arising from this study. These are highlighted in the following sections, while the recommendations in each area are listed in Chapter 16.

\section{Clinical implications}

The major clinical implications relate to the assessment and treatment of JSAs with different ages of onset of SAB, and JSAs with ESPD traits. The study suggests that specific risk factors associated with these groups should be considered in addition to those normally assessed within a developmental assessment framework.

\section{JSAs on different age of onset trajectories}

In relation to young people with different ages of onset of $S A B$, the current findings suggest that the assessment of those with an Early Onset should include the following.

- Parental and family factors: parental mental health problems and care histories, inconsistent parenting, family sexual boundaries, and parental supervision.

- Attachment-related factors: difficult temperament in infancy, multiple changes in home placement, and insecure attachment to care-givers.

- Child factors: the presence of persistent challenging and anti-social behaviour from early childhood including challenging behaviour in primary school, aggressive, impulsive or hyperactive behaviour, and sexual and physical cruelty to animals.

- Trauma factors: all forms of abuse and neglect.

For those with a Late Onset of $\mathrm{SAB}$, the study findings suggest the need to conduct a similar assessment, although there are likely to be fewer behavioural problems in infancy, and less anti-social behaviour in the childhood period. In the child factors, those with Late Onset SAB appear to require an assessment of their substance misuse.

With regard to assessing the sexually abusive behaviours of those on the different age of onset trajectories, the current findings suggest that the motivation for the SAB is likely to differ for those on the two trajectories, and may be relevant for assessing the risk of SAB recidivism.

Finally, the assessment process should also consider the developmental continuity of nonsexual anti-social behaviour. The study suggests that the EO trajectory will have a lengthy history of such behaviour, while those on the LO trajectory are only likely to exhibit major problems in adolescence. Nonetheless, both profiles indicate the need to assess the underlying attitudes and beliefs that support such behaviour to determine the need for treatment to reduce recidivism.

Treatment plans should relate to the assessed risks for recidivism; therefore, it is likely that JSAs with an Early Onset of SAB will benefit from interventions designed to address their own victimisation, their ability to recognise and regulate internal feeling states, and their attitudes and beliefs about sexual and personal identity. JSAs with a Late Onset of sexually abusive behaviour, in addition to the above, are likely to benefit from interventions that address sexual arousal and/or fantasy as well as the development and maintenance of intimate relationships. As impulsive behaviour is common to all anti-social juveniles, treatment with both groups should address consequential thinking and gratification delay, as a means of reducing antisocial behaviour. 


\section{JSAs with ESPD traits}

In relation to juvenile sexual abusers with emerging severe personality disorder traits the current findings suggest that if it is suspected that the child has emerging personality disorder traits the assessment should include the following.

- Parental factors: parents who have experienced childhood abuse themselves, who present with mental health problems, and are known to provide inconsistent parenting.

- Attachment factors: Being placed in care, having multiple changes of placement, showing insecure attachment to care-givers, and a difficult early temperament.

- Child factors: The presence of challenging behaviour in primary school, a history of school exclusion, impulsive or hyperactive behaviour, and evidence of both sexual and physical cruelty to animals.

The assessment should also consider the developmental continuity of behavioural difficulties. For example, around a third to a half of the JSAs with ESPD traits showed evidence of physical aggression before the age of seven. Similarly, a third were reported to show clear evidence of a difficult temperament in infancy. Information in relation to each of the features should be obtained, ideally from more than one source. Evidence for a pattern of features across the domains should inform the clinical assessment of risk.

With regard to assessing the SAB of juvenile sexual abusers with ESPD traits, the study suggests that evidence of the behaviour should be sought from early childhood, and examples of predatory and instrumental sexual aggression should be specifically assessed.

The data presented here suggest that children with a developmental profile of emerging severe personality disorder traits represent a high-risk group for committing both violent and non-violent crimes. Evidence of a developmental pattern of psychosocial and behavioural characteristics should therefore be used to prioritise intervention resources for these children and young people.

A separate assessment issue in relation to ESPD traits is whether a direct assessment of personality functioning, using, for example, the PCL-YV, should be more commonly carried out. This issue is likely to raise anxiety among many clinicians because of concern that children may be inappropriately labelled as 'psychopaths'. In the current study the focus was on the identification of emerging anti-social personality traits, which, in conjunction with conduct disorder problems, have been shown to isolate a high-risk group with a distinct developmental trajectory. The use of personality assessments, as part of a broader clinical assessment, may have some utility over and above that to be gained from a consideration of the developmental factors outlined above. This is an empirical question that requires further research.

\section{Policy implications}

The primary policy implications concern the provision of specialist services for juvenile sexual abusers. The findings suggest that subgroups of juvenile sexual abusers exist, whether defined by age of onset of the SAB, or the presence of ESPD traits. Therefore, services for juvenile sexual abusers cannot adopt a 'one size fits all' approach to treatment and hope to meet all the needs of their clients. The current and prior research indicates that JSAs present with multiple problems across a range of domains; therefore, to appropriately meet all these needs an integrated inter departmental approach is required to produce a national strategy for addressing the issue of SAB in juveniles. Since there is a wide age range of JSAs and a diverse spectrum of need, it is suggested that service provision will be required at a number of levels. 
A further policy implication arises from the consistent research findings that childhood psychosocial risk factors are directly implicated in juvenile anti-social behaviour, including sexually abusive behaviour. Policy makers therefore need to adopt long-term solutions to try and reduce juvenile anti-social behaviour such as: introducing a national programme of parenting skills; improving the ability of schools to meet the needs of children who lack basic classroom skills; or introducing national programmes of forensic foster care that will enable high-risk children who have to be removed from home to benefit from foster care.

\section{Research implications}

Research generally on juvenile sexual abusers is woefully under-represented and under resourced, but is particularly so in the U.K. Therefore, the main research implications arising from this study concern the need to develop more thorough conceptualisations of the subgroups of JSAs. This will necessitate both retrospective, and most importantly, prospective studies to determine the aetiological factors in the development of different types of JSA, and determine their long-term outcomes in adulthood. In addition, research is needed to evaluate the treatments offered to JSAs to determine what works, for whom and why. Only by conducting such a programme of research will there be any real possibility of reducing the total incidence of sexually abusive behaviour by juveniles, or of making the assessment and treatment offered to JSAs more relevant for reducing recidivism.

Research on ESPD traits in young people is also under-represented, although, the researchers do have the benefit of conducting retrospective studies with adults who have severe personality disorders to help inform the development of early intervention strategies for juveniles with emerging traits. However, research is still needed to understand the presentation of ESPD traits in young people, and particularly how this can be translated into developmentally sensitive assessment tools.

Finally, consideration should be given to commissioning pilot studies evaluating the efficacy of multidimensional treatment foster care (Chamberlain and Reid, 1998), or forensic foster care (Yokely and Boettner, 2002). Both are community-based alternatives for children and young people who cannot be contained at home, but who do not require the intensive supervision or treatment provided by residential services. 


\section{Recommendations}

The clinical, policy and research recommendations stemming from this research are outlined below.

\section{Clinical recommendations}

\section{Assessment}

- $\quad$ Since an Early Onset of SAB appears to be a marker for a long-term trajectory involving persistent anti-social behaviour, as well as enduring emotional problems, it is recommended that professionals respond as early as possible to children presenting in such a manner, to improve the chances of moving the young person off the trajectory.

- $\quad$ Since research indicates that SAB can begin at any age, professionals who work with JSAs should ensure that the assessment is conducted within a developmental framework. The additional assessment of psychiatric disorders will contribute to a comprehensive needs assessment (Kroll et al., 1999) and help construct the risk management strategy.

- $\quad$ Since research indicates that emerging severe personality disorder traits can be assessed in childhood and adolescence, professionals in both local and specialist forensic Child and Adolescent Mental Health Services (CAMHS) should consider routinely including assessments of personality functioning with children presenting with anti-social behaviour.

- $\quad$ All risk assessments of children and young people presenting with SAB and ESPD traits should include a needs assessment (Kroll et al., 1999) so that appropriate resources can be identified to deal with the assessed risks and needs.

\section{Intervention}

- $\quad$ Pre-adolescent children presenting with $S A B$ appear to require interventions that reduce their exposure to adverse parenting and family environments, and improve their ability to develop secure attachments to care-givers.

- $\quad$ Children and adolescents presenting with ESPD traits require assessment and intervention to be conducted by professionals who are suitably trained in child and adolescent mental health. This training should include familiarity with the personality disorder and psychopathy literature, and clinical training in the assessment of these features.

- $\quad$ There should be specialist service provision for juveniles presenting with ESPD traits covering all levels of security from community to high security.

Finally, it is recommended that consideration should be given to including both $S A B$ and ESPD traits in the official diagnostic manuals (DSM and ICD), as a means of helping professionals to identify these problems, and to initiate assessment and treatment.

\section{Policy recommendations}

\section{Primary prevention}

The current findings highlight that a range of individual and family risk factors are associated with the later emergence of serious and diverse patterns of offending. In particular, ESPD traits appear associated with high levels of early psychosocial risk factors. Therefore, primary 
prevention strategies targeting those families and individuals at most risk for poor outcomes could play a primary role in reducing levels of anti-social behaviour. Such a public health model would need to identify a core set of evidence-based risk factors that would identify the need for multi-systemic interventions operating at the level of the individual, family and community (Kaufman, Barber, Mosher and Carter, 2002). Such an approach requires a new integrated, multidisciplinary service focused on providing skills-based interventions to highrisk parents and young people. Ideally, those at high risk should be identified early.

\section{Juvenile sexual abusers}

In relation to juvenile sexual abusers an integrated inter departmental strategy for service development is essential. Many CAMHS do not accept referrals of young people presenting with sexually abusive behaviour, even though such children often have extremely high levels of need. As many of these youths have not been convicted of an offence at this stage, they tend not to be accepted by Youth Offending Teams either. This anomaly needs to be addressed. Difficulties include professionals who lack expertise in relation to such cases and the high level of anxiety that such cases can produce.

A solution could involve the strategic development of services for juvenile sexual abusers at three levels:

- $\quad$ Community-based teams, including CAMHS, who can assess and treat younger children and less disturbed adolescents presenting with over-sexualised or sexually abusive behaviour supported with input from a specialist service with consultation and training.

- A small, national network of specialist teams could be established with the remit to provide such case consultation, and a range of teaching and training programmes, to facilitate CAMHS services in the local assessment and treatment of these cases. Complex cases with additional serious mental health concerns could also be referred to these specialist teams for direct assessment and treatment.

- $\quad$ A small number of residential facilities for children and young people with sexually abusive behaviour should also be established around the UK to allow for the intensive, supervised treatment of children whose needs cannot be met safely in the community.

\section{Anti-social behaviour}

Since juveniles presenting with anti-social behaviour, including SAB, and ESPD traits, experience problems in multiple domains such as health, education and criminal justice, a multifaceted approach to reducing the problems is required. This can be achieved by the development of joined-up inter departmental strategies in which all government departments take responsibility for juvenile anti-social behaviour and work together to reduce the problem. Such inter departmental strategic planning is essential in light of the current lack of appropriately coordinated services for children with sexually abusive behaviour. Specific recommendations are shown below:

- A standing inter departmental government committee, with representation from the Youth Justice Board, Department of Health, and Department for Education and Skills should be established. This should hold responsibility for prevention and service provision for children with antisocial behaviour. Such a committee should report at regular intervals to the relevant departmental ministers on their progress.

- $\quad$ A proactive, long-term approach should be taken to the development of strategies to reduce the causes and consequences of juvenile anti-social behaviour. Such strategy development should come within the remit of the standing inter departmental government committee mentioned above. 


\section{Research recommendations}

\section{Juvenile sexual abuse}

In relation to JSAs a comprehensive research programme is required to improve the validity of risk assessments, and provide interventions that will reduce recidivism. To this end it is important to understand the factors that trigger $S A B$ in children and adolescents, as well as the factors that subsequently maintain the expression of sexual aggression. Such a programme should include research on the following.

- Prospective longitudinal studies with JSAs are needed to determine adult outcomes. This can help in the identification of specific factors associated with those young people who commit sexual offences as adults. This could be partly achieved by identifying, using the Offenders Index, a subgroup in the current sample who go on to commit sexual offences in adulthood over the next ten years.

- Further investigations of different developmental trajectories are required. Young people presenting with sexually abusive behaviour are not a homogeneous group. It will be important to identify both protective and resilience factors in future studies.

- A large-scale evaluation of multi-systemic therapy with JSAs should be commissioned in the UK. This type of intervention programme has proved very successful for general anti-social behaviour, and two pilot studies with JSAs in the USA have shown promising results (Borduin, Henggeler, Blaske and Stein, 1990; Borduin, Schaeffer and Heiblum, 2003). A large-scale study is therefore warranted.

- Promising early results from North American community based, forensic foster care interventions for JSAs (Chamberlain and Reid, 1998; Yokely, 2002; Yokely and Boettner, 2002) suggest the need for pilot studies in the UK.

\section{Emerging severe personality disorder traits}

In relation to ESPD traits, this study only explored their expression in juvenile sexual abusers, however, these traits are not confined to JSAs. Indeed, all types of anti-social youth may develop ESPD traits. The following research recommendations therefore address the issue of ESPD traits in all anti-social juveniles. To improve the ability to identify young people at risk of developing severe personality disorders, and provide appropriate interventions, the following research is required.

- Studies to develop and evaluate developmentally sensitive clinical measurement tools for assessing ESPD traits in young people.

- Retrospective studies with adults who have severe personality disorders to help identify childhood and adolescent developmental trajectories.

- Prospective studies with children and adolescents at risk of developing ESPD traits to test hypotheses about the aetiology of the disorder, and to improve understanding of the resilience factors that might help some children move off the ESPD trajectory.

- Evaluation studies of interventions designed to address the behavioural and personality traits of juveniles with ESPD traits.

- Neurological studies to explore the functioning deficits associated with ESPD traits, and neurobiological studies to explore the affected brain mechanisms. 


\title{
Appendix 1. Glossary of terms
}

\author{
Abused with co-abusers \\ Perpetrated any or all SAB with one or more additional perpetrators for example, with a 'gang' \\ of other young people.
}

Any convictions

Convicted of any type of offence, for example sexual, violent, acquisitive etc.

Any substance misuse

Evidence that alcohol or drugs are being consumed to excess.

Childhood sexual abuse

Actual or suspected sexual assault of child or adolescent (under 16 years old).

Cruelty to animals

Acts of physical harm perpetrated against any animal, for example hitting, drowning, burning, killing.

Dangerous and Severe Personality Disorder (DSPD) Programme

The inter departmental programme tasked with designing and implementing services for adult dangerous offenders with severe personality disorders, as well as overseeing the DSPD integrated research and development programme.

Disruptive behaviour in primary school

The presence of any of the following types of behaviour: the child is physically and/or verbally aggressive to teachers and/or pupils in the classroom; the child does not get on with set work; the child gets up and runs around the classroom disrupting other people's work; the child runs out of the classroom and around the school; the child destroys their own or other people's work.

Early difficult temperament

Defined by the presence of any of the following in the first three years of life: hyperactivity; excessive temper tantrums; aggression towards others; oppositional or defiant behaviour towards others.

Early Onset sexually abusive behaviour

Any sexually abusive behaviour, towards a person or animal that occurs before the abuser reaches 11 years of age.

Emerging severe personality disorder (ESPD) traits

In this study this term refers to the presence in childhood or adolescence of above average levels of both conduct disordered behaviour and psychopathic personality disorder traits. The term 'emerging' is used to signify that at the time of assessment these traits were observed, but it is recognised that they may not persist into adulthood.

\section{Emotional abuse}

Actual or suspected persistent or severe emotional or psychological maltreatment, for example rejection, emotional neglect, abandonment.

Ever on the Child Protection Register

Whether the child has ever been registered following sexual, physical, emotional abuse, or physical neglect.

\section{Excessive force (in $S A B$ )}

The use of force that is in excess of what is needed to perpetrate the sexual abuse, for example threatening with a weapon, tying up, hitting, punching, kicking. 


\section{Excluded from school}

The individual is permanently excluded from attending a particular school, and thereby forced to attend an alternative schooling environment.

\section{Exposure to domestic violence}

Exposure to an environment of aggression/violence between adults in the home, for example verbal or physical aggression.

\section{Fetishist sexual behaviour}

Obtaining sexual arousal from contact with objects such as female clothing and nappies.

\section{Fire-setting}

Any evidence of intentionally setting fires (other than to heat a house or for a bonfire).

\section{Fighting and stealing}

Evidence that the child engages in both types of anti-social behaviour rather than only one or the other.

\section{Frotteurism}

Rubbing against another person in public places for example, on a train, for sexual gratification.

\section{Hyperactive/impulsive behaviour}

The presence of any of the following type of behaviours: constant fidgeting; restlessness; inability to sit still for even short periods of time; constant interrupting; inability to wait; acting on the spur of the moment; difficulty following instructions; difficulty concentrating for long.

\section{Impulsivity}

Evidence of acting 'on the spur of the moment' without considering the consequences.

\section{Inadequate family sexual boundaries}

Families in which there are no, or only poorly supervised, boundaries about children and adolescents accessing pornographic images in magazines, on TV, in videos, or through the internet. Similarly, young people are exposed to adults engaging in sexual activity, both consenting and non-consenting.

\section{Inconsistent parenting}

Evidence that the child is receiving mixed messages from two parents about their behaviour, e.g. one is disciplinarian while the other is very lax about boundaries, or that the same parent gives the child different messages about behaviour at different times and is not consistent in his/her approach to behaviour management.

\section{Insecure attachment}

Evidence that young people do not have a secure attachment bond to their caregivers e.g. they are over familiar with strangers; they do not seek comfort from their care-givers when distressed; they respond in a contradictory manner to their care-givers, i.e., sometimes close and loving and at other times angry and resistant.

\section{Instrumental aggression}

Any aggression, including sexual aggression, that is proactive and premeditated rather than reacting to a provoking situation. Instrumental aggression is therefore planned. It also refers to aggression that is used to meet a need within the individual, for example to meet a sexual need the abuser will go looking for anybody to meet that need, irrespective of age or gender.

\section{Juvenile sexual abuser (JSA)}

A child or adolescent who has perpetrated sexually abusive behaviour. (The term 'juvenile sexual offender' is not used in this study because many of the sample have not been convicted of the behaviour, and the term offender often connotes conviction.) 
Lack of parental supervision

Evidence that for large periods of time parents are not aware of where their children are, what they are doing, or who they are with, and the parents do not seem to care.

Late Onset sexually abusive behaviour

Any sexually abusive behaviour towards a person or animal that occurs after the abuser reaches 11 years of age.

Lifetime conviction profile and associated time at risk

Conviction profile for the time between the individual's tenth birthday and December 2003.

Time spent at risk of being convicted during this period, e.g. any time not in prison.

Marital separation/divorce

Separation or divorce between the biological parents of the child in the sample.

Non-sexual/non-violence convictions

Convictions for arson, theft, burglary, stealing, fraud, criminal damage, drug offences, motoring offences, breach of orders, absconding and any other minor offences.

Odds ratio

The 'odds' indicates the strength of a relationship between two factors, e.g., having ESPD traits and being physically abused. The 'odds ratio' indicates the ratio of the odds for the two groups being compared, e.g. how much more likely is it that the ESPD group will have been physically abused compared to the non-ESPD group being physically abused.

\section{Oppositional behaviour}

Evidence of hostile, defiant or argumentative behaviour by the child against other people, e.g. argues a lot, often loses temper, annoys others, confrontational.

\section{Oral-genital contact with the victim}

Evidence of the abuser performing fellatio or cunnilingus on the victim, or the abuser making the victim perform such acts on the abuser.

Parental childhood abuse

Parents who themselves were victims of sexual, physical, emotional abuse or physical neglect, while they were children.

\section{Parental criminality}

Parents who have been convicted of any criminal offences.

Parental mental health problems

Parents who have had, or currently suffer from, any of the following: mental illness; personality disorder; post-natal depression; or who attempted suicide.

Parental time in care

Parents who themselves were removed into Local Authority Care during their childhoods or adolescence.

\section{Peri natal problems}

The presence of any of the following: pre-eclampsia; forceps delivery; oxygen deprivation at/during birth; low birth weight; or spent time in a special care baby unit.

Physical abuse

Actual or suspected physical injury to a child or adolescent, for example hitting, burning, strangling.

\section{Physical coercion}

The use of actual physical aggression to coerce the victim into complying with the abuse, or the use of actual physical aggression against the victim to try and ensure his/her silence following the abuse. 
Physical cruelty to animals

The intentional infliction of injury or death to animals.

Physical neglect

Actual, or suspected, persistent or severe neglect of a child or adolescent's physical needs, for example lack of food, warmth, medical attention.

Physically aggressive behaviour

Any physical aggression displayed by the young person against other people, for example hitting, punching, kicking, spitting.

Post-YAP conviction profile and associated time at risk

Conviction profile for the time between the original YAP assessment and December 2003.

Time spent at risk of being convicted during this period, e.g. any time not in prison.

'Predatory' sexually abusive behaviour

Evidence of the perpetration of any of the following behaviours: grooming a potential victim; abducting or luring a victim; anally penetrating the victim; using excessive force; tying up the victim.

Pre-YAP conviction profile and associated time at risk

Conviction profile for the time between the individual's tenth birthday and the date of the original YAP assessment. Time spent at risk of being convicted during this period, e.g. any time not in prison.

\section{Prior grooming}

Using strategies to isolate the victim from other people and enable the abuse to take place, for example encouraging the victim to go into the abuser's bedroom to play on a computer.

Raped adult women

Vaginal penetration of females aged 18 years and over.

Reckless behaviour

Engaging in excessively risky behaviour without fear or consideration of the potential consequences for example, climbing on roofs, lying down in the road.

Removal to local authority care

The individual is removed by Social Services to live either in foster care or residential children's homes.

Sadistic sexual behaviour

Sexual behaviour that intentionally humiliates or inflicts injury on the victim.

Sexual convictions

Convicted of sexual offences, e.g. rape, indecent assault, indecent exposure.

Sexually Abusive Behaviour (SAB)

Any sexual behaviour perpetrated against, or in front of, a non-consenting individual. In this study non-consenting individuals include those who by virtue of age (e.g. child under 16 years old) or intellectual ability, cannot legally consent to the behaviour, as well as those who are legally able to give consent and withhold it.

Sexual activity with animals

Sexual acts performed with animals, e.g. getting an animal to lick the child's genitals, the child sexually fondling the animal's genitals, or sexually penetrating the animal.

Socially isolated

Evidence that the young person has few, or no, close friends, and finds it difficult to initiate making friends. 
Speech and language problems

Evidence that the young person has difficulties articulating sounds, e.g. speech defect such as stammering, or they have difficulty expressing themselves, for example putting their thoughts and feelings into spoken language.

\section{Stalked victims}

Following and/or clandestinely observing victims.

\section{Statement of Educational Need (SEN)}

The individual is subject to an SEN following an assessment of education and/or behavioural difficulties. The SEN makes provision for additional educational support, for example classroom assistant or special classes.

\section{Stealing}

Any evidence of taking items that do not belong to the child, for example stealing from shops, as well as stealing food or money in school.

\section{Verbal coercion}

Examples of this behaviour include, making threats to hurt the victim or members of the victim's family if the victim doesn't allow the perpetrator to abuse them; or making threats to hurt the victim if he/she tell anyone about the abuse after it has happened.

\section{Violence convictions}

Convictions for offences of murder, manslaughter, any form of assault or wounding, abduction or kidnapping, or robbery.

\section{Six or more changes in home placement}

Home placements include living with different family members as well as living in different settings such as foster families and residential accommodation. A move is any change in permanent living arrangements, e.g. moving from living permanently with mother to living permanently with grandparents, or moving from one foster family to another.

\section{Fourth tier CAMH Service}

The most specialised tier of Child and Adolescent Mental Health Services. Includes residential services, forensic services and specialist out patient services with a national remit. Assessment and interventions are delivered by specialist treatment providers. Referrals to such services represent the most severe and worrying children and young people, who have often been previously referred to second or third tier CAMH services but have not been able to benefit and require a more specialised type of input. 


\section{Appendix 2. Items on the Psychopathy Checklist Youth Version}

Impression management

Grandiose sense of self-worth

Stimulation seeking

Pathological lying

Manipulation for personal gain

Lack of remorse

Shallow affect

Callous/lacking empathy

Parasitic orientation

Poor anger control

Impersonal sexual behaviour

Early behaviour problems

Lacks goals

Impulsivity

Irresponsibility

Failure to accept responsibility

Unstable interpersonal relationships

Serious criminal behaviour

Serious violation of conditional release

Criminal versatility 


\section{Appendix 3. Survival rate graphs for first sexual and violent convictions post-YAP for Chapters 8 to 10}

Figure 8.1: Survival rates for first sexual conviction post-YAP for the whole sample

Survival Function

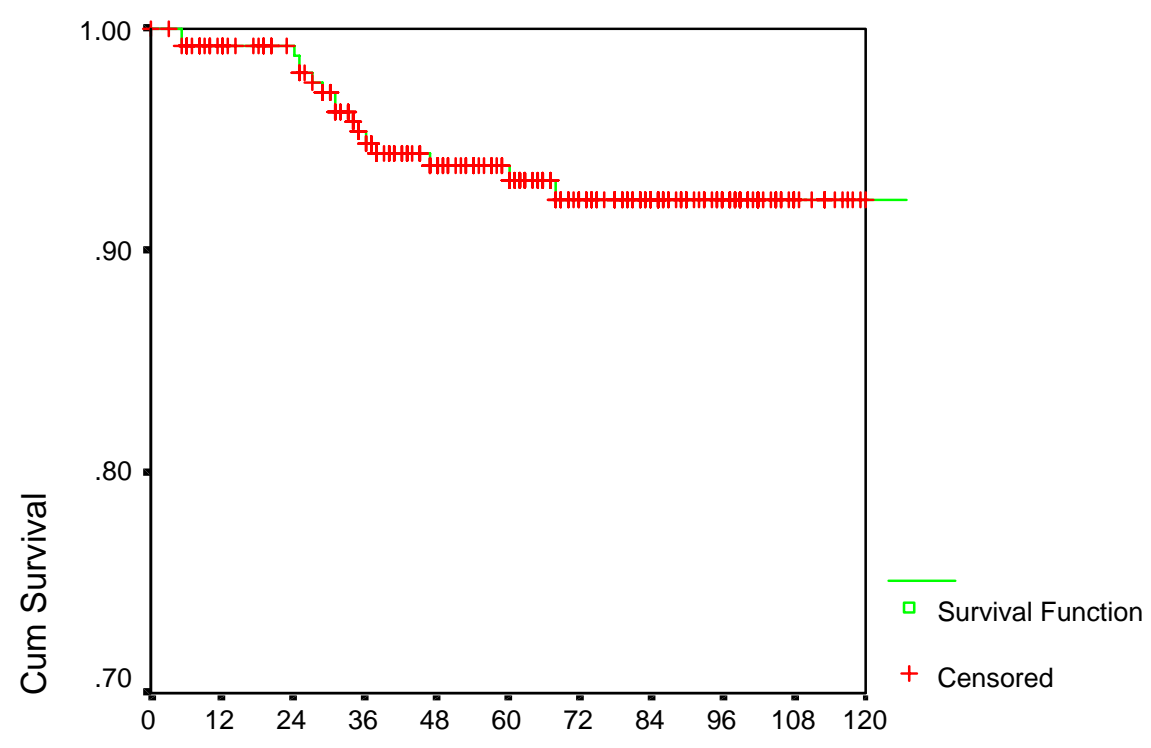

Months at risk to 1st Sexual Conviction Post YAP

Figure 8.2: Survival rates for first violent conviction post-YAP for the whole

Survival Function

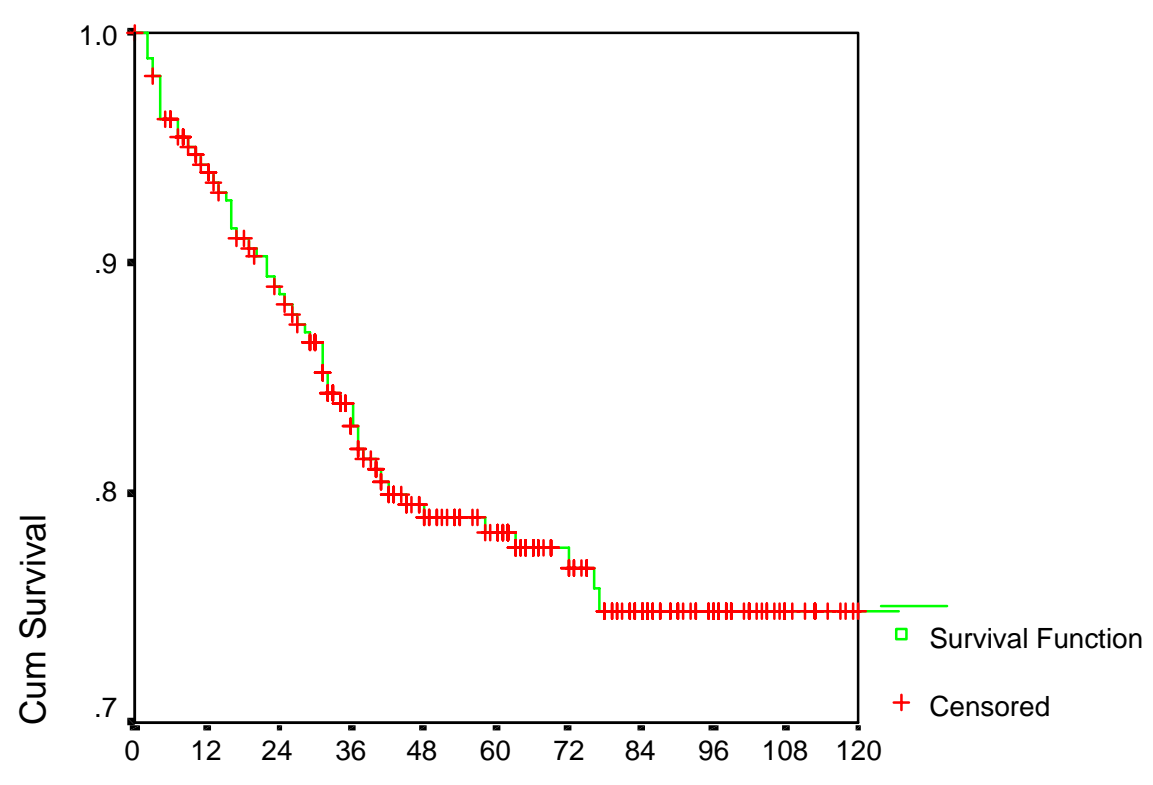

Months at risk to 1st Violent conviction post YAP 
Figure 9.1: Survival rates for first sexual conviction post-YAP for the Early and Late onset trajectories

Survival Functions

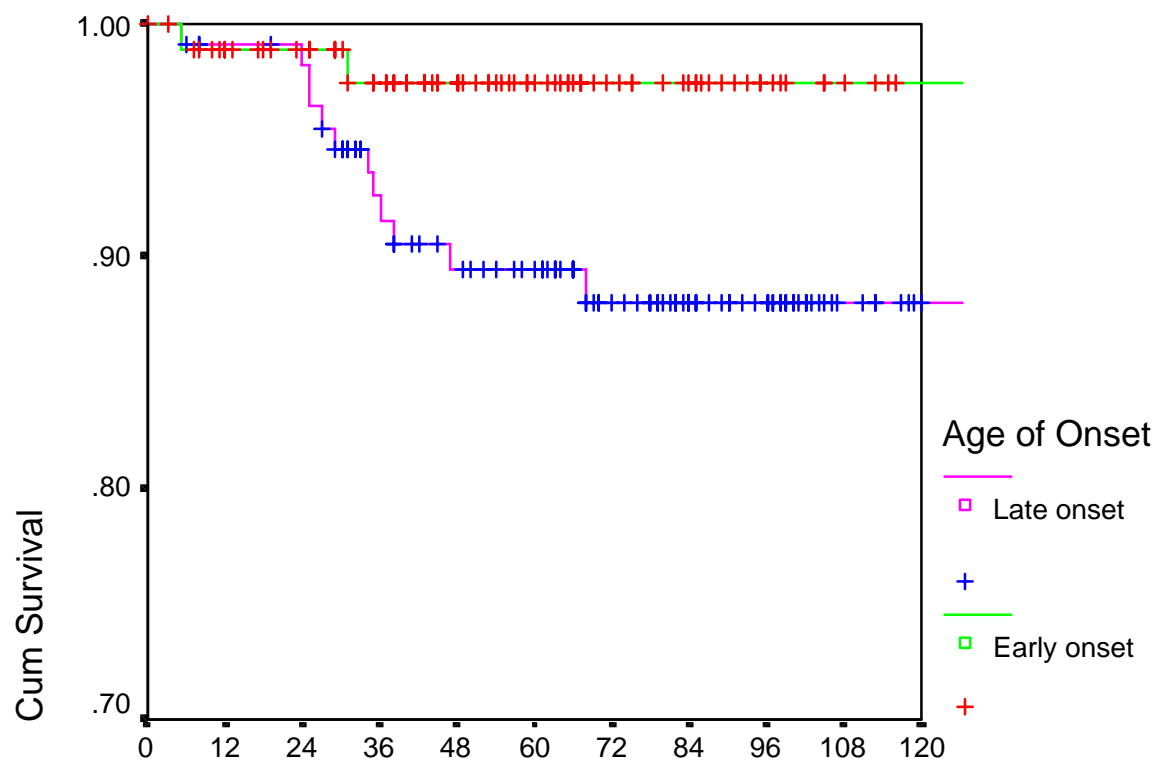

Months at risk to 1st Sexual Conviction Post YAP

Figure 9.2: Survival rates for first violent conviction post-YAP for the Early and Late onset trajectories

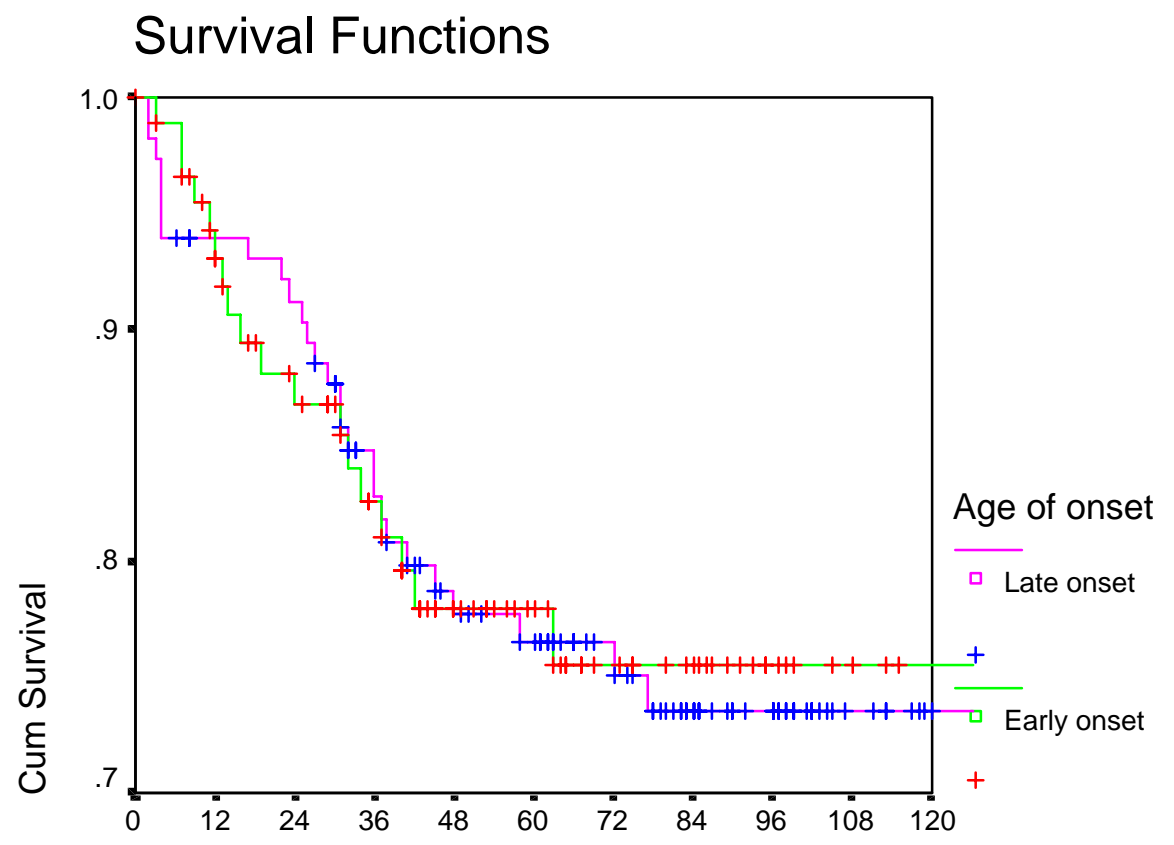

Months at risk to 1st Violent conviction post YAP 
Figure 10.1: Survival rates for first sexual conviction post-YAP for the ESPD traits groups

\section{Survival Functions}

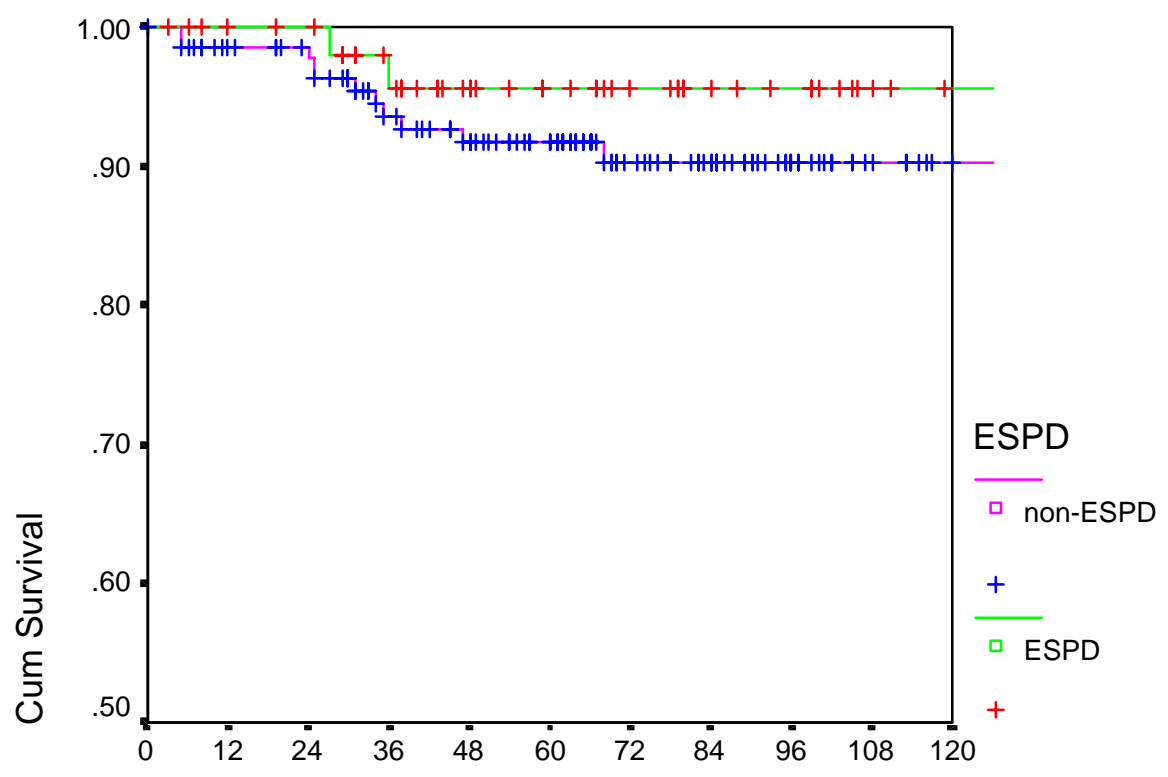

Months at risk to 1st Sexual Conviction Post YAP

Figure 10.2: Survival rates for first violent conviction post-YAP for the ESPD traits groups

\section{Survival Functions}

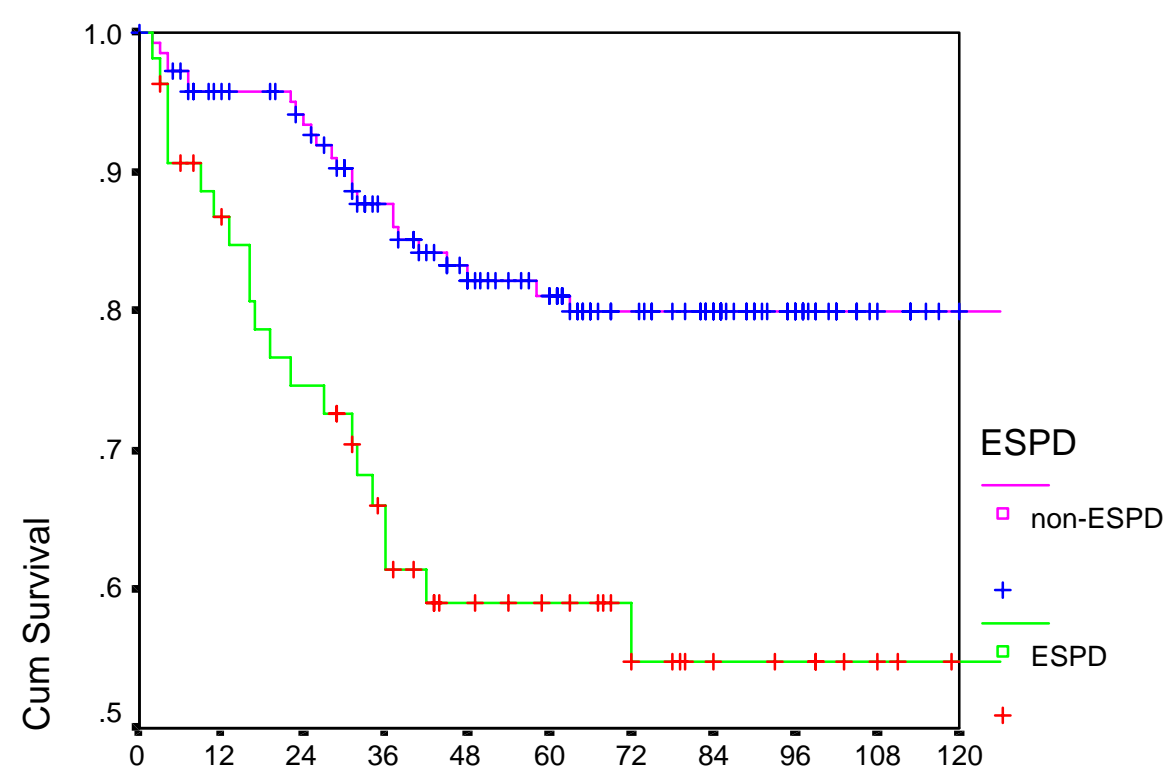

Months at risk to 1st Violent conviction post YAP 


\section{Appendix 4. Comparing 'included' and 'excluded' samples}

Table A.1: Comparisons between those included $(n=213)$ and those excluded $(n=67)$ in the Early and Late Onset trajectory analyses

\begin{tabular}{rccc}
\hline & $\begin{array}{c}\text { Included } \\
(\mathrm{n}=213) \\
\%\end{array}$ & $\begin{array}{c}\text { Excluded } \\
(\mathrm{n}=67) \\
\%\end{array}$ & Significance \\
$\begin{array}{r}\text { Male } \\
\text { Caucasian }\end{array}$ & 93 & 87 & $n s$ \\
\hline Intellectual disability (IQ $\leq 70)$ & 25 & 87 & $n s$ \\
Experienced any abuse or neglect & 91 & 21 & $n s$ \\
Marital separation or divorce & 73 & 94 & $n s$ \\
Removed to Local Authority Care & 77 & 72 & $n s$ \\
& & 73 & $n s$ \\
\hline
\end{tabular}

Table A.2: Comparisons between those included $(n=203)$ and those excluded $(n=77)$ in the ESPD trait group analyses

\begin{tabular}{rccc}
\hline & $\begin{array}{c}\text { Included } \\
(\mathrm{n}=203) \\
\%\end{array}$ & $\begin{array}{c}\text { Excluded } \\
(\mathrm{n}=77) \\
\%\end{array}$ & Significance \\
$\begin{array}{r}\text { Male } \\
\text { Caucasian }\end{array}$ & 93 & 88 & $n s$ \\
Intellectual disability (IQ $\leq 70)$ & 83 & 82 & $n s$ \\
Experienced any abuse or neglect & 92 & 22 & $n s$ \\
Marital separation or divorce & 73 & 91 & $n s$ \\
Removed to Local Authority Care & 79 & 73 & $n s$ \\
& & 69 & $n s$ \\
\hline
\end{tabular}

Table A.3: Comparisons between those included $(n=50)$ and those excluded $(n=137)$ in the ESPD trait groups on the Early and Late Onset trajectory analyses

\begin{tabular}{rccc}
\hline & $\begin{array}{c}\text { Included } \\
(\mathrm{n}=50) \\
\%\end{array}$ & $\begin{array}{c}\text { Excluded } \\
(\mathrm{n}=137) \\
\%\end{array}$ & Significance \\
$\begin{array}{r}\text { Male } \\
\text { Caucasian }\end{array}$ & 96 & & $n$ \\
\hline Intellectual disability (IQ $\leq 70)$ & 80 & 93 & $n s$ \\
Experienced any abuse or neglect & 32 & 82 & $n s$ \\
Marital separation or divorce & 96 & 22 & $n s$ \\
& 70 & 91 & $n s$ \\
\hline
\end{tabular}




\section{References}

Abel, G.G., Osborn, C.A. and Twigg, D.A. (1993) Sexual assault through the lifespan: Adult offenders with juvenile histories. In Barbaree H. E., Marshall W. L., and Hudson S.M. (Eds.). The juvenile sexual offender. New York: Guilford Press.

American Psychiatric Association (1994) Diagnostic and Statistical Manual of Mental Disorders - IV. Washington DC.

Awad, G.A. and Saunders, E.B. (1991) Male adolescent sexual assaulters: clinical observations. Journal of Interpersonal Violence, 6 (4), 446-460.

Barry, C.T., Frick, P.J., Grooms, T., McCoy, M.G., Ellis, M. and Loney, B.R. (2000) The importance of callous-unemotional traits for extending the concept of psychopathy to children. Journal of Abnormal Psychology, 109, 335-340.

Becker, J.V., Cunningham-Rathner, J. and Kaplan, M.S. (1986) Adolescent sex offenders: Demographics, criminal, and sexual histories, and recommendations for reducing future offences. Journal of Interpersonal Violence, 1, 431-445.

Becker, J.V. and Kaplan, M.S. (1988) The assessment and treatment of adolescent sexual offenders. Advances in Behavioural Assessment of Children and families, 4, 97-118.

Bernstein, D.P., Cohen, P., Skodol, A., Bezirganian, S. and Brook, J.S. (1996) Childhood antecedents of adolescent personality disorders. American Journal of Psychiatry, 153(7), 907913.

Blair, R.J.R. (2002) Neurological basis of psychopathy. British Journal of Psychiatry, 182, 57.

Borduin, C.M., Henggeler, S.W., Blaske, D.M. and Stein, R. (1990) Multisystemic treatment of adolescent sexual offenders. International Journal of Offender Therapy and Comparative Criminology, 34, 105-113.

Borduin, C. M., Schaeffer, C. M. and Heiblum, N. (2004) Multisystemic treatment of juvenile sexual offenders: Effects on adolescent social ecology and criminal activity. Manuscript submitted for publication.

Bowlby, J. (1951) Maternal care and mental health. Switzerland: World Health Organisation.

Boyd, N.J., Hagan, M. and Cho, M.E. (2000) Characteristics of adolescent sex offenders: A review of the research. Aggression and Violent Behaviour, 5(2), 137-146.

Broidy, L.M., Tremblay, R.E., Brame, B., Fergusson, D., Horwood, J.L., Laird, R., Moffitt, T.E., Nagin, D.S., Bates, J.E., Dodge, K.A., Loeber, R., Lynam, D.R. and Pettit, G.S. (2003) Developmental trajectories of childhood disruptive behaviours and adolescent delinquency: A six-site cross-national study. Developmental Psychology, 39(2), 222-245.

Brown, S.L. and Forth, A.E. (1997) Psychopathy and sexual assault: Static risk factors, emotional precursors and rapist subtypes. Journal of Consulting and Clinical Psychology, 65(5), 848-857.

Butler, S.M. and Seto, M.C. (2002) Distinguishing two types of adolescent sex offenders. Journal of the American Academy of Child and Adolescent Psychiatry, 41, 83-90.

Caldwell, M.F. (2002) What we do not know about juvenile sexual reoffense risk. Child Maltreatment, 7(4), 291-302. 
Campbell, M.A., Procter, S. and Santor, D. (2004) Psychopathic traits in adolescent offenders: An evaluation of criminal history, clinical and psychosocial correlates. Behavioural Sciences and the Law, 22, 23-47.

Cann, J., Falshaw, L. and Friendship, C. (2004) Sexual offenders discharged from prison in England and Wales: A 21-year reconviction study. Legal and Criminological Psychology, 9, 110.

Caspi, A., Moffitt, T.E., Silva, P.A., Stouthamer-Loeber, M., Krueger, R.F. and Schmutte, P.S. (1994) Are some people crime prone? Replications of the personality-crime relationship across countries, genders, races and methods. Criminology, 32, 163-195.

Chamberlain, P. and Reid, J. (1998) Comparison of two community alternatives to incarceration for chronic juvenile abusers. Journal of Consulting and Clinical Psychology, 66(4), 624-633.

Christian, R.E., Frick, P.J., Hill, N.L., Tyler, L. and Frazer, D.R. (1997) Psychopathy and conduct problems in children: Implications for subtyping children with conduct problems. Journal of the American Academy of Child and Adolescent Psychiatry, 36, 23 -241.

Coid, J. (1999) Aetiological risk factors for personality disorders. British Journal of Psychiatry, 174, 530-538.

Coie, J.D., Terry, R., Zakriski, A. and Lochman, J.E. (1995) Early adolescent social influences in delinquent behaviour. In J. McCord (Ed.), Coercion and Punishment in long-term perspectives. New York: Cambridge University Press.

Davis, G.E. and Leitenberg, H. (1987) Adolescent sex offenders. Psychological Bulletin, 101, 417-427.

Dodge, K.A. and Coie, J.D. (1987) Social information-processing factors in reactive and proactive aggression in children's peer groups. Journal of Personality and Social Psychology, 53, 1146-1157.

Dolan, M., Holloway, J., Bailey, S. and Kroll, L. (1996) The psychosocial characteristics of juvenile sexual offenders referred to an adolescent forensic service in the UK. Medicine, Science and the Law, 36 (4), 343-352.

Egeland, B. and Sroufe, L.A. (1981) Developmental sequelae of maltreatment in infancy. In Rizley R. and Cicchetti D. (Eds.). Developmental perspectives in child maltreatment. San Francisco: Jossey-Bass.

Farrington, D.P. (1995) The development of offending and antisocial behaviour from childhood: Key findings from the Cambridge Study in Delinquent Development. Journal of Child Psychology and Psychiatry, 36, 929-964.

Farrington, D.P. (2005) The importance of child and adolescent psychopathy. Journal of Abnormal Child Psychology, 33(4), 489-497.

Farrington, D.P. (in press) Family background and psychopathy. In Patrick C.J. (Ed.), Handbook of psychopathy. New York: Guilford Press.

Farrington, D.P. and Coid, J. W. (2003) Early prevention of adult antisocial behaviour. Cambridge: Cambridge University Press.

Fehrenbach, P.A., Smith, W., Monastersky, C. and Deisher, R.W. (1986) Adolescent sexual offenders: Offender and offence characteristics. American Journal of Orthopsychiatry, 56(2), 225-233. 
Forth, A.E., Kosson, D. and Hare R.D. (2003) The Hare Psychopathy Checklist: Youth Version. Toronto: Multi-Health Systems.

Frick, P.J. (2004) Developmental pathways to conduct disorder: Implications for serving youth who show severe aggressive and antisocial behaviour. Psychology in the Schools, 41(8), 823-834.

Frick, P.J., Cornell, A.H., Bodin, S.D., Dane, H.A., Barry, C.T. and Loney, B.R. (2003) Callous-Unemotional traits and developmental pathways to severe conduct problems. Developmental Psychology, 39(2), 246-260.

Frick, P.J., O'Brien, B.S., Wootton, J.M. and McBurnett, K. (1994) Psychopathy and conduct problems in children. Journal of Abnormal Psychology, 103, 700-707.

Gebhard, P.H., Gagnon, J.H., Pomeroy, W.B. and Christenson, C.V. (1965) Sex offenders: An analysis of types. New York: Harper and Row.

Grann, M., Langstrom, N., Tengstrom, A. and Stalenheim, E.G. (1998) The reliability of file-based retrospective ratings of psychopathy with the PCL-R. Journal of Personality Assessment, 70, 416-426.

Greenberg, M., Siegal, J. and Leitch, C. (1984) The nature and importance of attachment relationships to parents and peers during adolescence. Journal of Youth and Adolescence, 12, 373-386.

Gretton, H.M., Catchpole, R.E., McBride, M., Hare, R.D. and Regan, K.V. (2005) The relationship between psychopathy, treatment completion and criminal outcome over ten years: A study of adolescent sex offenders. In Calder M. (Ed.) Children and young people who sexually abuse. Dorset: Russell House Publishing.

Gretton, H.M., McBride, M., Hare, R.D., O'Shaughnessy, R. and Kumka, G. (2001) Psychopathy and recidivism in adolescent sex offenders. Criminal Justice and Behaviour, 28(4), 427-449.

Groth, A.N. (1977) The adolescent sex offender and his prey. International Journal of Offender Therapy and Comparative Criminology, 21, 249-254.

Hare, R.D. (2004) The Hare Psychopathy Checklist - Revised Second Edition. Toronto: Multi Health Systems.

Home Office (2003) Criminal Statistics: England and Wales 2002. Statistics relating to Criminal proceedings for the year 2002. London: The Stationery Office.

Hsu, L.K.G. and Strazynski, J. (1990) Adolescent rapists and adolescent child sexual assaulters. International Journal of Offender Therapy and Comparative Criminology, 34, 2331.

Hudson, S.M. and Ward, T. (1997) Intimacy, loneliness and attachment style in sex offenders. Journal of Interpersonal Violence, 12(3), 323-339.

Hunter, J.A., Figueredo, A.J., Malamuth, N.M. and Becker, J.V. (2003) Juvenile sexual offenders: Towards the development of a typology. Sexual Abuse: A Journal of Research and Treatment, 15(1), 27-48.

Jack, L.A. (2000) Psychopathy, risk/need factors and psychiatric symptoms in high-risk youth: Relationships between variables and their link to recidivism. Unpublished doctoral dissertation. Simon Fraser University: British Columbia.

James, A.C. and Neil, P. (1996) Juvenile sexual offending: One year period prevalence study within Oxfordshire. Child Abuse and neglect, 20(6), 477-485. 
Kahn, T.J. and Chambers, H.J. (1991) Assessing reoffense risk with juvenile sexual offenders. Child Welfare League of America, 70 (3), 333-345.

Kaufman, K., Barber, M., Mosher, M. and Carter, M. (2002) Reconceptualising child sexual abuse as a public health concern. In Scheme P.A. (Ed.), Preventing violence in relationships: Interventions across the lifespan. Washington DC: American Psychological Association.

Kroll, L., Woodham, A., Rothwell, J., Bailey, S., Tobias, C., Harrington, R., Marshall, M. and Lockwood, A. (1999) The reliability and validity of the Needs Assessment Schedule for Adolescents. Psychological Medicine, 29, 8891-902.

Lahey, B.B. and Waldman, I.D. (2003) A Developmental Propensity Model of the Origins of Conduct Problems during Childhood and Adolescence. In Lahey B.B., Moffitt T.E. and Caspi A. (Eds.), Causes of Conduct Disorder and Delinquency. London: The Guilford Press

Långström, N. and Grann, M. (2000) Risk of criminal recidivism among young sex offenders. Journal of Interpersonal Violence, 15(8), 855-871.

Lewis, D.O., Shankok, S.S. and Pincus, J.H. (1979) Juvenile sexual assaulters. American Journal of Psychiatry, 136, 1194-1196.

Loeber, R., Green, S.M. and Lahey, B.B. (2003) Risk factors for adult antisocial personality. In D.P. Farrington and J.W. Coid (Eds.), Early prevention of adult antisocial behaviour. Cambridge: Cambridge University Press.

Loeber, R. and Stouthamer-Loeber, M. (1998) Development of juvenile aggression and violence: Some common misconceptions and controversies. American Psychologist, 53, $242-$ 259.

Loeber, R., Wung, P., Keenan, K., Giroux, B., Stouthamer-Loeber, M., Van Kammen, W.B. and Maughan, B. (1993) Developmental pathways in disruptive child behaviour. Development and Psychopathology, 5, 103-133.

Lussier, P. (2005) The criminal activity of sexual offenders in adulthood: Revisiting the specialization debate. Sexual Abuse: A Journal of Research and Treatment, 17(5), 269-292.

Manocha, K. and Mezey, G. (1998) British adolescents who sexually abuse: A descriptive study. Journal of Forensic Psychiatry, 9(3), 588-608.

Mason, D.A. and Frick, P.J. (1994) The heritability of antisocial behaviour: A meta-analysis of twin and adoption studies. Journal of Psychopathology and Behavioural Assessment, 16, 301-323.

Marsee, M.A., Silverthorn, P. and Frick, P.J. (2005) The association of psychopathic traits with aggression and delinquency in non-referred boys and girls. Behavioral Sciences and the Law, 23, 803-817.

McCord, J. (1979) Some child-rearing antecedents of criminal behaviour in adult men. Journal of Personality and Social Psychology, 37,1477-1486.

McCord, W. and McCord, J. (1964) The psychopath: An essay on the criminal mind. Princeton NJ: van Nostrand.

McEachran, A, (2001) The predictive validity of the PCL:YV and the SAVRY in a population of adolescent offenders. Unpublished master's thesis. Simon Fraser University: British Columbia.

Moffitt, T.E. (1993) Adolescence-limited and life-course-persistent antisocial behaviour: A developmental taxonomy. Psychological Review, 100, 674-701. 
Moffitt, T.E. and Caspi, A. (2001) Childhood predictors differentiate life-course persistent and adolescence-limited antisocial pathways among males and females. Development and Psychopathology, 13, 355-375.

Moffitt, T.E., Caspi, A., Dickson, N., Silva, P. and Stanton, W. (1996) Childhood-onset versus adolescent-onset antisocial conduct problems in males: Natural history from ages 3 to 18 years. Development and Psychopathology, 8, 399-424.

Moffitt, T.E., Caspi, A., Harrington, H. and Milne, B.J. (2002) Males on the life-course persistent and adolescence-limited antisocial pathways: Follow-up at age 26 years. Development and Psychopathology, 14, 179-207.

Moffitt, T.E. (2003) Life-Course-Persistent and Adolescence-Limited Antisocial Behaviour. A 10 year Research review and a Research Agenda. In Lahey B.B., Moffitt T.E. and Caspi A. (Eds.). Causes of Conduct Disorder and Delinquency. London: The Guilford Press.

Moran, P. and Hagell, A. (2001) Intervening to prevent antisocial personality disorder: A scoping review. Home Office Research Study 225. Home Office: Communications and Development Unit.

Muthén, B. (2001) Latent variable mixture modelling. In Marcoulides G.A. and Schumacker R.E. (Eds.), New developments and techniques in structural equation modelling. Washington: APA.

Nagin, D.S., Farrington, D.P. and Moffitt, T.E. (1995) Life-course trajectories of different types of offenders. Criminology, 33, 111-139.

Nisbet, I.A., Wilson, P.H. and Smallbone, S.W. (2004) A prospective longitudinal study of sexual recidivism among adolescent sex offenders. Sexual Abuse: $A$ Journal of Research and Treatment, 16(3), 223-234.

O'Halloran, M., Carr, A., O'Reilly, G., Sheerin, D., Cherry, J., Turner, R., Beckett, R. and Brown, S. (2002) Psychological profiles of sexually abusive adolescents in Ireland. Child Abuse and Neglect, 26, 349-370.

Pardini, D.A., Lochman, J.E. and Frick, P.J. (2003) Callous/Unemotional traits and socialcognitive processes in adjudicated youths. Journal of the American Academy of Child and Adolescent Psychiatry, 42(3), 364-371.

Patterson, G.R., De Baryshe, B.D. and Ramsey, E. (1989) A developmental perspective on antisocial behaviour. American Psychologist, 44, 329-335.

Plomin, R., Chipuer, H.M. and Loehlin, J.C. (1990) Behavioural genetics and personality. In Pervin L.A. (Ed.), Handbook of personality theory and research. New York: Guilford Press.

Prentky, R., Harris, B., Frizell, K. and Righthand, S. (2000) An actuarial procedure for assessing risk in juvenile sex offenders. Sexual Abuse: A Journal of Research and Treatment, 11, 69-85.

Richardson, G., Graham, F. and Bhate, S.R. (1995) A British sample of sexually abusive adolescents: Abuser and abuse characteristics. Criminal Behaviour and Mental Health, 5, 187-208.

Robinson, S.L. (2005) Considerations of the assessment of female sexually abusive youth. In M.C. Calder (Ed.), Children and young people who sexually abuse: New theory, research and practice developments (pp 171-195). London: Russell House Publishing.

Royal College of Psychiatrists (1999) Offenders with Personality Disorder. Council report CR71: Gaskell. 
Rubinstein, M., Yeager, C.A., Goodstein, C. and Lewis, D.O. (1993) Sexually assaultive male juveniles: A follow-up. American Journal of Psychiatry, 150, 262-265.

Rutter, M., Giller, H., and Hagell, A. (1998) Antisocial behaviour by young people. Cambridge: Cambridge University Press.

Ryan, G. (1989) Victim to victimiser. Journal of Interpersonal Violence, 4, 325-341.

Salekin, R.T. and Frick, P.J. (2005) Psychopathy in children and adolescents: The need for a developmental perspective. Journal of Abnormal Child Psychology, 33(4), 403-409.

Scott, S., Knapp, M., Henderson, J. and Maughan, B. (2001) Financial cost of social exclusion: Follow-up study of anti-social children into adulthood. British Medical Journal, 323, 191-194.

Seagrave, D. and Grisso, T. (2002) Adolescent development and the measurement of juvenile psychopathy. Law and Human Behaviour, 26, 219-239.

Seto, M.C. and Barbaree, H.E. (1997) Sexual aggression as antisocial behaviour: a developmental model. In Stoff D., Breiling J. and Maser J.D. (Eds.), Handbook of Antisocial Behaviour. New York: Wiley.

Shiner, R., and Caspi, A. (2003) Personality differences in childhood and adolescence: Measurement, development and consequences. Journal of Child Psychology and Psychiatry, $44,2-32$.

Simonoff, E., Elander, J., Holmshaw, J., Pickles, A. and Murray, R. (2004) Predictors of antisocial personality: Continuities from childhood to adult life. British Journal of Psychiatry, 118-127.

Sipe, R., Jensen, E.L. and Everett, R.S. (1998) Adolescent sexual offenders grown up: Recidivism in young adulthood. Criminal Justice and Behaviour, 25(1), 109-124.

Skilling, T.A., Quinsey, V.L. and Craig, W.M. (2001) Evidence of a taxon underlying serious antisocial behaviour in boys. Criminal Justice and Behavior, 28(4), 450-470.

Smith, W.R. and Monastersky, C. (1986) Assessing juvenile sexual offenders' risk for reoffending. Criminal Justice and Behaviour, 13 (2), 115-140.

Smith, W.R., Monastersky, C. and Deisher, R.M. (1987) MMPI based personality types among juvenile sexual offenders. Journal of Clinical Psychology, 43, 422-430.

Soothill, K., Francis, B., Sanderson, B. and Ackerley, E. (2000) Sex offenders: Specialists, generalists - or both? British Journal of Criminology, 40, 56-67.

Taylor, J.F. (2003) Children and young people accused of child sexual abuse: A study within a community. Journal of Sexual Aggression, 9(1), 57-70.

The Psychological Corporation (1992) Manual for the Wechsler Intelligence Scale for Children-Third Edition (WISC-III). San Antonio: Psychological Corporation.

Tremblay, R.E., Phil, R.O., Vitaro, F. and Dobkin, P.L. (1994) Predicting early onset of male antisocial behaviour from preschool behaviour. Archives of General Psychiatry, 51, 732-739.

Van Ness, S.R. (1984) Rape as instrumental violence: A study of youth offenders. Journal of Counseling, Services and Rehabilitation, 9, 161-170.

Vaughan, M.G., and Howard, M.O. (2005) The construct of psychopathy and its potential contribution to the study of serious, violent, and chronic youth offending. Youth Violence and Juvenile Justice, 3(3), 235-252. 
Veneziano, C. and Veneziano, L. (2002) Adolescent sex offenders: A review of the literature. Trauma, Violence and Abuse, 3(4), 247-260.

Viding. E. (2004) Annotation: Understanding the development of psychopathy. Journal of Child Psychology and Psychiatry, 45(8), 1329-1337.

Viding, E., Blair, J.R., Moffitt, T.E. and Plomin, R. (2005) Evidence for substantial genetic risk for psychopathy in 7-year-olds. Journal of Child Psychology and Psychiatry, 46(6), 592597.

Vizard, E., French, L., Hickey, N. and Bladon, E. (2004) Severe personality disorder emerging in childhood: A proposal for a new developmental disorder. Criminal Behaviour and Mental Health, 14, 17-28.

Wasserman, J. and Kappel, S. (1985) Adolescent sex offenders in Vermont. Burlington, VT: Vermont Dept of Health.

Werner, E.E. (1985) Stress and protective factors in children's lives. In Nicol A.R. (Ed.). Longitudinal Studies in Child Psychology and Psychiatry. Chichester. Wiley.

Werner, E.E. and Smith, R.S. (1982) Vulnerable but invincible: A study of resilient children. New York: McGraw-Hill.

White, H.R., Bates, M.E. and Buyske, S. (2001) Adolescence limited versus persistent delinquency: Extending Moffitt's hypothesis into adulthood. Journal of Abnormal Psychology, 110(4), 600-609.

Wiesner, M. and Capaldi, D.M. (2003) Relations of childhood and adolescent factors to offending trajectories of young men. Journal of Research in Crime and Delinquency, 40(3), 231-262.

Wong, S. (1988) Is Hare's psychopathy checklist reliable without the interview? Psychological Reports, 62, 931-934.

World Health Organisation (1992) The Classification of Mental and Behavioural Disorder 10. Geneva.

Worling, J.R. (2001) Personality based typology of adolescent male sexual offenders: Differences in recidivism rates, victim selection characteristics and personal victimisation histories. Sexual Abuse: A Journal of Research and Treatment, 13(3),149-166.

Worling, J.R. and Curwen, T. (2000) Adolescent sexual offender recidivism: Success of specialised treatment and implications for risk prediction. Child Abuse and Neglect, 24(7), 965-982.

Yokely, J. (2002) The treatment of multiple abusers youth in forensic foster care: A social responsibility therapy programme description. In Schwartz B. (Ed.). The sex offender. Volume 4. Chapter 21. Kingston NJ: Civic Research Institute.

Yokely, J. and Boettner, S. (2002) Forensic Foster Care for Young People Who Sexually Abuse: Lessons from Treatment. In Calder M.C. (Ed.). Young People who Sexually Abuse. Building the Evidence Base for Your Practice. Dorset: Russell House Publishing. 